UNIVERSIDADE DE SÃO PAULO

FACULDADE DE ECONOMIA, ADMINISTRAÇÃO E CONTABILIDADE DEPARTAMENTO DE ADMINISTRAÇÃO PROGRAMA DE PÓS-GRADUAÇÃO EM ADMINISTRAÇÃo

ANÁLISE DOS EFEITOS MOMENTO E CONTRÁRIO NO MERCADO ACIONÁRIO BRASILEIRO

José Eduardo Martins Leoni

Orientador: Prof. Dr. José Roberto Ferreira Savoia 
Prof. Dr. Marco Antonio Zago Reitor da Universidade de São Paulo

Prof. Dr. Adalberto Américo Fischmann Diretor da Faculdade de Economia, Administração e Contabilidade

Prof. Dr. Roberto Sbragia

Chefe do Departamento de Administração

Prof. Dr. Moacir de Miranda Oliveira Júnior Coordenador do Programa de Pós-Graduação em Administração 
JOSÉ EDUARDO MARTINS LEONI

\section{ANÁLISE DOS EFEITOS MOMENTO E CONTRÁRIO NO MERCADO ACIONÁRIO BRASILEIRO}

Dissertação apresentada ao Departamento de Administração da Faculdade de Economia, Administração e Contabilidade da Universidade de São Paulo como requisito para a obtenção do título de Mestre em Ciências.

Orientador: Prof. Dr. José Roberto Ferreira Savoia

Versão original

SÃO PAULO 
FICHA CATALOGRÁFICA

Elaborada pela Seção de Processamento Técnico do SBD/FEA/USP

Leoni, José Eduardo Martins

Análise dos efeitos momento e contrário no mercado acionário brasileiro / José Eduardo Martins Leoni. -- São Paulo, 2015.

$73 \mathrm{p}$.

Dissertação (Mestrado) - Universidade de São Paulo, 2015.

Orientador: José Roberto Ferreira Savoia.

1. Finanças 2. Efeito momento 3. Efeito contrário 4. Mercado acionário 5. Eficiência de mercado I. Universidade de São Paulo. Faculdade de Economia, Administração e Contabidade. II. Título.

CDD - 332 
À minha esposa,

Bruna Fernanda. 


\section{AGRADECIMENTOS}

Primeiramente, à minha esposa e melhor amiga Bruna Fernanda da Costa Barbosa, que apoiou minha decisão em trilhar o caminho do mestrado quando éramos namorados. Aos meus familiares Hagilson, Laís (in memorian), Denise, Sérgio e família e Lucas pela atenção dada, educação ensinada e companheirismo nos momentos alegres ou difíceis. Aos avós, tios e primos das famílias De Luca, Martins, Cunha e Leoni.

Aos pais de minha esposa José Ricardo (in memorian) e Sônia Aparecida (in memorian), que deixaram saudades em meados de 2013.

Ao Bruno, Olivia e Apollo, Henrique e Fernanda, meus novos parentes em Jundiaí. Aos professores convidados de minha banca de qualificação Dr. Eduardo Augusto do Rosário Contani e Dra. Fabiana Lopes da Silva pelos pertinentes comentários.

A todos os professores da FEA-USP, em especial Dr. José Roberto Securato, Dr. Eduardo Kazuo Kayo, Dr. Roy Martelanc, Dra. Liliam Sanchez Carrete e Dr. Daniel Reed Bergmann, grandes conhecedores e disseminadores das finanças.

A meus colegas administradores Fernando Lima, Diego Videira, Herman Yuji, Júlia Valery, André Ferraz, Bruno Wittmaack, Daniel Albuquerque e Carlos Malaguti.

Aos colegas mestrandos Vitor Palazzo, Marcel Cabral, Marcus Steffen, Thiago Imai e doutorandos Elaine Borges, Fernando Pinheiro, Greici Sarturi e Taiguara Langrafe.

A meus ex-colegas da BM\&FBOVESPA Rogério Santana, Mariana Carmo, Claudio Jacob, André Pitta, Bruna Moura, Carla Biasotto, Edna Holanda, Gabriel Lansac, Gustavo Adolfo, Cristiana Pereira, Carlos Rebello, Nelson Ortega, Jorge Tambucci, Veridiana Augusto, Paulo Claver e Eduardo Guardia.

A meus colegas de trabalho Thiago Rocha, Livia Torelli, Pedro Torres, Fabrini Fontes e aos fundadores da Senior Solution Srs. Bernardo Gomes e Luciano Camargo.

A meus amigos de longa data Marco Casaroli e Diana, Fernando Casaroli, Leonardo Deliberador, Saulo Venâncio, Rodrigo Domit, Maurício Nakao e Tatiane, Rafael Beleboni e Fabiano Scalassara.

Especialmente a meu orientador Prof. Dr. José Roberto Ferreira Savoia, que acompanha e auxilia meu desenvolvimento desde a graduação na FEA-USP.

Registro meus sinceros agradecimentos. 
"The efficient market theory is one of the better models in the sense that it can be taken as true for every purpose I can think of. For investment purposes, there are very few investors that shouldn't behave as if markets are totally efficient." 


\section{RESUMO}

O trabalho tem como objetivo identificar a existência do efeito momento, de comprar ações com alto desempenho relativo no passado e vender as de baixo desempenho relativo no passado, e do efeito contrário, de comprar ações com baixo desempenho relativo no passado e vender as de alto desempenho relativo no passado. A análise considerou 662 ações negociadas na BM\&FBOVESPA entre julho de 1994 e junho de 2015, considerando quatro períodos de formação (3, 6, 9 e 12 meses) e seis de manutenção (3, 6, 9 e 12, 18 e 24 meses) das carteiras. A metodologia adotada para o efeito momento utiliza a abordagem de Jegadeesh e Titman (1993) e, para o efeito contrário, optou-se por De Bondt e Thaler (1985). A partir da identificação das carteiras vencedoras e perdedoras, passou-se a calcular as diferenças dos retornos acumulados mensais com uma janela móvel para expurgar o viés de seleção. Das 24 estratégias analisadas, verificou-se que apenas uma não apresentou significância para o efeito momento e rejeitou-se a hipótese de existência do efeito contrário. Constatou-se o efeito momento em 23 estratégias, sendo que duas apresentaram desempenho médio mensal superior ao Ibovespa no mesmo período, nas carteiras " $12 \times 3$ " e "9x6", respectivamente, de 1,60\% e 1,48\%. As principais contribuições do trabalho foram a adoção de uma carteira móvel para a avaliação do desempenho das carteiras, o amplo período utilizado na análise e o grande número de ativos, o que proporciona maior robustez aos resultados encontrados.

Palavras-chave: Finanças, efeito momento, efeito contrário, mercado acionário, eficiência de mercado. 


\begin{abstract}
The work aims to find momentum effect, that buys stocks with relative high return in the past and sells stocks with relative poor return in the past, and the contrarian effect, that buys stocks with relative poor return in the past and sells stocks with relative high performance in the past. The analysis included 662 stocks traded on BM\&FBOVESPA between July 1994 and June 2015, considering four formation periods (3, 6, 9 and 12 months) and six holding periods (3, 6, 9 and 12, 18 and 24 months) for the portfolios. The methodology adopted for momentum effect uses the theory of Jegadeesh and Titman (1993) and the contrarian effect uses De Bondt and Thaler (1985) theory. From the identification of winners' portfolios and losers' portfolios, it was calculated the differences in monthly cumulative returns with a rolling window to purge the selection bias. Of the 24 strategies analyzed, it was found that only one has no significance for momentum effect, and the hypothesis of contrarian effect was rejected. Momentum effect was found in 23 strategies, and two had average monthly performance superior to Ibovespa in the same period in the "12x3" portfolios and "9x6" portfolios, respectively, $1.60 \%$ and $1.48 \%$. The main contributions of this study was to adopt a rolling window for evaluating the performance of the portfolios, the extended period used in the analysis and the large number of stocks, which provides greater robustness to the results found.
\end{abstract}

Keywords: Finance, momentum effect, contrarian effect, stock market, market efficiency. 


\section{SUMÁRIO}

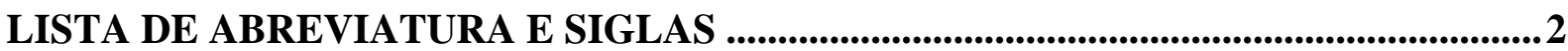

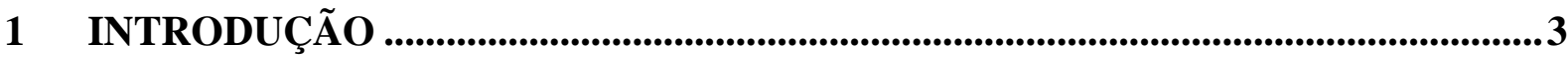

1.1 PROBLEMA DE PESQUISA ...............................................................................................4

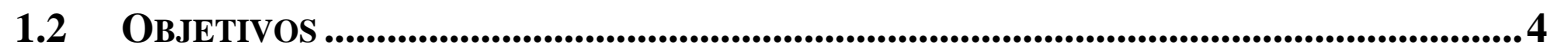

1.3 HIPÓTESES ........................................................................................................................4

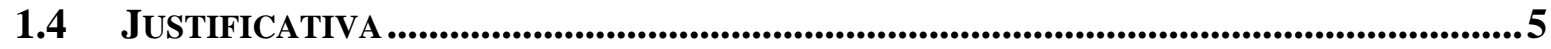

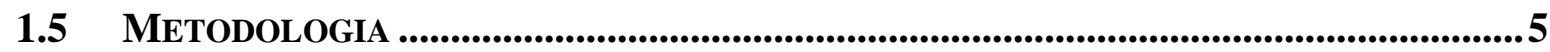

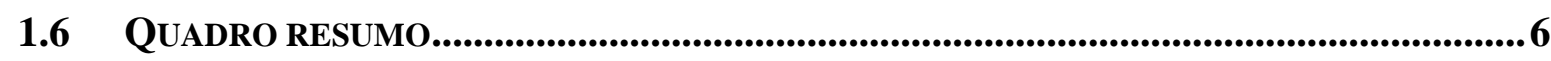

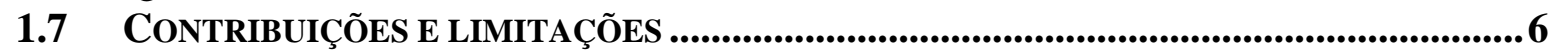

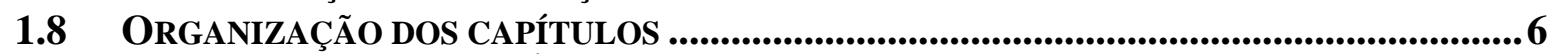

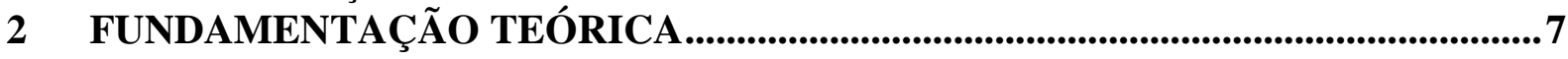

2.1 A HIPÓTESE dOS MERCADOS EFICIENTES...............................................................

2.2 TEORIA COMPORTAMENTAL DE FINANÇAS ............................................................10

2.3 ESTUDOS INTERNACIONAIS SOBRE EFEITOS MOMENTO E CONTRÁRIO .....................13

2.4 ESTUDOS NACIONAIS SOBRE EFEITOS MOMENTO E CONTRÁRIO ...............................28

2.5 COMPILAÇÃO DOS TRABALHOS MAIS RELEVANTES POR ASSUNTO ..........................31

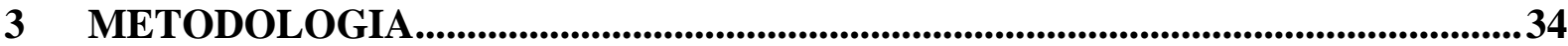

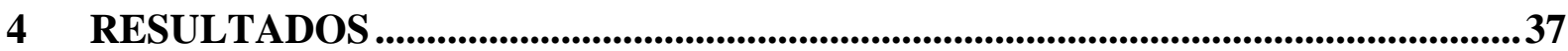

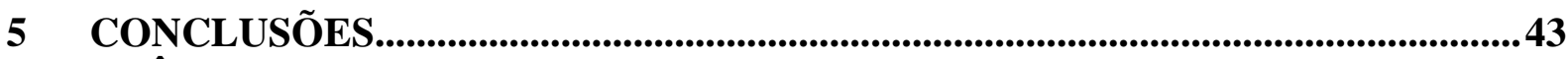

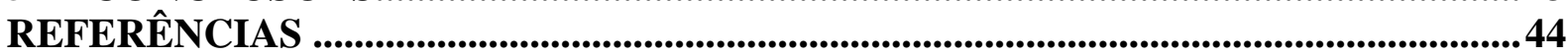

APÊNDICE 1 - SCRIPT UTILIZADO NO MATLAB .....................................................50

APÊNDICE 2 - LISTA DE ATIVOS CONSIDERADOS ........................................5.

APÊNDICE 3 - RETORNOS MENSAIS DAS CARTEIRAS GANHADORAS E PERDEDORAS DA ESTRATÉGIA “12X3" EM COMPARÇAO COM O IBOVESPA

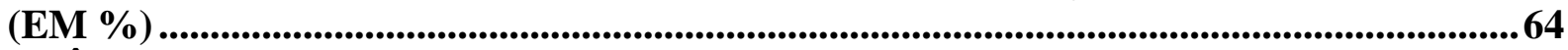
APÊNDICE 4 - RETORNOS MENSAIS DAS CARTEIRAS GANHADORAS E PERDEDORAS DA ESTRATÉGIA "9X6" EM COMPARÇAO COM O IBOVESPA (EM \%) 


\section{LISTA DE ABREVIATURA E SIGLAS}

ADRs: American Depositary Receipts

AMEX: American Stock Exchange

AZFinText: Arizona Financial Text system

B/M: Book-to-Market Value

BE/ME: Book Equity to Market Equity

BM\&FBOVESPA: Bolsa de Valores, Mercadorias e Futuros

BMV: Bolsa Mexicana de Valores

CAA: Classical Asset Allocation

CAPM: Capital Asset Pricing Model

CRSP: Center for Research in Security Prices

EMDB: Emerging Markets Database

EUA: Estados Unidos da América

EWI: Equal-Weighted Index of stocks

FSE: Frankfurt Stock Exchange

HME: Hipótese dos Mercados Eficientes

HML: High Minus Low

Ibovespa: Índice Bovespa da BM\&FBOVESPA

IBrX: Índice Brasil 100 da BM\&FBOVESPA

ICE: Intercontinental Exchange

IFC: International Finance Corporation

LSE: London Stock Exchange

MSCI: Morgan Stanley Capital International

Nasdaq: National Association of Securities Dealers Automated Quotation

NYSE: New York Stock Exchange

S\&P 500: Índice Standard and Poor's 500

SMB: Small Minus Big

UMD: Up Minus Down 


\section{INTRODUÇÃO}

A busca por maiores retornos de mercado é uma das principais motivações dos investidores em ativos e valores mobiliários. Desta forma, a literatura de finanças apresenta um amplo espectro de técnicas e modelos que tratam do tema empregando conceitos variados, mas, em sua maior parte, oriundos da moderna teoria de finanças.

O pressuposto das análises tem sua origem nas discussões sobre a eficiência de mercado. A esse respeito, o prêmio Nobel de Economia de 2013 foi concedido a Eugene Fama, Lars Peter Hansen e Robert Shiller, todos eles autores que, de alguma forma, atuaram na evidenciação da Hipótese dos Mercados Eficientes (HME), desenvolvida originalmente por Fama (1970).

De acordo com Copeland, Weston e Shastri (2005), a hipótese dos mercados eficientes atraiu muito interesse e crítica, sendo que ninguém conseguiria superar o desempenho do mercado, ou seja, o efeito momento não deveria existir por contrariar a HME proposta por Fama (1970).

Assim, a existência de gestores de recursos que conseguem superar o índice de mercado em longos períodos de tempo é considerada uma anomalia e, a exemplo de outros fenômenos, precisa ser melhor estudada.

De forma assemelhada, tanto o efeito momento quanto o efeito contrário são apontados como anomalias da HME. O efeito momento é definido como a estratégia de manutenção de uma carteira de ações relativamente ganhadoras no passado (JEGADEESH E TITMAN, 1993, 2001) e o efeito contrário é a estratégia baseada na manutenção de uma carteira de ações relativamente perdedoras no passado (DE BONDT E THALER, 1985, 1987). Ambas estratégias podem apresentar retornos superiores à média dos retornos das demais ações.

Tanto o efeito momento quanto o efeito contrário foram estudados por diversos autores em mercados internacionais e no Brasil. Um dos precursores do efeito contrário é De Bondt e Thaler (1985), que identificaram retornos superiores com a estratégia de comprar e manter ações perdedoras em períodos passados no longo prazo. Tal efeito era mais pronunciado para empresas de menor porte, não tendo sido identificado nas empresas maiores. Com relação ao efeito momento, Jegadeesh e Titman (1993) identificaram retornos superiores com a estratégia de comprar e manter ações ganhadoras em períodos passados no médio prazo. 
De forma geral, os investidores que seguem o efeito momento buscam ações mais famosas, que estão na moda no curto prazo, enquanto investidores que seguem o efeito contrário buscam justamente as barganhas, ações de empresas que estão desvalorizadas por, quase sempre, serem pouco conhecidas, mas com grande potencial de valorização no longo prazo.

\subsection{Problema de pesquisa}

Cabe ao presente trabalho responder a seguinte pergunta-problema: Existem evidências do efeito momento ou do efeito contrário no mercado de ações brasileiro para o período estudado?

\subsection{Objetivos}

O objetivo principal desta dissertação é analisar a existência do efeito momento (JEGADEESH E TITMAN, 1993, 2001) e do efeito contrário (DE BONDT E THALER, 1985, 1987) para o mercado de ações brasileiro, utilizando retornos das empresas listadas na BM\&FBOVESPA entre julho de 1994 e junho de 2015.

\subsection{Hipóteses}

As quatro hipóteses de pesquisa são definidas a seguir para atender aos objetivos do trabalho:

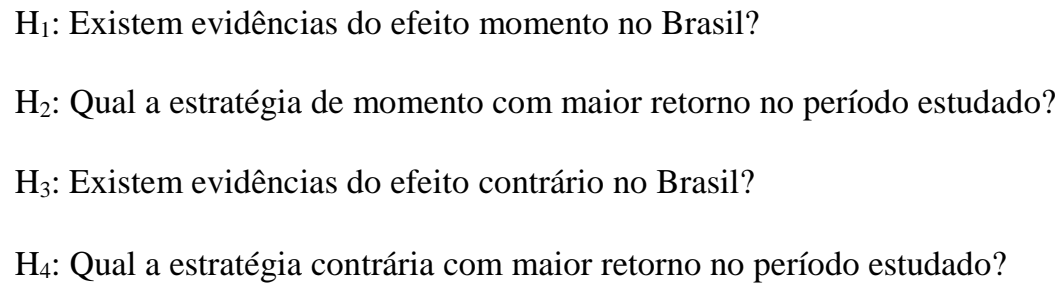




\subsection{Justificativa}

Dada a importância das discussões sobre eficiência de mercado atualmente, cabe realizar estudos sobre comportamento do mercado e, em particular, avaliar para o Brasil as ideias propostas por Jegadeesh e Titman (1993) em seu artigo fundamental "Returns to buying winners and selling losers: Implications for stock market efficiency".

Embora já tenham se passado trinta anos da publicação daquele artigo, sua relevância para o mercado de capitais brasileiro continua válida. Assim, a amostra considera um período de maior estabilidade econômica do país, mesmo que entremeada por crises ao redor do mundo como as de: 1995 no México; 1997 na Ásia; 1998 na Rússia; 1999 no Brasil; 2000 na bolsa de empresas de tecnologia Nasdaq; 2008 com quebra do banco Lehman Brothers; e 2011 com o aumento das dívidas públicas de diversos países da zona do Euro.

Minha experiência no mercado de capitais, tendo ocupado posições em algumas áreas da BM\&FBOVESPA e atualmente como Gerente de Relações com Investidores em empresa de capital aberto negociada em bolsa, despertou interesse em fazer uma contribuição ao tema na literatura acadêmica.

\subsection{Metodologia}

Esta dissertação analisou a bibliografia nacional e internacional sobre o assunto para identificar quais períodos de formação e manutenção da carteira seriam mais adequados à análise dos efeitos momento e contrário no Brasil.

Foi escolhida uma amostra intencional de 662 ações de empresas nacionais, coletadas no sistema Economática, para o período de julho de 1994 até junho de 2015. Os critérios de escolha do período foram: (i) ser o mais amplo possível; e (ii) preservar a condição de comparação entre os dados. Desta forma, escolheu-se o período após o início do Plano Real.

Foram levantados os retornos mensais dessas ações em negociação no mercado a vista da BM\&FBOVESPA, ajustados por proventos. Como critério de exclusão de ações sem liquidez, manteve-se na amostra apenas as ações com cotação no período analisado. 
Em seguida, utilizou-se o software MATLAB R2015a para tratamento dos dados. As ações foram classificadas conforme retorno no período e subdivididos em decís. Chegou-se a definição de um período de seleção de carteira de três, seis, nove e 12 meses e um período de manutenção da carteira de três, seis, nove, 12, 18 e 24 meses.

\subsection{Quadro resumo}

O Quadro 1 resume o problema de pesquisa, objetivos, hipóteses e metodologia dessa dissertação.

Quadro 1 - Resumo do trabalho

\begin{tabular}{|c|c|c|c|}
\hline $\begin{array}{c}\text { Problema de } \\
\text { pesquisa }\end{array}$ & Objetivos & Hipóteses & Metodologia \\
\hline \multirow{2}{*}{$\begin{array}{l}\text { Existem evidências } \\
\text { do efeito momento } \\
\text { ou do efeito } \\
\text { contrário no } \\
\text { mercado acionário } \\
\text { brasileiro entre } \\
1994 \text { e } 2015 ?\end{array}$} & $\begin{array}{l}\text { 1) Identificar evidências } \\
\text { do efeito momento no } \\
\text { mercado acionário } \\
\text { brasileiro }\end{array}$ & \multirow{2}{*}{$\begin{array}{l}\mathrm{H}_{1} \text { : Existem evidências do efeito } \\
\text { momento no Brasil? } \\
\mathrm{H}_{2} \text { : Qual a estratégia de momento } \\
\text { com maior retorno no período } \\
\text { estudado? } \\
\mathrm{H}_{3} \text { : Existem evidências do efeito } \\
\text { contrário no Brasil? } \\
\mathrm{H}_{4} \text { : Qual a estratégia contrária } \\
\text { com maior retorno no período } \\
\text { estudado? }\end{array}$} & $\begin{array}{l}\text { 1) Revisão } \\
\text { bibliográfica } \\
\text { 2) Estatística }\end{array}$ \\
\hline & $\begin{array}{l}\text { 2) Identificar evidências } \\
\text { do efeito contrário no } \\
\text { mercado acionário } \\
\text { brasileiro }\end{array}$ & & $\begin{array}{l}\text { descritiva } \\
\text { 3) Análise } \\
\text { quantitativa } \\
\text { univariada } \\
\text { 4) Testes de hipótese }\end{array}$ \\
\hline
\end{tabular}

\subsection{Contribuições e limitações}

O Brasil, por possuir importante mercado acionário global, líder na América Latina, carecia de um estudo atualizado sobre o assunto efeito momento, apesar de alguns autores terem feito algo semelhante no passado.

\subsection{Organização dos capítulos}

Após a introdução, em que são abordados o problema de pesquisa, justificativa e objetivos, apresenta-se a fundamentação teórica no capítulo 2, seguida da metodologia no capítulo 3, análise de resultados no capítulo 4, conclusões no capítulo 5 e, por fim, as referências bibliográficas utilizadas. 


\section{FUNDAMENTAÇÃO TEÓRICA}

Este trabalho utiliza a metodologia de efeito contrário de De Bondt e Thaler (1985), que preconiza a compra de ações que obtiveram no passado, medido entre três a cinco anos, desempenho relativo inferior (perdedoras) com vistas a produzir retorno anormal positivo durante períodos subsequentes. De forma inversa, utiliza o estudo de Jegadeesh e Titman (1993), cujos resultados apontam para a existência do efeito momento, que se caracteriza pela compra de ações com desempenho relativo superior (vencedoras), em períodos passados de até 12 meses, e que apresentaram retornos anormais positivos por períodos subsequentes de até 12 meses.

\subsection{A Hipótese dos Mercados Eficientes}

A Hipótese dos Mercados Eficientes (HME) foi formulada na década de 1970 e, desde então, teve grande repercussão no meio acadêmico, com diversos estudos e artigos a favor e contrários a seus pressupostos, principalmente, ao fato de assumir que os investidores tomam decisões racionais.

Graham e Dodd (1934), tidos como os pais do value investing, identificaram ações que estavam bastante depreciadas em relação a seus pares, sendo que tais papeis seriam os com maior potencial de retorno no futuro.

Para Fama (1970), mercado eficiente é aquele em que as cotações refletem integralmente todas informações disponíveis sobre os ativos financeiros. Em complemento, seria impossível obter retornos anormais em relação a carteira passiva de mercado, uma vez que um investidor médio não consegue superar consistentemente o mercado, desperdiçando recursos na gestão ativo dos investimentos (SHLEIFER, 2000).

Cabe destacar que Fama (1970) classifica a eficiência de mercado em três formas: (i) fraca, ou quando as informações passadas estão integralmente refletidas nos preços ou retornos históricos; (ii) semiforte, em que a preocupação é a velocidade de ajuste de preços a novas informações públicas, cujos exemplos mais evidentes são anúncios de desdobramento de ações, relatórios anuais e novas emissões de ações; (iii) forte, em que qualquer investidor ou gestor de fundo de investimento têm acesso exclusivo a qualquer informação relevante para a 
formação de preços antes dos demais. Naquela época, não havia evidências relevantes contra as hipóteses fraca e semiforte e apenas evidências limitadas contrárias a forma forte de eficiência de mercado.

Esse artigo suscitou diversas discussões no meio acadêmico nas décadas de 1970 e 1980 . Entre eles, Jensen (1978) cita que começaram a aparecer evidências de inconsistências da teoria de eficiência de mercado com a maior disponibilidade de informações e sofisticação econométrica. Para ele, a HME é um paradigma em finanças e seria a extensão da condição de equilíbrio de lucro zero, no qual não haveria lucro econômico nas negociações baseadas em um conjunto de informações, após considerar os custos. Para justificar as anomalias encontradas, cita alguns autores que rejeitaram a HME em seus artigos baseados em dados estatísticos provenientes do mercado real. Inclusive, Shiller (1980) afirmou que a HME seria um modelo "acadêmico", pois não descrevia os movimentos observados em seus dados.

Fama (1991), em seu segundo artigo sobre mercados eficientes vinte anos após sua primeira publicação sobre o tema, apresentou evidências de que os estudos de evento com dados diários de retorno mostram a rápida velocidade do ajuste de preços a novas informações e que insider traders com informações privadas conseguem retornos anormais, resultando em ineficiência de mercado e desequilíbrio de preços. Também citou a tentativa de previsão de retornos futuros de dias ou semanas baseadas em informações passadas, com evidências de autocorrelação dos retornos diários de ações de grandes empresas no curto prazo. Abordou brevemente o efeito contrário de De Bondt e Thaler (1985, 1987), bem como algumas críticas sobre seus resultados e metodologia, mas obviamente não analisou o efeito momento, que foi publicado apenas em 1993.

La Porta, Lakonishok, Shleifer e Vishny (1997) estudaram variações de preços próximo ao anúncio dos resultados para ações de valor e para ações renomadas em um período de cinco anos após formação das carteiras. Parcela significativa da diferença de retornos das ações de valor sobre as ações renomadas pós divulgação dos resultados pode ser explicada pela surpresa nos resultados das ações de valor, que são sistematicamente mais positivas. Além disso, as evidências apresentadas apontam inconsistência nas explicações baseadas em risco. Assim, tal estudo comprovou a forma semiforte de eficiência de mercado proposta por Fama (1970). 
Fama e French (1992) verificaram que o CAPM (Capital Asset Pricing Model) proposto por Sharpe (1964) não era suficiente para explicar o retorno dos ativos e propuseram o modelo de 3-fatores (FAMA e FRENCH, 1993). Nele, além do Beta, adicionaram o fator tamanho e a capitalização - relação do valor contábil em relação ao valor mercado - para explicar os retornos dos ativos, que capturava a maior parte das anomalias não assimiladas pelo fator mercado (no caso o Beta), ficando ainda de fora a anomalia denominada "momento".

O modelo de 3-fatores proposto por Fama e French (1993) afirma que o retorno esperado de uma carteira acima da taxa livre de risco é explicado por: (i) retorno excedente de uma carteira de mercado; (ii) a diferença de retorno entre retorno carteira de pequenas ações e de grandes ações (SMB, pequenas menos grandes); e (iii) diferença de retorno de carteiras de alto valor patrimonial sobre valor de mercado (BE/ME) as de baixo B/M (HLM, alto menos baixo).

Lakonishok, Shleifer e Vishny (1994) apresentaram evidências de que as estratégias de investimento em valor exploram o comportamento irracional dos investidores típicos, não por serem mais arriscadas. Assim, as estratégias contrárias em adquirir ações com bons retornos passados em relação as demais eram mais rentáveis.

Fama e French (1996) notaram que o modelo de 3-fatores de Fama e French (1993) capturava o efeito contrário apresentado por De Bondt e Thaler (1985), mas não explicava o retorno de todos os ativos e carteiras devido a anomalias de mercado. Entre eles, não foi possível explicar os retornos de curto prazo de carteiras vencedoras proposto por Jegadeesh e Titman (1993).

Carhart (1997) passou a adicionar o efeito momento de um ano identificado por Jegadeesh e Titman (1993) ao modelo dos 3-fatores proposto por Fama e French (1993) para analisar fundos de investimento, que explicava de forma mais assertiva os retornos de um ativo ao considerar alguns múltiplos de mercado. Assim, surge como o modelo de 4-fatores de Carhart (1997) para melhor explicar retornos das ações listadas na NYSE, AMEX e Nasdaq (National Association of Securities Dealers Automated Quotation).

No Brasil, Camargos e Barbosa (2003) fizeram um apanhado dos estudos sobre eficiência do mercado de capitais brasileiro, tendo identificado 24 pesquisas sobre o tema na bibliografia 
nacional, dispostos da seguinte forma: (i) 10 trabalhos sobre a forma fraca, com sete confirmações da HME; (ii) oito trabalhos sobre a forma semiforte, com duas confirmações da HME; (iii) 3 trabalhos sobre anomalias, com uma confirmação da HME. Assim, 14 das 24 análises não identificaram eficiência de mercado no país.

Antunes e Procianoy (2003) e Camargos e Romero (2006) realizaram estudos de evento com o objetivo de analisar a eficiência do mercado brasileiro. O primeiro estudo (Id., 2003) aponta resultados que indicam relação entre variação do ativo permanente e do preço das ações, evidenciando que o mercado de capitais pode reagir aos sinais divulgados pelas empresas. $\mathrm{O}$ segundo estudo (Ibid., 2006) atestou impacto na precificação de ações em anúncios de fusões e aquisições e adesão aos níveis diferenciados de governança, sem confirmação em lançamento de ADRs no mercado internacional.

\subsection{Teoria comportamental de finanças}

Tversky e Kahneman (1974) abordaram três heurísticas na tomada de decisão em situações que envolvem incerteza, levando a erros na tomada de decisão: (i) representatividade, quando há simplificação de algum problema e os julgamentos são feitos com base em eventos predeterminados; (ii) disponibilidade, quando os eventos mais frequentes ou mais prováveis são mais lembrados que os demais; (iii) ancoragem, quando há valores iniciais de referência que impactam a decisão.

Além disso, a Teoria do Prospecto ou Teoria da Perspectiva de Kahneman e Tversky (1979) trouxe grandes contribuições para o entendimento das Finanças Comportamentais e da tomada de decisão em situações de risco, inconsistentes com a Teoria da Utilidade Esperada de Von Neumann e Morgenstern (1944). As características mais marcantes foram a aversão ao risco em escolhas de ganho certo e busca por risco em escolhas com certeza de perda, o que contraria a racionalidade na tomada de decisão.

De Bondt e Thaler (1995) alegam que as finanças modernas querem soluções racionais para resolver problemas observados empiricamente e que é bom que haja diversificação nos métodos para a ciência evoluir. Algumas anomalias observadas na prática do contexto econômico podem ser explicadas pelo comportamento das pessoas, conhecidos pela psicologia. 
Fama (1998) afirmou que a literatura financeira apresentou diversas anomalias na análise de retornos no longo prazo, mas evidências não sugerem que a hipótese de eficiência de mercado deveria ser abandonada. Em discordância com as Finanças Comportamentais, ele destacou que as anomalias de retorno a longo prazo eram frágeis e tenderiam a desaparecer com as mudanças na forma de medi-las.

Daniel, Hirshleifer e Subrahmanyam (1998) apresentaram uma teoria das reações nos preços de ativos baseada em dois conceitos psicológicos bastante conhecidos: excesso de confiança dos investidores sobre a precisão de informações privadas; e viés de auto atribuição (selfattribution bias), em que resultados bem-sucedidos devem-se a própria habilidade e resultados malsucedidos à falta de sorte. Tais aspectos seriam as causas das mudanças na confiança dos investidores em decorrência dos resultados obtidos nos investimentos. Os resultados apontam que o excesso de confiança ocasiona autocorrelações negativas de longo prazo e aumento da volatilidade. O viés de auto-atribuição provoca autocorrelações positivas de curto prazo (“momentum”), não sendo fáceis de explicar a precificação de ativos de forma racional.

Halfeld e Torres (2001) revisaram pesquisas sobre finanças comportamentais no cenário internacional e os primeiros estudos sobre anomalias encontrados no mercado financeiro nacional. Os autores citam a sobre-reação observada no mercado financeiro brasileiro como evidência de irracionalidade, apesar de os estudos sobre finanças comportamentais serem pouco abordados no país até então.

De forma análoga, Lima (2003) abordou o tema pela elevada repercussão internacional, que não era observada amplamente no Brasil. O objetivo proposto pelo autor era introduzir o tema e as análises de autores consagrados, sem apresentar novos resultados ao aplicar a metodologia internacional a dados de mercado nacional.

Milanez (2003) afirma que a manipulação de dados de mercado pelas empresas emissoras, em princípio, não deveria preocupar os reguladores, uma vez que o pressuposto de racionalidade dos investidores acabaria com a distorção nos preços. No entanto, conforme teoria comportamental, há alguns vieses cognitivos que induzem os investidores a erros, por isso 
seria necessário garantir proteção aos investidores em ocasiões oportunistas dos agentes de mercado financeiro.

Rabelo Junior e Ikeda (2004) estudaram a importância da arbitragem no contexto dos mercados eficientes. Em mercados reais, a arbitragem não consegue atuar como ferramenta reguladora do mercado para refletir corretamente os preços dos ativos, por ser custosa ou de realização limitada. Assim, possíveis arbitradores podem evitar realizar determinadas transações, fazendo com que a anomalia na precificação seja perpetuada ou aumentada. Tal fato ocorre pela presença de pessoas no mercado, que claramente não são racionais o tempo todo.

Kimura, Basso e Krauter (2006) replicaram a Teria do Prospecto (KAHNEMAN E TVERSKY, 1979) em uma amostra no Brasil. Os resultados encontrados apresentam vieses de percepção nas decisões, independente da evolução do mercado acionário, aspectos culturais ou nacionalidade dos indivíduos. Assim, no estudo nacional também houve violação da premissa de busca por maximização da utilidade esperada, corroborando o artigo original.

De forma semelhante, Rogers, Securato e Ribeiro (2007) buscaram replicar a metodologia de Kahneman e Tversky (1979). Os resultados indicam que as decisões desviam da racionalidade em muitos casos, corroborando a Teoria do Prospecto, sem que haja efeitos relevantes de vieses culturais.

Famá, Cioffi e Coelho (2008) verificaram que o mercado de capitais nacional apresenta tanto anomalias quanto eficiências. As Finanças Comportamentais foram importantes para explicálas em parte, mas sugeriram que os modelos que consideram os investidores racionais devem ser aperfeiçoados e incorporar estudos sobre irracionalidade.

Mussa, Yang, Trovão e Famá (2008) fizeram uma análise da evolução das teorias de eficiência de mercado e de Finanças Comportamentais. Até meados da década de 1980, os trabalhos concluíam que o mercado era eficiente. Posteriormente, com a evolução da computação, surgira, evidências de ineficiência do mercado. Nesse novo contexto, surgiram as Finanças Comportamentais - junção de finanças, sociologia, psicologia e antropologia para explicar as teorias favoráveis e contrárias a eficiência de mercado, ampliando as controvérsias existentes. 
Yoshinaga, Oliveira, Silveira e Barros (2008) citam que as teorias tradicionais de finanças consideram a racionalidade dos agentes econômicos como paradigma central. No entanto, tal paradigma não consegue explicar satisfatoriamente diversos fenômenos do mercado financeiro que ocorrem na prática, pois as pessoas nem sempre agem racionalmente, conforme explicado pela psicologia. Assim, de acordo com estudos da área de Finanças Comportamentais, a irracionalidade dos agentes econômicos pode influenciar bastante os preços dos ativos.

\subsection{Estudos internacionais sobre efeitos momento e contrário}

O artigo de De Bondt e Thaler (1985) mostrou a tendência dos compradores de reagir de forma exagerada em eventos ou notícias inesperadas, afetando o preço das ações negociadas no mercado. $\mathrm{O}$ resultado constatou que em um período de três a cinco anos, comprar ações que tiveram desempenho ruim (comprar perdedores) atingiram maiores retornos em semelhante período no futuro do que ações com desempenho positivo no passado, algo que sugeria uma reação exagerada do mercado, favorecendo as estratégias contrárias.

Segundo os autores (Id., 1985), caso o preço das ações tenha oscilação sistematicamente grande em uma direção, a direção contrária consegue ser prevista apenas com base em retorno passado e não com base em dados contábeis. Assim, sugerem duas hipóteses: (1) movimentos extremos no preço das ações são seguidos por movimentos nos preços na direção oposta; (2) quanto mais extremo for o movimento de preços, maior será o ajuste subsequente.

O estudo focou em ações que apresentaram retornos extremos, tanto positivos quanto negativos, em períodos de até cinco anos. As carteiras formadas levaram em conta retornos passados e não suas informações financeiras, utilizando retornos mensais das ações negociadas na bolsa de Nova Iorque (NYSE, New York Stock Exchange), entre janeiro de 1926 e dezembro de 1982, utilizando como índice de mercado a média de todos as ações ordinárias compiladas pelo CRSP (Center for Research in Security Prices) da Universidade de Chicago.

Os resultados encontrados corroboram a hipótese de reação exagerada, com carteiras "perdedoras" (baixo retorno passado) de 35 ações com desempenho, em média, 19,6\% 
superior ao do índice de mercado 36 meses após formação da carteira. Por outro lado, as carteiras "ganhadoras" (alto retorno passado), apresentaram desempenho, em média, 5,0\% inferior à do índice de mercado; ou seja, a diferença acumulada das médias foi de 24,6\% . Cabe notar que a reação exagerada foi demasiadamente maior para carteiras perdedoras; boa parte dos retornos anormais foram encontrados no mês de janeiro; o fenômeno foi mais evidente entre o segundo e terceiro anos do período de teste.

Pouco depois, De Bondt e Thaler (1987) publicaram novo estudo com evidências da reação dos investidores. Dessa vez, a hipótese de reação do mercado (ações perdedoras apresentarem desempenho superior as ganhadoras) supostamente seria inconsistente com a de tamanho das empresas e diferença de risco medida pelo CAPM. O forte retorno nos meses de janeiro estaria relacionado tanto com o retorno de curto e longo prazos quanto ao retorno do mercado no ano anterior.

Para explicar o efeito momento, o estudo de Jegadeesh e Titman (1993) analisou retorno de ações entre 1965 e 1989, sugerindo um viés nos investidores por comprarem ações que tiveram bom desempenho passado em relação as demais, esperando que esse desempenho seria repetido no futuro, e vendessem ações com desempenho relativo ruim, utilizar períodos mais curtos do que os utilizados por De Bondt e Thaler (1985). Os autores identificaram que a rentabilidade da estratégia de comprar "vencedores" e vender "perdedores" não se deveu ao atraso nas reações no preço das ações, apesar dos retornos anormais terem sido identificados no primeiro ano após formação das carteiras, sendo dissipados nos dois anos seguintes.

Nesse estudo (Id., 1993), foram utilizados períodos entre três e 12 meses para formação da carteira quanto para a estimação dos resultados, das empresas negociadas na AMEX (American Stock Exchange) e NYSE, atualmente parte dos negócios da ICE (Intercontinental Exchange), entre os anos de 1965 a 1989.

Os resultados mostraram que os vencedores do passado apresentaram desempenho melhor que o dos perdedores, contrapondo os estudos de De Bondt e Thaler (1985), apesar de terem sido encontradas algumas exceções que reverteram esse resultado. A estratégia considerada foi selecionar ações de acordo com seus retornos em períodos de um a quatro trimestres, com períodos de apuração de um a quatro trimestres, totalizando 16 estratégias possíveis. Também se examinou as 16 estratégias com uma semana de defasagem entre o período de formação de 
carteira e de estimação, reduzindo a diferença entre ofertas de compra e venda e eventuais preços nos preços.

Quanto à análise de retorno das ações próximo ao anúncio de resultados, encontrou-se que ganhadores no passado tiveram retornos superiores consistentes nos sete meses seguintes à data de formação da carteira do que os perdedores. No entanto, após 13 meses, os perdedores tiveram retornos superiores ao dos ganhadores próximo a divulgação dos resultados.

Isso seria evidência de que a reação exagerada - positiva ou negativa - tem atraso para ser manifestada no mercado. Das 16 estratégias estudadas, os autores identificaram que em 15 houve retornos anormais positivos, contrariando a hipótese de eficiência de mercado de Fama (1970), em que o pressuposto era de o mercado reagir racionalmente e de forma rápida as variações de preços.

Jegadeesh e Titman (1993) ranquearam as ações em ordem crescente de retornos passados, então divididas em 10 decis, com os mesmos pesos nas 10 subcarteiras, sendo a carteira superior (de menor retorno passado) chamada de "perdedora" e a carteira inferior (de maior retorno passado) de "ganhadora". Foram utilizados retornos diários de todas as ações com dados disponíveis nos $\mathrm{J}$ meses ( $\mathrm{J}=3,6,9$ ou 12 meses) anteriores a formação da carteira entre 1965 e 1989, das carteiras de retorno dos vencedores menos perdedores (carteiras de custo zero) para as 32 estratégias. A manutenção de cada subcarteira se deu por $\mathrm{K}$ meses $(\mathrm{K}=3,6$, 9 ou 12 meses.

O retorno de todas as carteiras de custo zero foram positivos e estatisticamente significativos, exceto para a carteira " $3 \times 3$ ”, de três meses (formação) contra três meses (estimação) que não tinham defasagem de uma semana, com valores suficientemente altos da estatística $t$. Dessas carteiras, a com maior retorno relativo foi formada em 12 meses anteriores com manutenção por três meses, ou carteira "12x3", com retorno superior a 1,31\% ao mês. Se considerar a carteira " $12 \times 3$ " formada com defasagem de uma semana, o retorno foi de 1,49\%, apresentados na Tabela 1 a seguir: 
Tabela 1 - Retornos das estratégias de Jegadeesh e Titman (1993)

\begin{tabular}{|c|c|c|c|c|c|c|c|c|c|c|c|}
\hline & \multirow[b]{2}{*}{$J$} & \multicolumn{5}{|c|}{ Panel A } & \multicolumn{5}{|c|}{ Panel B } \\
\hline & & $K=$ & 3 & 6 & 9 & 12 & $K=$ & 3 & 6 & 9 & 12 \\
\hline \multirow[t]{2}{*}{3} & Sell & & 0.0108 & 0.0091 & 0.0092 & 0.0087 & & 0.0083 & 0.0079 & & \\
\hline & & & $(2.16)$ & (1.87) & (1.92) & $(1.87)$ & & (1.67) & (1.64) & (1.77) & $(1.7$ \\
\hline \multirow[t]{2}{*}{3} & Buy & & 0.0140 & 0.0149 & 0.0152 & .0156 & & 0.0156 & 0.0158 & 0.0158 & 0.0 \\
\hline & & & (3.57) & (3.78) & (3.83) & (3.89) & & (3.95) & (3.98) & (3.96) & (3.9 \\
\hline \multirow[t]{2}{*}{3} & Buy-sell & & 0.0032 & 0.0058 & 0.0061 & & & 0.0073 & 0.0078 & 0.0074 & 0.0 \\
\hline & & & (1.10) & $(2.29)$ & (2.69) & (3.5 & & (2.61) & $(3.16)$ & (3.36) & $(4.0$ \\
\hline \multirow[t]{2}{*}{6} & Sell & & 0.0087 & 0.0079 & 0.0072 & & & 0.0066 & 0.0068 & 0.0067 & \\
\hline & & & (1.67) & $(1.56)$ & $(1.48$ & (1.6 & & $(1.28)$ & $(1.35)$ & (1.38) & $(1.5$ \\
\hline \multirow[t]{2}{*}{6} & Buy & & 0.0171 & 0.01 & 0.0 & & & 0.0 & 0.0178 & 0.0175 & \\
\hline & & & $(4.28)$ & (4.33) & $(4.3]$ & $(4.1$ & & $(4.4$ & (4.41) & $(4.3$ & $(4.1$ \\
\hline \multirow[t]{2}{*}{6} & Buy-sell & & 0.0084 & 0.0095 & 0.0102 & 0.0 & & 0.0114 & 0.0110 & 0.0108 & \\
\hline & & & (2.44) & $(3.07)$ & $(3.76)$ & (3.3 & & (3.3 & $(3.61)$ & $(4.0$ & $\left(3 . t^{2}\right)$ \\
\hline \multirow[t]{2}{*}{9} & Sell & & 0.0077 & 0.0065 & 0.0071 & 0.0082 & & 0.0058 & 0.0058 & 0.0066 & 0.0 \\
\hline & & & (1.47) & (1.29) & (1.43) & $(1.66)$ & & (1.13 & (1.15) & (1.34) & $(1.5$ \\
\hline \multirow[t]{2}{*}{9} & Buy & & 0.0186 & 0.0186 & 0.0176 & 0.0164 & & 0.0193 & 0.0188 & 0.0176 & 0.0164 \\
\hline & & & $(4.56)$ & (4.53) & $(4.30)$ & $(4.03$ & & $(4.72)$ & $(4.56)$ & $(4.30)$ & $(4.04)$ \\
\hline \multirow[t]{2}{*}{9} & Buy-sell & & 0.0109 & 0.0121 & 0.0105 & 0.0082 & & 0.0135 & 0.0130 & 0.0109 & 0.0085 \\
\hline & & & $(3.03)$ & $(3.78)$ & $(3.47)$ & $(2.89)$ & & $(3.85)$ & $(4.09)$ & $(3.67)$ & $(3.04)$ \\
\hline \multirow[t]{2}{*}{12} & Sell & & 0.0060 & 0.0065 & 0.0075 & 0.0087 & & 0.0048 & 0.0058 & 0.0070 & 0.0085 \\
\hline & & & (1.17) & (1.29) & (1.48) & (1.74) & & $(0.93)$ & (1.15) & $(1.40)$ & (1.71) \\
\hline \multirow[t]{2}{*}{12} & Buy & & 0.0192 & 0.0179 & 0.0168 & 0.0155 & & 0.0196 & 0.0179 & 0.0167 & 0.0154 \\
\hline & & & (4.63) & $(4.36)$ & $(4.10)$ & & & $(4.73)$ & $(4.36)$ & $(4.09)$ & (3.79) \\
\hline \multirow[t]{2}{*}{12} & Buy-sell & & 0.0131 & 0.0114 & 0.0093 & 0.0068 & & 0.0149 & 0.0121 & 0.0096 & 0.0069 \\
\hline & & & & & & & & $(4.28)$ & (3.65) & $(3.09)$ & $(2.31)$ \\
\hline
\end{tabular}

FONTE: Jegadeesh e Titman (1993)

A conclusão encontrada por Jegadeesh e Titman (1993) foi a de que comprar ganhadores do passado e vender perdedores do passado proporcionou retornos anormais significativos entre 1965 e 1989. A estratégia "6x6", usar retorno relativamente altos nos seis meses anteriores e manter essa carteira por seis meses, examinada em maior detalhe, proporcionou um retorno composto anual, em média, superior a 12\%. Além disso, o estudo identificou que esses ganhos não podem ser atribuídos a reações atrasadas no preço das ações decorrentes de fatores comuns, sendo dissipados nos dois anos seguintes ao do retorno.

Chopra, Lakonishok e Ritter (1992) tentaram prever o retorno de ações com base em informações passadas, um dos temas mais controversos das finanças. A grande questão era se as ações negociadas em bolsa apresentaram reação exagerada à alguma informação. A abordagem utilizada levou em consideração outra forma de estimar o Beta das ações e o tamanho das empresas. As carteiras perdedoras tiveram desempenho superior as carteiras vencedoras em 6,5\% ao ano. Com dados mensais de retorno, o desempenho foi $9,5 \%$ ao ano superior para as carteiras perdedoras, predominante em empresas pequenas. 
Lakonishok, Shleifer, Vishny (1994) identificaram, um ano após os estudos de Jegadeesh e Titman, o efeito contrário, ou seja, retornos negativos (positivos) após períodos positivos (negativos) de retorno. Assim, foi identificado justamente o oposto daquilo que havia sido encontrado no início da década de 1990 no mercado americano por Jegadeesh e Titman (1993), mas confirmou-se os estudos anteriores de De Bondt e Thaler (1985).

O pressuposto de Lakonishok, Shleifer, Vishny (1994) foi o de que investir na estratégia de valor (value investing), ou seja, em ações com múltiplos baixos, por exemplo de preço sobre lucro, tem desempenho superior ao da média ou índice de mercado. Embora haja certa concordância quanto a isso, os motivos para isso são controversos. Esse estudo traz evidências de que essa estratégia contraria popularmente seguidas pelos investidores (como esperar que a rentabilidade passada se repita no futuro) e não por terem maior risco, medidos pelos Betas e desvio padrão, que explicariam o maior retorno.

Ao contrário da razão, alguns investidores ingênuos são atraídos a comprar ações que tiveram bom desempenho passado, criando ações que "estão na moda" naquele momento, notadamente, com preços muito elevados. O contraponto é que esses investidores repelem ações que tiveram desempenho ruim, fazendo com que elas se tornem subavaliadas; assim, investidores que apostam contrariamente aos ingênuos e têm mais paciência superam o mercado por comprar ações menos prestigiadas e mais baratas, exatamente o que identificou De Bondt e Thaler (1985). O pressuposto anterior, de ações de valor (value stocks) identificadas por Graham e Dodd (1934), era de que as ações mais atrativas possuíam bom desempenho passado e as menos atrativas eram as que tiveram desempenho ruim, sem esperança de melhora.

Lakonishok, Shleifer, Vishny (1994) analisaram o mercado norte-americano entre abril de 1963 e abril de 1990, com amostra de cerca de seis mil empresas ações listadas apenas na NYSE e AMEX, disponibilizadas pelo CRSP e COMPUSTAT. Ressalta-se que nessa amostra foi identificado potencial viés de sobrevivência das empresas nos resultados, tendo sido mitigado por requerer cinco anos de informações para que fossem iniciadas a análise das estratégias, excluídas as empresas listadas na Nasdaq.

Além disso, Lakonishok, Shleifer, Vishny (1994) usaram medida de desempenho passado como crescimento de vendas, lucro, fluxo de caixa (lucro mais depreciação); como 
performance esperada, múltiplos de preço/lucro e fluxo de caixa. Depois, separaram a amostra entre ações glamorosas e ações de valor com base no crescimento passado e estimado para o futuro. Assim, identificaram que o retorno maior foi da estratégica contrária de seguir a estratégia de comprar ações de valor, em valores de $10 \%$ a $11 \%$ ao ano, sendo também superior quando restritas às 50\% e 20\% maiores companhias em valor de mercado. Os resultados foram ajustados pelo tamanho das empresas, divididas em decís de capitalização de mercado no ano anterior.

Grinblatt, Titman e Wermers (1995) analisaram fundos de investimento que tiveram retornos anormais positivos ao utilizarem a estratégia do efeito momento, sem considerar as taxas de administração e custos de transação. Fundos mútuos apresentaram tendência de comparar ações que tiveram bom desempenho passado, ou seja, seguiam um "comportamento de manada" e tinham as mesmas estratégias dos demais fundos, selecionando as mesmas ações, mas não necessariamente no mesmo tempo. No entanto, após os custos de transação, os ganhos do efeito momento eram perdidos.

Os autores identificaram que $77 \%$ dos fundos de investimentos eram investidores de momento, comprando ações vencedoras no passado, mas muitos não vendiam ações de empresas perdedoras. Os dados levaram em conta dados trimestrais de 274 fundos mútuos entre 31 de dezembro de 1974 a 31 de dezembro de 1984 e retornos mensais de ações listadas na NYSE e AMEX compiladas pela CRSP. Essa tendência de comprar vendedores é altamente correlacionada com a performance dos fundos, mas, como disse Jegadeesh e Titman (1993), a performance dessa estratégia tende a se dissipar no futuro, bem como o retorno dos fundos que a seguem.

Chan, Jegadeesh e Lakonishok (1996) examinaram se a previsibilidade de retornos futuros utilizando retornos passados deve-se à reação do mercado abaixo do esperado em relação à informação, notadamente, divulgação de resultados. Foi encontrada pouca evidência de reviravoltas nos retornos de ações com preço elevado e momento de ganhos, sugerindo que o mercado responde apenas gradualmente a novas informações, o que contraria Fama (1970).

Foram consideradas todas as ações listadas na NYSE, AMEX e Nasdaq entre janeiro de 1977 e janeiro de 1993, ranqueadas de acordo com o retorno ou resultados passados, divulgados pelo menos três meses antes. Confirmou-se que retornos futuros entre seis e 12 meses são 
previsíveis a partir do retorno e de notícias passadas. Mas os resultados sugerem que ações com baixo retorno passado, em média, tendem a obter baixo retorno subsequente, tomadas por um longo período de pessimismo.

Carhart (1997) identificou que fundos de investimentos com performance ruim persistiam com desempenho baixo no futuro, por isso deviam ser evitados. Os dados utilizados eram de retornos mensais de 1.892 fundos de ações diversificados entre janeiro de 1962 a dezembro de 1993 livres de viés de sobrevivência, apesar de um terço terem deixado de operar até o final de 1993.

Além disso, Carhart (1997) concluiu que a persistência de curto prazo (um ano) dos retornos dos fundos de investimento em ações é explicada por fatores como retorno das ações da carteira e custos de transação. Comprar fundos do decíl de maior retorno no ano anterior e vender fundos do decíl de menor desempenho apresentaram retorno $8 \%$ ao ano superior à média, mas esse efeito momento em fundos não foi persistente por mais de um ano. Desse percentual, 4,6\% é explicado pelo valor de mercado e efeito momento nas ações, $0,7 \%$ por diferença nas despesas cobradas e $1 \%$ por diferença nos cursos de transação, ou seja, quanto maior forem os custos, despesas e taxas, menor o retorno dos fundos.

Na Europa, Rouwenhorst (1998) confirmou o efeito momento para mercados acionários fora dos Estados Unidos, demonstrando que o retorno das ações está relacionado ao desempenho passado. Foram utilizadas informações de 2.190 ações de 12 países europeus entre 1978 e 1995, focado no retorno de médio prazo.

O autor identificou que comprar ações vencedoras e vender ações perdedoras, ambas no médio prazo, davam um retorno aproximadamente $1 \%$ ao mês superior à média de mercado, sendo que esse efeito momento foi identificado em todos mercados analisados (Áustria, Bélgica, Dinamarca, França, Alemanha, Itália, Holanda, Noruega, Espanha, Suécia, Suíça e Reino Unido), cobrindo de $60 \%$ a $90 \%$ da capitalização bursátil ou valor de mercado de cada país, convertidas para a moeda alemã da época.

A metodologia utilizada replicou a de Jegadeesh e Titman (1993), ou seja, as ações com retorno nos 12 meses anteriores foram divididas decis, com base no retorno passado de três, seis, nove ou 12 meses. Após ordenar os retornos em ordem crescente de retornos passados, a 
primeira subcarteira (menor desempenho) era a perdedora e décima subcarteira a ganhadora (maior desempenho). Tais subcarteiras foram mantidas por períodos de três, seis, nove ou 12 meses, sem qualquer rebalanceamento. $\mathrm{O}$ valor das carteiras vencedoras menos perdedoras ficou entre $0,64 \%$ e $1,35 \%$ ao mês, todas significantes a $5 \%$ pelo teste-t de Student.

Conrad e Kaul (1998) identificaram lucros significativos no mercado norte-americano tanto com a estratégia do momento (continuidade da alta de preços) quanto com a estratégia contrária (reversão de preços em queda), dependendo do período analisado. Em resumo, apesar de ambas estratégias serem bem-sucedidas, a estratégia de momento era rentável para prazos médios (três a 12 meses, exceto entre 1926 e 1947), enquanto a estratégia contrária era mais rentável para intervalos mais longos, mas apenas entre 1926 e 1947 elas eram estatisticamente significantes.

Schiereck, De Bondt e Weber (1999) estudaram o mercado germânico, compreendendo 357 empresas alemãs listadas no segmento principal na FSE (Frankfurt Stock Exchange, hoje parte da Deutsche Börse AG) entre 1961 e 1991. Como as regras de negociação na bolsa alemã eram diferentes de Nova Iorque, os autores queriam verificar a presença do efeito momento no curto prazo e do efeito contrário no longo prazo, a exemplo do que foi encontrado no mercado norte-americano. Entre as conclusões, foram encontradas evidências de que o efeito momento - para períodos curtos - e o efeito contrário - para períodos longos superaram o índice de mercado utilizado, corroborando os estudos realizados no Estados Unidos.

Em outra análise, Rouwenhorst (1999) refez seus estudos nos mercados emergentes e confirmou o efeito momento presente nos mercados desenvolvidos, sendo que (1) ações de empresas menores tiveram desempenho superior ao das empresas maiores; (2) ações com de valor (value stocks, com elevados múltiplos de valor patrimonial sobre valor de mercado, lucros sobre preço e fluxo de caixa sobre preço) tiveram desempenho melhor que das ações de crescimento (growth stocks, com baixos múltiplos listados anteriormente); (3) não encontrou evidencias de que ações com betas maiores têm rentabilidade maior do que ações com betas menores; (4) há correlação forte entre os fatores de desempenho e a liquidez das ações.

A amostra de Rouwenhorst (1999) possuía dados de 1.750 ações de 20 mercados emergentes, extraídos do EMDB (Emerging Markets Database) do IFC (International Finance 
Corporation), contendo pelo menos sete anos de histórico. Com isso, foram excluídos da base de dados inicial 11 países por ausência de histórico de preços. O período utilizado era de janeiro de 1982 a abril de 1997, dos seguintes países: Argentina, Brasil, Chile, Colômbia, Grécia, Indonésia, Índia, Jordânia, Coréia do Sul, Malásia, México, Nigéria, Paquistão, Filipinas, Portugal, Taiwan, Tailândia, Turquia, Venezuela e Zimbábue.

Para o Brasil, a amostra continha 87 ações entre 1982 e 1997, com retorno anormal (carteira dos vencedores menos a dos perdedores) positivo de apenas $0,01 \%$ ao mês. A mediana do múltiplo B/M (book-to-market value) teve seu maior valor na amostra de ações brasileiras de 1,62 , ou seja, elas estavam relativamente mais descontadas que nos outros mercados.

Hong e Stein (1997, 1999), identificaram duas hipóteses principais: informações específicas das empresas difundem-se gradualmente ao mercado e que investidores não conseguem extrair informações racionalmente a partir do preço das ações. Essas premissas em conjunto geram sub-reações (underreaction) e autocorrelações com retornos positivos. Com isso, empresas com dispersão mais lenta de informações apresentariam maior efeito momento.

Jegadeesh (1990) apresentou evidencias da previsibilidade no comportamento dos retornos individuais das ações. Foram encontradas correlações fortes entre os retornos mensais das ações em diferentes períodos, sendo que a diferença entre o retorno anormal da carteira do decil mais rentável no período entre 1934 e 1987 foi de 2,49\% ao mês, de 2,20\% excluído o mês de janeiro e de 4,37\% apenas em janeiro. Assim, os resultados rejeitam a hipótese de passeio aleatório (random walks).

Hong, Lim e Stein (2000) testaram o modelo de difusão gradual de informações proposto por Hong e Stein (1999), estabelecendo três resultados principais. Primeiro, que a rentabilidade da estratégia do momento reduz fortemente com o aumento do tamanho da empresa; segundo, que considerando o mesmo tamanho, a estratégia do momento é mais efetiva para ações com menor cobertura de analistas; terceiro, que o efeito da cobertura de analistas é mais relevante para ações perdedoras do que para ganhadoras. Esse diagnóstico é, segundo os autores, consistente com a hipótese de que informações específicas das empresas, especialmente as negativas, são difundidas gradualmente para os investidores. 
Os retornos das ações estudadas (Id., 2000) foram retirados do CRSP, contendo dados mensais da NYSE, AMEX e Nasdaq, com testes do efeito momento foram aplicados em um período entre 1980 e 1996, para período de formação da carteira considerando o retorno seis meses antes e mantida pelo período de seis meses (carteira 6x6). Para o período de formação, a amostra foi dividida de acordo com os retornos, ordenados de forma crescente, dividida em apenas três subcarteiras (P1, com 30\% piores retornos; P2, com 40\% retornos médias; e P3, com 30\% melhores retornos) e não 10 subcarteiras de mesmo peso como proposto por Jegadeesh e Titman (1993).

Também se considerou o tamanho das empresas, separando-as em decis, podendo ser identificado o efeito momento (P3 - P1) decrescer com o aumento do tamanho das empresas, desconsiderando aquelas muito pequenas, que apresentaram momento negativo. $\mathrm{O}$ retorno dessa estratégia foi positivo em $0,53 \%$ ao mês, estatisticamente significante (teste-t $=2,61$ ).

Ang, Chen e Xing (2001) verificaram uma parte da rentabilidade de investir na estratégia de momento pode ser explicado como uma compensação por suportar alta exposição a ações que possuem maior risco de queda nos preços (downside risk), ou ações com maior correlação com o mercado (Beta) em momentos descendentes. Depois de controlar o Beta de mercado, o efeito tamanho e o efeito valor contábil sobre valor patrimonial (B/M, ou book-to-market value), a carteira de maior risco de queda superou a de menor risco de queda em $6,55 \%$ ao ano. Os dados utilizados consideram ações ordinárias da NYSE e AMEX, extraídos do CRSP, com dados diários de retorno entre $1^{\circ}$ de janeiro de 1964 e 31 de dezembro de 1999. Os dados da Nasdaq, disponíveis após 1972, também foram incluídos na amostra.

Jegadeesh e Titman (2001) refizeram o estudo de Jegadeesh e Titman (1993), também para o mercado norte-americano, e confirmaram aquilo que haviam feito anteriormente, ou seja, identificaram novamente o efeito momento na década de 1990, sugerindo que os resultados não sofreram viés na base de dados. $\mathrm{O}$ artigo também analisou se a rentabilidade do efeito momento devia-se a reações atrasadas e exageradas, que eventualmente seriam revertidas. Dessa vez, analisou-se três períodos: (i) de 1965 a 1989, ou seja, o mesmo utilizado no estudo de 1993; (ii) mais nove anos, ou de 1990 a 1998; e (iii) toda a série, de 1965 a 1998.

Dessa vez foram analisadas todas as ações negociadas na NYSE, AMEX e Nasdaq (em 1993 analisou-se apenas NYSE e AMEX), excluídas as cotadas abaixo de US\$ 5,00 no início do 
período de formação da carteira ou com valor de mercado do menor decil da NYSE. Assim, as ações muito pequenas ou ilíquidas ficaram de fora. As 10 carteiras foram formadas com base nos retornos nos seis meses anteriores e manutenção por seis meses (estratégia "6x6”), sendo novamente significativas estatisticamente pelo teste-t. Para as ações da mostra, antes de dividi-las em small cap e large cap, a estratégia momento gerou retornos superiores a carteira igualmente balanceada (EWI - equal-weighted index of stocks).

Também se analisou o retorno da estratégia de comprar vencedores e vender perdedores para até 60 meses após a formação da carteira. Para o período todo de 1965 a 1998, o retorno acumulado da estratégia momento foi positiva para os primeiros 12 meses, mas negativa do período de 13 a 60 meses, consistentes com as teorias comportamentais no longo prazo (JEGADEESH E TITMAN, 2001), conforme Tabela 2.

Tabela 2 - Retornos das estratégias de Jegadeesh e Titman (2001)

\begin{tabular}{|c|c|c|c|c|c|c|c|c|c|}
\hline & \multicolumn{3}{|c|}{ All Stocks } & \multicolumn{3}{|c|}{ Small Cap } & \multicolumn{3}{|c|}{ Large Cap } \\
\hline & $1965-1998$ & 1965-1989 & $1990-1998$ & $1965-1998$ & $1965-1989$ & $1990-1998$ & $1965-1998$ & $1965-1989$ & $1990-1998$ \\
\hline P1 (Past winners) & 1.65 & 1.63 & 1.69 & 1.70 & 1.69 & 1.73 & 1.56 & 1.52 & 1.66 \\
\hline $\mathrm{P} 2$ & 1.39 & 1.41 & 1.32 & 1.45 & 1.50 & 1.33 & 1.25 & 1.24 & 1.27 \\
\hline P3 & 1.28 & 1.30 & 1.21 & 1.37 & 1.42 & 1.23 & 1.12 & 1.10 & 1.19 \\
\hline $\mathrm{P} 4$ & 1.19 & 1.21 & 1.13 & 1.26 & 1.34 & 1.05 & 1.10 & 1.07 & 1.20 \\
\hline P5 & 1.17 & 1.18 & 1.12 & 1.26 & 1.33 & 1.06 & 1.05 & 1.00 & 1.19 \\
\hline P6 & 1.13 & 1.15 & 1.09 & 1.19 & 1.26 & 1.01 & 1.09 & 1.05 & 1.20 \\
\hline P7 & 1.11 & 1.12 & 1.09 & 1.14 & 1.20 & 0.99 & 1.09 & 1.04 & 1.23 \\
\hline P8 & 1.05 & 1.05 & 1.03 & 1.09 & 1.17 & 0.89 & 1.04 & 1.00 & 1.17 \\
\hline P9 & 0.90 & 0.94 & 0.77 & 0.84 & 0.95 & 0.54 & 1.00 & 0.96 & 1.09 \\
\hline P10 (Past losers) & 0.42 & 0.46 & 0.30 & 0.28 & 0.35 & 0.08 & 0.70 & 0.68 & 0.78 \\
\hline P1-P10 & 1.23 & 1.17 & 1.39 & 1.42 & 1.34 & 1.65 & 0.86 & 0.85 & 0.88 \\
\hline$t$ statistic & 6.46 & 4.96 & 4.71 & 7.41 & 5.60 & 5.74 & 4.34 & 3.55 & 2.59 \\
\hline EWI & 1.09 & 1.10 & 1.04 & 1.13 & 1.19 & 0.98 & 1.03 & 1.00 & 1.12 \\
\hline
\end{tabular}

FONTE: Jegadeesh e Titman (2001)

Goetzmann e Massa (2002) utilizaram contas individuais em um fundo mútuo passivo do índice S\&P 500 para analisar o comportamento de mais de 91 mil investidores durante dois anos, onde foi possível identificar classes de investidores da estratégia de momento e da estratégia contrária.

No mercado acionário chinês, Kang, Liu e Ni (2002) encontraram evidências de retornos anormais estatisticamente significantes para algumas estratégias contrárias de curto prazo e estratégias de momento de médio prazo. O elevado retorno para as ações perdedoras (estratégia contrária) deve-se a reação exagerada a alguma informação divulgada pela empresa, considerando-se que o mercado é dominado por investidores individuais, falta 
informações confiáveis, especialmente sobre empresas pequenas, que levam os investidores a tomarem decisões baseadas em rumores de mercado e tendências de preços passados.

Mengoli (2004) estudou o mercado acionário italiano entre 1950 e 1995 e observou que adquirir as melhores ações em termos de desempenho e vender as piores (efeito momento) resultava em lucros superiores para períodos de três meses a um ano. No entanto, para períodos mais longos, essa estratégia era superada pela contrária, de adquirir as ações com desempenhos mais fracos.

Shen, Szakmary e Sharma (2005) analisaram a relação da estratégia do momento para investimento em ações de valor (value stocks) e de crescimento (growth stocks) nos mercados internacionais. Seus estudos mostraram que foram observados lucros do efeito momento em índices que apresentaram crescimento, sendo mais evidentes anteriormente a dezembro de 1987. Neste caso, os estudos de Jegadeesh e Titman (2001) foram estendidos aos índices Morgan Stanley Capital International (MSCI) internacionais.

Diferentemente de outros artigos, Miffre e Rallis (2007) estudaram o efeito momento e contrário no mercado futuro de mercadorias (commodities). As estratégias contrárias de reversão de preços não funcionaram, mas identificou-se 13 de 56 estratégias lucrativas de momento, entre um e 12 meses, que apresentaram aproximadamente $10 \%$ de retorno anual.

Galariotis, Holmes e Ma (2007) estudaram as estratégias contrária e momento das 6.531 as ações listadas na bolsa de Londres (LSE - London Stock Exchange) entre 1964 e 2005. Evidências demonstraram que os lucros não puderam ser explicados por sazonalidade, tamanho, ou modelo de risco de apenas um fator. No entanto, o modelo de 3-fatores de Fama e French (1993) explica os lucros das estratégias contrárias (ações muito depreciadas que subiram).

Na América Latina, Muga e Santamaría (2007) confirmaram o efeito momento na Argentina, Brasil, Chile, México utilizando dados trimestrais de janeiro de 2004 a janeiro de 2005 para estimação e depois extrapolando a análise de 1996 a 2001. Contudo, Cervantes, Montoya e Cueto (2014) não identificaram efeito momento ou efeito contrário no mercado acionário mexicano entre 1993 e 2006, analisando preços da BMV (Bolsa Mexicana de Valores). 
Nos mercados asiáticos, McInish, Ding, Pyun e Wongchoti (2008) testaram as estratégias de momento e contrária de curto prazo (uma, duas ou quatro semanas). O estudo comtemplou as bolsas de valores do Japão, Taiwan, Coréia, Hong Kong, Malásia, Tailândia e Cingapura entre 1990 e 2000. Em cinco países, exceto Taiwan e Coréia, os resultados apontaram que as ações vencedoras apresentaram reversão de desempenho. De forma geral, as estratégias de investimento que combinam ações vencedoras e perdedoras baseadas em preços passados não eram efetivamente rentáveis, uma vez que não conseguiram produzir lucros significativos que duram mais de uma semana. Cabe destacar que os resultados mais significativos foram encontrados no Japão.

Kaniel, Saar e Titman (2008) estudaram a relação da negociação dos investidores individuais com os retornos de curto prazo das ações negociadas na NYSE. As evidências encontradas indicam que esses investidores tendem a comprar ações que caíram no mês anterior e vender as ações que subiram. Esse comportamento contrário dos investidores individuais faz com que tais investidores forneçam liquidez para os investidores profissionais, além de indicar que há certa tendência dos indivíduos em vender rápido as ações lucrativas e comprá-las quando seus preços estão relativamente mais baixos.

Schumaker e Chen (2008) estudaram em conjunto a seleção quantitativa de carteiras com um sistema de previsão de notícias financeiras AZFinText (SCHUMAKER E CHEN, 2009). Com um período de formação de carteira de uma semana, obtiveram um retorno de 20,79\% utilizando a estratégia de momento e de 4,54\% usando a estratégia contrária em um período de cinco semanas de estimação.

O AZFinText, proposto por Schumaker e Chen (2009), utiliza a análise preditiva do preço de ações baseada na análise textual de artigos financeiros. Foram investigadas 9.211 notícias e 10.259.042 cotações de ações do S\&P 500 durante cinco semanas. O modelo de aprendizado utilizando termos do artigo e o preço das ações no momento da divulgação das notícias apresentou desempenho superior para prever os preços das ações após 20 minutos.

Fama e French (2008) analisaram a persistência de anomalias no retorno de três categorias de tamanho de empresas: muito pequenas (microcap), pequenas (small stocks) e grandes (big stocks). Com análise de regressão, os autores identificaram relação positiva entre momento e retorno nos três grupos, sendo menos intenso no grupo de microcap. 
Haan e Kakes (2011) analisaram as estratégias de investimento dos investidores institucionais holandeses entre 1999 e 2005. De forma geral, os resultados apontam que esses investidores, principalmente os fundos de pensão, tendem a seguir a estratégia contrária, ou seja, comprar os perdedores do passado e vender os ganhadores do passado. Isso indica que os investidores institucionais da Holanda possuem papel estabilizados do mercado acionário.

Yao (2012) reexaminou o sucesso aparente da estratégia contrária para o longo prazo e de momento para o médio prazo. Seus resultados indicam que o efeito contrário é bastante rentável em janeiro, onde o efeito momento resulta em perda devido a venda a descoberto de empresas pequenas, ao invés de reação exagerada do mercado proposta por De Bondt e Thaler (1985). Também foi identificado que o efeito momento deve-se a sazonalidade anual dos retornos. O período analisado foi de 1926 a 2009 e mostra que o efeito contrário desaparece fora de janeiro.

Fama e French novamente abordaram o efeito momento, desta vez em quatro regiões: América do Norte, Europa, Japão e Ásia-Pacífico. Há retorno com o momento e os retornos médios diminuem conforme o tamanho das empresas aumenta, exceto para o Japão. Ou seja, as empresas menores possuem maior efeito momento (FAMA E FRENCH, 2012).

Asness, Moskowitz e Pedersen (2013) encontraram prêmios consistentes de retorno nos investimentos em valor e em momento em oito mercados diferentes. $\mathrm{O}$ fato comum entre os retornos, foi que valor e momento correlacionam mais fortemente entre as classes de ativos do que a simples exposições passiva aos mesmos ativos, mas valor e momento são negativamente correlacionados entre si, tanto na mesma quanto em outra classe de ativo. Os resultados representam um desafio às teorias comportamentais, institucionais e racionais de precificação existentes focadas em ações americanas.

Asness, Frazzini, Israel e Moskowitz (2014), 20 anos da descoberta por Jegadeesh e Titman (1993), esclareceram grande parte do que é sabido sobre o efeito momento e refutaram alguns de seus mitos, utilizando resultados de grandes trabalhos acadêmicos e informações públicas disponíveis sobre o assunto. Os autores esclarecem que o efeito momento não deve ser confundido com tendência, pois sempre analisa o desempenho dos ativos em relação a seus pares no mesmo período de tempo, já a tendência leva em consideração apenas variação de 
preços absolutos. Assim, ativos são classificados como vendedores ou perdedores independentes do desempenho médio do mercado (representado por uma carteira teórica).

Asness, Frazzini, Israel e Moskowitz (2014) destacam que os mitos mais comuns sobre o efeito momento são acreditar que não se trata de uma estratégia séria de investimento, que dura pouco tempo, que funciona apenas com ações de pequenas empresas e não são rentáveis após subtraídos os custos de transação. Ao acreditar nisso, as pessoas ignoram os dados e verdades sobre o efeito momento que, quando combinada ao investimento em valor (value investing), apresenta resultados ainda melhores.

Para capturar o efeito momento, os estudos focaram em carteiras que compravam ações com alto desempenho relativo no ano anterior e vendiam as que tiveram desempenho relativo baixo no mesmo período (UMD, ou up minus down). Para os que acreditam que não há teoria por trás do efeito momento, diversos artigos abordam a teoria como comportamental ou a compensação pelo risco como base.

Keller, Butler e Kipnis (2015) analisaram a estratégia de momento em um período de até 12 meses, com a estratégia de alocação de ativos clássica (CAA - Classical Asset Allocation) para carteiras de longo prazo, comparando o desempenho a carteiras igualmente ponderadas, utilizando um século de dados entre 1915 a 2014. De modo geral, ficou demonstrado que a estratégia CAA superou o modelo de ponderação 1/N, onde $\mathrm{N}$ é o número de ativos. Assim, a combinação do momento de curto prazo com a fronteira eficiente proposta por Markowitz (1952) era bastante favorável aos investidores.

Por fim, Geczy e Samonov (2015) analisaram diversas classes de ativos entre 1800 e 2014, incluindo 47 índices de ações de diferentes países (inclusive do Brasil), 43 índices de títulos públicos, 76 mercadorias (commodities), 301 índices setores globais, 34.795 ações norteamericanas. Os dados desses 215 anos de estudo confirmaram a significância do momento nesses ativos no longo prazo, mas com aumento no risco dessa estratégia, sendo que em muitas décadas da série analisada apresentaram retornos negativos.

Como pode-se observar, há muita controvérsia sobre a existência do efeito momento e do efeito contrário em diversos estudos ao redor do mundo. Ambas estratégias foram comprovadas e contestadas em diversas épocas e mercados financeiros de vários países. 


\subsection{Estudos nacionais sobre efeitos momento e contrário}

Um dos primeiros estudos que se propôs a verificar o efeito contrário no Brasil foi o de Costa Jr. (1994). O autor estudou a reação exagerada nos preços dos ativos no mercado acionário do Brasil entre 1970 e 1989, com base na estratégia de De Bondt e Thaler (1985). Foram detectadas evidências de reversões de preços de forma semelhante à encontrada no mercado dos Estados Unidos.

Bonomo e Dall'Agnol (2003), baseados na metodologia de De Bondt e Thaler (1985), encontraram evidências de lucratividade da estratégia contrária no curto e longo prazos (três meses a três anos) para ações negociadas nos mercados de bolsa de valores e balcão organizado entre 1986 e 2000, com declínio expressivo de lucratividade pós Plano Real em meados de 1994. Neste trabalho não foram identificados indícios do efeito momento quando a metodologia de Jegadeesh e Titman (1993) foi utilizada para o mesmo período.

Não houve evidências para efeito momento e contrário no estudo de Kimura (2003). O autor verificou a viabilidade das estratégias contrária e momento para apenas 38 ações entre junho de 1994 e dezembro de 2001. Os resultados apresentados sugerem rentabilidade superior das estratégias de momento entre 13 a 15 semanas pós investimento, ao nível de significância de $5 \%$. No entanto, após realizados ajustes de retornos pelo risco sistemático, os resultados não permitiram rejeitar a hipótese de eficiência da carteira de mercado, sendo que as estratégias contrárias ou de momento não apresenta ganhos estatisticamente significantes.

Yoshinaga (2004) analisou a sobre-reação de preços o mercado de ações entre $1^{\circ}$ de janeiro de 1995 e 31 de dezembro de 2003. Os resultados apresentados demonstraram que era possível obter ganhos de curto prazo com a estratégia contrária de investimento para períodos entre um e três meses. Utilizou-se três medidas para analisar os desempenhos dos ativos: retorno total, excesso de retorno de mercado e retorno ajustado ao risco. Como critério de acumulação de retornos, utilizou-se tanto o método aritmético quanto o método composto, com o objetivo de comprar os diferentes resultados. Foram aplicados testes estatísticos de diferença de médias entre os retornos das carteiras perdedoras e vencedoras. 
Minardi (2004) evidenciou para o mercado brasileiro que existe alguma previsibilidade de retornos com base em dados passados, conforme metodologia de Jegadeesh (1990). O estudo nacional analisou 649 ações entre setembro de 1994 e agosto de 2000 e identificou resultados significativamente superiores ao do equilíbrio de mercado medido pelo índice IBrX.

O efeito momento foi confirmado por Mussa, Trovão, Famá e Santos (2008) para o mercado brasileiro entre 1995 e 2006, considerando os retornos mensais de todas as ações listadas na Bovespa. Em três das 16 estratégias testadas, quantidade bastante inferior a identificada por Jegadeesh e Titman (1993) no mercado norte-americano, os ganhos anormais entre 0,9\% e 1,4\% foram estatisticamente significativos pelo teste-t de Student. A estratégia mais rentável foi de formação de carteira com base nos retornos de três meses com manutenção por seis meses (carteira “3x6”).

Ao contrário do estudo anterior, Cruz (2009) encontrou evidências de que o efeito momento de longo prazo não se aplica ao Brasil, devido às particularidades da dinâmica do nosso mercado. $\mathrm{O}$ autor analisou simultaneamente as estratégias de momento e contrária no mercado brasileiro, cuja amostra era composta por ações do índice Bovespa de janeiro de 1994 a maio de 2009, excluídas as instituições financeiras.

Teixeira (2011) analisou o desempenho de três estratégias de investimento entre 2001 e 2010: valor, momento e combo, ou seja, uma combinação de 50/50 das duas anteriores. O autor também analisou o desempenho antes e depois da crise de 2008, sendo que a estratégia combo foi mais rentável pós-crise (2008 a 2010) e a valor no período todo. Tais resultados diferem dos encontrados por Asness, Moskowitz e Pedersen (2013) nos EUA, Reino Unido, Europa Continental e Japão, onde a estratégia combo apresentou melhor desempenho. Ainda, identificou-se que o efeito momento não é uma boa estratégia e que há efeito contrário no Brasil, corroborando com os achados nacionais de Bonomo e Dall'Agnol (2003).

Mussa, Securato, Santos e Famá (2011) investigaram o comportamento do momento no mercado acionário brasileiro de junho de 1995 a junho de 2007 em duas condições: alta e baixa do mercado acionário e expansão e retração monetária. Nos resultados, o prêmio pelo fator de risco momento mostrou-se positivo somente para períodos de baixa do mercado acionário e na fase de restrição monetária. Cabe destacar que, quando a amostra não é segregada, o fator momento apresenta prêmio praticamente nulo, contrastando com Jegadeesh 
e Titman (1993; 2001). Além disso, para o momento, em nenhuma situação tal retorno mostrou-se estatisticamente diferente de zero uma vez que o $p$-value foi superior a $5 \%$.

Em outro artigo, Santos, Famá, Mussa (2012) adicionaram o efeito momento ao modelo de 3fatores para analisar retornos no Brasil. Assim, a precificação dos ativos do CAPM passou a considerar os 4-fatores proposto por Carhart (1997): retorno do mercado, prêmio pelo tamanho da empresa, prêmio pelo índice BE/ME (book equity to market equity, ou seja, valor patrimonial dividido pelo valor de mercado) e as anomalias do efeito momento.

Nesse artigo, o teste de significância com a estatística $t$ de Student apresentaram evidências de que o modelo de 4-fatores é válido para o mercado brasileiro, sendo superior ao modelo de 3fatores na explicação das variações dos retornos das carteiras da amostra entre 1995 e 2006, corroborando com o estudo do mercado norte-americano de Carhart (1997). No entanto, o prêmio para o fator momento foi negativo, contrariando os estudos do mercado norteamericano de Jegadeesh e Titman (1993).

Improta (2012) analisou o efeito momento e contrário no mercado acionário brasileiro entre janeiro de 1999 e junho de 2012. Seus resultados, baseados em 1.296 estratégias, não apontaram evidências do efeito contrário e apenas fraca evidência de momento de curto prazo para empresas menores.

Silva Neto, Silva, Raboni e Carmona (2012) analisaram a estratégia de investimento em valor contrário entre 1995 e 2010, analisando o desempenho das carteiras de 36 a 60 meses posteriores ao período de formação. Destaca-se que se verificou sucesso na estratégia, e que tal fato não pode ser explicado pelo tamanho das empresas, medido pelo valor de mercado.

Pires (2013) estudou o efeito disponibilidade e momento, de forma muito semelhante a Jegadeesh e Titman (1993), fazendo a diferença entre carteira vencedora e perdedora. O período analisado foi de agosto de 2006 e janeiro de 2011 e compreendeu 70 ações negociadas na BM\&FBOVESPA. Sobre o efeito momento, das 16 estratégias analisadas de retornos trimestrais (três, seis, nove e 12 meses), apenas a de formação com três meses de antecedência e manutenção por três meses (3x3) apresentou retornos positivos de $2,01 \%$ ao nível de significância de $10 \%$. 
Silva, Piccoli, Cruz e Clemente (2014) identificaram que o efeito momento é observado em sete períodos entre janeiro de 1994 e setembro de 2009, considerando carteiras formadas com retornos em seis meses passados, com análise ao longo de 36 meses subsequentes, formadas em base semestral ao invés de janelas mensais de Jegadeesh e Titman (1993).

Silva Neto, Silva Raboni e Oliveira (2014) identificaram o efeito momento para carteiras montadas com base em retornos passados de seis meses e mantidas por pelo menor três meses, sendo mais rentáveis após seis meses de manutenção. O período de análise considerado estava compreendido entre abril de 1995 e setembro de 2011, levando-se em conta o volume financeiro negociado. Os maiores retornos foram encontrados para ações vencedoras com volume baixo, que em média tiveram desempenho 3,24\% em seis meses. A amostra continha 621 ações negociadas na BM\&FBOVESPA.

\subsection{Compilação dos trabalhos mais relevantes por assunto}

O Quadro 2 sintetiza, de forma resumida, os principais autores, hipóteses, metodologias, resultados e conclusões presentes nesse estudo, por assunto abordado no capítulo 2.

Quadro 2 - Resumo dos principais autores, metodologia e resultados

\begin{tabular}{|c|c|c|}
\hline \multicolumn{3}{|c|}{ MERCADOS EFICIENTES } \\
\hline Autor(es) & Objetivos/metodologia & Resultados/conclusões \\
\hline Fama (1970) & $\begin{array}{l}\text { Desenvolveu a teoria de eficiência de } \\
\text { mercado, em que as cotações refletem } \\
\text { integralmente todas informações } \\
\text { disponíveis sobre os ativos financeiros. }\end{array}$ & $\begin{array}{l}\text { Não encontrou evidências relevantes contra as } \\
\text { hipóteses fraca e semiforte e apenas evidências } \\
\text { limitadas contrárias a forma forte de eficiência de } \\
\text { mercado. }\end{array}$ \\
\hline Jensen (1978) & $\begin{array}{l}\text { Surgimento de evidências } \mathrm{de} \\
\text { inconsistências da teoria de eficiência de } \\
\text { mercado com a maior disponibilidade de } \\
\text { informações e sofisticação econométrica. }\end{array}$ & $\begin{array}{l}\text { Não haveria lucro econômico nas negociações } \\
\text { baseadas em um conjunto de informações, após } \\
\text { considerar os custos. }\end{array}$ \\
\hline Shiller (1980) & $\begin{array}{l}\text { Cita alguns autores que rejeitaram a HME } \\
\text { em seus artigos baseados em dados } \\
\text { estatísticos provenientes do mercado real. }\end{array}$ & $\begin{array}{l}\text { Afirmou que a HME seria um modelo } \\
\text { "acadêmico", pois não descrevia os movimentos } \\
\text { observados em seus dados. }\end{array}$ \\
\hline $\begin{array}{l}\text { Fama e French } \\
\text { (1993) }\end{array}$ & $\begin{array}{l}\text { O retorno esperado de uma carteira acima } \\
\text { da taxa livre de risco é explicado por três } \\
\text { fatores. }\end{array}$ & $\begin{array}{l}\text { São fatores determinantes para o retorno o } \\
\text { tamanho das empresas, seus múltiplos de valor de } \\
\text { patrimonial e de valor de mercado. }\end{array}$ \\
\hline $\begin{array}{l}\text { Fama (1991, } \\
1998)\end{array}$ & $\begin{array}{l}\text { Afirmou que a literatura financeira } \\
\text { apresenta diversas anomalias na análise de } \\
\text { retornos no longo prazo, mas evidências } \\
\text { não sugerem que a hipótese de eficiência } \\
\text { de mercado deveria ser abandonada. }\end{array}$ & $\begin{array}{l}\text { Destacou que as anomalias de retorno a longo } \\
\text { prazo eram frágeis e tenderiam a desaparecer após } \\
\text { alterar a forma de medi-las. Apresentou evidências } \\
\text { de que os estudos de evento que mostram rapidez } \\
\text { no ajuste de preços a novas informações. }\end{array}$ \\
\hline
\end{tabular}




\begin{tabular}{|c|c|c|}
\hline \multicolumn{3}{|c|}{ FINANÇAS COMPORTAMENTAIS } \\
\hline Autor(es) & Objetivos/metodologia & Resultados/conclusões \\
\hline $\begin{array}{l}\text { Tversky e } \\
\text { Kahneman } \\
(1974)\end{array}$ & $\begin{array}{l}\text { Abordaram três heurísticas na tomada de } \\
\text { decisão em situações que envolvem } \\
\text { incerteza, levando a erros na tomada de } \\
\text { decisão. }\end{array}$ & $\begin{array}{l}\text { Identificaram como fatores que levam a erros na } \\
\text { tomada de decisão: representatividade, } \\
\text { disponibilidade e ancoragem. }\end{array}$ \\
\hline $\begin{array}{l}\text { Kahneman e } \\
\text { Tversky (1979) }\end{array}$ & $\begin{array}{l}\text { Formularam a Teoria do Prospecto ou } \\
\text { Teoria da Perspectiva, que trouxe grandes } \\
\text { contribuições para o entendimento da } \\
\text { tomada de decisão em situações de risco. }\end{array}$ & $\begin{array}{l}\text { A característica mais marcante é a aversão ao risco } \\
\text { em escolhas de ganho certo e busca por risco em } \\
\text { escolhas com certeza de perda, contrários a } \\
\text { racionalidade na tomada de decisão. }\end{array}$ \\
\hline $\begin{array}{l}\text { Halfeld e } \\
\text { Torres (2001) }\end{array}$ & $\begin{array}{l}\text { Revisaram pesquisas sobre finanças } \\
\text { comportamentais no cenário internacional e } \\
\text { os primeiros estudos sobre anomalias } \\
\text { encontrados no mercado financeiro } \\
\text { nacional. }\end{array}$ & $\begin{array}{l}\text { Os autores brasileiros citam a sobre-reação } \\
\text { observada no mercado financeiro brasileiro como } \\
\text { evidência de irracionalidade, apesar de os estudos } \\
\text { sobre finanças comportamentais serem pouco } \\
\text { abordados no país até então. }\end{array}$ \\
\hline $\begin{array}{l}\text { Daniel, } \\
\text { Hirshleifer e } \\
\text { Subrahmanyam } \\
(1998)\end{array}$ & $\begin{array}{l}\text { Apresentaram os conceitos psicológicos do } \\
\text { excesso de confiança dos investidores e } \\
\text { viés de auto atribuição (self-attribution } \\
\text { bias) como as causas das mudanças na } \\
\text { confiança dos investidores em decorrência } \\
\text { dos resultados obtidos nos investimentos. }\end{array}$ & $\begin{array}{l}\text { Os resultados apontam que o excesso de confiança } \\
\text { ocasiona autocorrelações negativas de longo prazo } \\
\text { e aumento da volatilidade. O viés de auto- } \\
\text { atribuição provoca autocorrelações positivas de } \\
\text { curto prazo ("momentum"), não sendo fáceis de } \\
\text { explicar a precificação de ativos de forma racional. }\end{array}$ \\
\hline \multicolumn{3}{|c|}{ EFEITO CONTRÁRIO } \\
\hline Autor(es) & Objetivos/metodologia & Resultados/conclusões \\
\hline $\begin{array}{l}\text { De Bondt e } \\
\text { Thaler }(1985 \text {, } \\
\text { 1987) }\end{array}$ & $\begin{array}{l}\text { Excesso de retornos ajustados ao mercado; } \\
\text { resíduos de mercado e retornos anormais } \\
\text { em relação a versão de Sharpe-Lintner do } \\
\text { CAPM. }\end{array}$ & $\begin{array}{l}\text { Reação exagerada do mercado, favorecendo as } \\
\text { estratégias contrárias, ou seja, retornos positivos } \\
\text { para compradores de ações que tiveram } \\
\text { desempenho ruim. }\end{array}$ \\
\hline $\begin{array}{l}\text { Chopra, } \\
\text { Lakonishok e } \\
\text { Ritter (1992) }\end{array}$ & $\begin{array}{l}\text { Tentaram prever o retorno de ações com } \\
\text { base em informações passadas e se as } \\
\text { ações negociadas em bolsa apresentaram } \\
\text { reação exagerada à alguma informação. }\end{array}$ & $\begin{array}{l}\text { A abordagem utilizada levou em consideração } \\
\text { outra forma de estimar o Beta das ações e o } \\
\text { tamanho das empresas. As carteiras perdedoras } \\
\text { tiveram desempenho superior as carteiras } \\
\text { vencedoras em } 6,5 \% \text { ao ano. Com dados mensais } \\
\text { de retorno, o desempenho foi } 9,5 \% \text { ao ano superior } \\
\text { para as carteiras perdedoras, predominante em } \\
\text { empresas pequenas. }\end{array}$ \\
\hline $\begin{array}{l}\text { Lakonishok, } \\
\text { Shleifer, } \\
\text { Vishny (1994) }\end{array}$ & $\begin{array}{l}\text { Utilizar os retornos anuais de carteiras } \\
\text { compostas por ações de acordo com } \\
\text { múltiplos contábeis de lucro sobre preço e } \\
\text { fluxo de caixa sobre preço, entre outros. }\end{array}$ & $\begin{array}{l}\text { Maior retorno na estratégia contrária de comprar } \\
\text { ações de valor, que tiveram desempenho ruim no } \\
\text { passado. }\end{array}$ \\
\hline $\begin{array}{l}\text { Costa Jr. } \\
(1994)\end{array}$ & $\begin{array}{l}\text { Propunha verificar o efeito contrário no } \\
\text { Brasil entre } 1970 \text { e } 1989 .\end{array}$ & $\begin{array}{l}\text { Foram detectadas evidências de reversões de } \\
\text { preços de forma semelhante à encontrada no } \\
\text { mercado dos Estados Unidos conforme } \\
\text { metodologia de De Bondt e Thaler (1985). }\end{array}$ \\
\hline $\begin{array}{l}\text { Bonomo e } \\
\text { Dall'Agnol } \\
(2003)\end{array}$ & $\begin{array}{l}\text { Utilizaram as metodologias de De Bondt e } \\
\text { Thaler (1985) e de Jegadeesh e Titman } \\
\text { (1993). }\end{array}$ & $\begin{array}{l}\text { Encontraram evidências da estratégia contrária no } \\
\text { curto e longo prazos (três meses a três anos) entre } \\
1986 \text { e } 2000 \text {, mas não identificaram indícios do } \\
\text { efeito momento para o mesmo período. }\end{array}$ \\
\hline $\begin{array}{l}\text { Kimura, Basso } \\
\text { e Krauter } \\
(2006)\end{array}$ & $\begin{array}{l}\text { Replicaram a Teria do Prospecto de } \\
\text { Kahneman e Tversky (1979) em uma } \\
\text { amostra no Brasil. }\end{array}$ & $\begin{array}{l}\text { Os resultados apresentam vieses de percepção nas } \\
\text { decisões, com violação da premissa de busca por } \\
\text { maximização da utilidade esperada, corroborando } \\
\text { o artigo original. }\end{array}$ \\
\hline
\end{tabular}




\begin{tabular}{|c|c|c|}
\hline \multicolumn{3}{|c|}{ EFEITO MOMENTO } \\
\hline Autor(es) & Objetivos/metodologia & Resultados/conclusões \\
\hline $\begin{array}{l}\text { Jegadeesh e } \\
\text { Titman }(1993, \\
\text { 2001) }\end{array}$ & $\begin{array}{l}\text { Teste-t para compra de } 32 \text { carteiras } \\
\text { "vencedoras" e venda das "perdedoras" nos } \\
\text { períodos de três, seis, nove e } 12 \text { meses de } \\
\text { formação e de manutenção das carteiras. } \\
\text { Em 2001, refeito os testes apenas para a } \\
\text { estratégia "6x6". }\end{array}$ & $\begin{array}{l}\text { Observadas estratégias de momento com elevado } \\
\text { grau de significância, envolvem a compra de ações } \\
\text { que tiveram um bom desempenho passado, } \\
\text { produzindo retornos anormais positivos. }\end{array}$ \\
\hline $\begin{array}{l}\text { Jegadeesh } \\
(1990)\end{array}$ & $\begin{array}{l}\text { Apresentou evidencias da previsibilidade } \\
\text { no comportamento dos retornos individuais } \\
\text { das ações. O pressuposto rejeitaria a } \\
\text { hipótese de passeio aleatório (random } \\
\text { walks). }\end{array}$ & $\begin{array}{l}\text { Foram encontradas correlações fortes entre os } \\
\text { retornos mensais das ações em diferentes períodos, } \\
\text { sendo que a diferença entre o retorno anormal da } \\
\text { carteira do decil mais rentável no período entre } \\
1934 \text { e } 1987 \text { foi de } 2,49 \% \text { ao mês, de } 2,20 \% \\
\text { excluído o mês de janeiro e de } 4,37 \% \text { apenas em } \\
\text { janeiro. }\end{array}$ \\
\hline $\begin{array}{l}\text { Grinblatt, } \\
\text { Titman e } \\
\text { Wermers } \\
(1995)\end{array}$ & $\begin{array}{l}\text { Verificar o quão aderente eram os fundos } \\
\text { de investimento ao efeito momento de } \\
\text { comprar ações com elevados retornos, } \\
\text { utilizando regressões cross-sectional e } \\
\text { teste-t e teste-F derivados de séries } \\
\text { temporais. }\end{array}$ & $\begin{array}{l}\text { Identificaram que } 77 \% \text { dos fundos de } \\
\text { investimentos eram investidores de momento, } \\
\text { comprando ações vencedoras no passado. }\end{array}$ \\
\hline $\begin{array}{l}\text { Chan, } \\
\text { Jegadeesh e } \\
\text { Lakonishok } \\
(1996)\end{array}$ & $\begin{array}{l}\text { Correlações entre retorno nos seis meses } \\
\text { anteriores e surpresa quanto aos resultados; } \\
\text { retorno médio das ações; análise } \\
\text { multivariada e regressões cross-sectional. }\end{array}$ & $\begin{array}{l}\text { Não identificaram efeito contrário, apenas o efeito } \\
\text { momento para prever retornos futuros. }\end{array}$ \\
\hline Carhart (1997) & $\begin{array}{l}\text { Medidas de performance dos fundos } \\
\text { utilizando CAPM e o modelo de 4-fatores. }\end{array}$ & $\begin{array}{l}\text { A boa performance dos fundos de investimentos } \\
\text { não reflete a melhor escolha das ações. Mas fundos } \\
\text { de baixo desempenho tendem a mantê-lo ruim. }\end{array}$ \\
\hline $\begin{array}{l}\text { Hong e Stein } \\
(1997,1999) \text {, }\end{array}$ & $\begin{array}{l}\text { Premissas de sub-reações (underreaction) e } \\
\text { autocorrelações com retornos positivos. } \\
\text { Com isso, defendiam que empresas com } \\
\text { dispersão mais lenta de informações } \\
\text { apresentariam maior efeito momento. }\end{array}$ & $\begin{array}{l}\text { Identificaram que informações específicas das } \\
\text { empresas se difundem gradualmente ao mercado e } \\
\text { que investidores não conseguem extrair } \\
\text { informações racionalmente a partir do preço das } \\
\text { ações. }\end{array}$ \\
\hline $\begin{array}{l}\text { Rouwenhorst } \\
(1998,1999)\end{array}$ & $\begin{array}{l}\text { Teste-t para compra de subcarteiras } \\
\text { "vencedoras" e venda das "perdedoras" nos } \\
\text { períodos de um a quatro trimestres } \\
\text { (formação e manutenção). Análise do } \\
\text { retorno anormal das carteiras ganhadoras } \\
\text { menos perdedoras. }\end{array}$ & $\begin{array}{l}\text { Identificado o efeito momento nos } 12 \text { países } \\
\text { europeus analisados, com grau de significância a } \\
5 \% \text {. Em 1999, identificado efeito momento em } 20 \\
\text { mercados emergentes de ações. }\end{array}$ \\
\hline $\begin{array}{l}\text { Hong, Lim e } \\
\text { Stein }(2000)\end{array}$ & $\begin{array}{l}\text { Testaram o modelo de difusão gradual de } \\
\text { informações proposto por Hong e Stein } \\
\text { (1999) e consideraram o tamanho das } \\
\text { empresas, separando-as em tercis (P1, com } \\
30 \% \text { piores retornos; P2, com } 40 \% \text { retornos } \\
\text { médias; e P3, com } 30 \% \text { melhores retornos). }\end{array}$ & $\begin{array}{l}\text { Como resultados principais, a rentabilidade da } \\
\text { estratégia do momento reduz com o aumento do } \\
\text { tamanho da empresa, a estratégia do momento é } \\
\text { mais efetiva para ações com menor cobertura de } \\
\text { analistas e o efeito da cobertura de analistas é mais } \\
\text { relevante para ações perdedoras do que para } \\
\text { ganhadoras. }\end{array}$ \\
\hline Minardi (2004) & $\begin{array}{l}\text { No estudo nacional foram analisadas } 649 \\
\text { ações entre setembro de } 1994 \text { e agosto de } \\
\text { 2000, conforme metodologia de Jegadeesh } \\
\text { (1990). }\end{array}$ & $\begin{array}{l}\text { Evidenciou para o mercado brasileiro que existe } \\
\text { alguma previsibilidade de retornos com base em } \\
\text { dados passados, com resultados significativamente } \\
\text { superior ao do equilíbrio de mercado medido pelo } \\
\text { índice IBrX. }\end{array}$ \\
\hline
\end{tabular}




\section{METODOLOGIA}

Para alcançar os objetivos propostos neste trabalho, analisou-se a bibliografia nacional e internacional sobre o assunto para identificar quais períodos de formação e manutenção da carteira seriam mais adequados à análise dos efeitos momento e contrário no Brasil. Chegouse à definição de um conjunto de períodos de formação de carteira de $k$ meses $(k=3,6,9$ ou 12) e um conjunto de períodos de manutenção da carteira de $n$ meses $(n=3,6,9,12,18$ e 24). Assim chegou-se a um total de 24 estratégias analisadas.

A abordagem quantitativa considerou uma amostra intencional de 662 ações de empresas nacionais, coletadas no sistema Economática e armazenadas em planilhas do Microsoft Excel 2013, compreendendo o período total entre julho de 1994 e junho de 2015, ou seja, 252 meses. Os critérios de escolha do período foram: (i) ser o mais amplo possível; e (ii) preservar a condição de comparação entre os dados. Desta forma, escolheu-se o período após o início do Plano Real.

De acordo com Gil (2010), a pesquisa pode ser classificada como quantitativa ex-post, uma vez que os dados utilizados são informações passadas sobre as oscilações nos preços, em que se busca a comprovação de hipóteses formuladas posteriormente, no caso os efeitos momento e contrário.

Inicialmente, foram levantados os retornos mensais, ajustados por proventos, da amostra. A seguir, para atender a uma condição de liquidez, foram excluídas as ações sem cotação no período analisado. Verificou-se também por meio de estatísticas descritivas, os retornos médio, mediana e desvio padrão para o Índice Bovespa (Ibovespa), bem como os maiores e menores retornos apresentados no índice. Para empresas com mais de uma classe de ação negociada, considerou-se apenas a mais líquida. Os retornos mensais foram calculados conforme a equação (1) abaixo:

$$
\begin{gathered}
R i, t=(P i, t-P i, t-1) / P i, t-1 \\
P i, t: \text { valor da ação } i \text { no período } t \\
P i, t-1: \text { valor da ação } i \text { no período } t-l
\end{gathered}
$$


Para tratamento dos dados utilizou-se o software MATLAB R2015a, cuja programação encontra-se no Apêndice 1. As ações foram classificadas em decís, conforme retorno no período. Com base em Jegadeesh e Titman (1993), os menores retornos, situados no primeiro decíl, foram classificadas como ações perdedoras $\mathrm{R}_{L}$ (losers) e os maiores retornos, situados no décimo decil, foram classificadas como ações ganhadoras $\mathrm{R}_{W}$ (winners). $\mathrm{O}$ efeito momento foi calculado como sendo a diferença entre os retornos acumulados, utilizando janelas móveis (rolling window), das ganhadoras e das perdedoras, ou seja, comprar ganhadoras e vender perdedoras, conforme equação (2) abaixo:

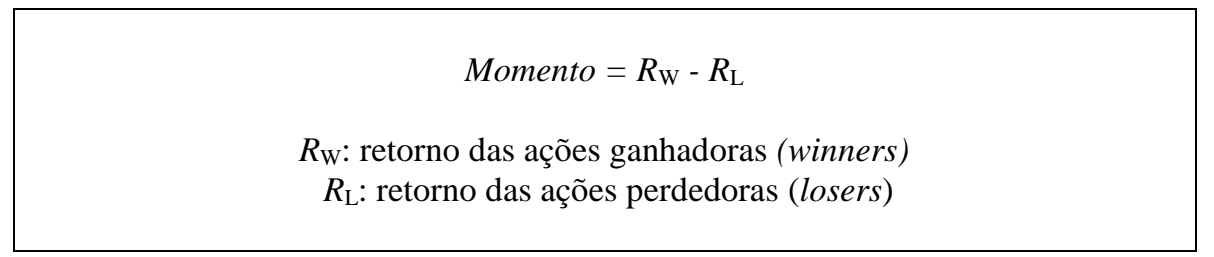

De forma oposta, o efeito contrário se dá pela subtração entre o retorno das perdedoras $\mathrm{R}_{L}$ (losers) e das ganhadoras $\mathrm{R}_{W}$ (winners), conforme equação (3) abaixo:

Contrário $=R_{\mathrm{L}}-R_{\mathrm{W}}$
$R_{\mathrm{W}}$ : retorno das ações ganhadoras (winners)
$R_{\mathrm{L}}:$ retorno das ações perdedoras (losers)

Ressalta-se que não foram considerados custos de transação, de oportunidade ou impostos, nem ajustes devidos à inflação. Assumiu-se uma carteira igualmente balanceada $(1 / \mathrm{N})$, sendo $\mathrm{N}$ o número de ações, ou seja, o montante investido em cada ação era idêntico.

O tratamento estatístico utilizou o teste- $t$ realizado no sistema MATLAB R2015a. Adotou-se como parâmetro de aceitação de hipóteses um p-valor menor ou igual a 5\% para verificação da diferença de médias entre os retornos das carteiras ganhadoras e perdedoras. Se o p-valor for inferior a $5 \%$, há evidência do efeito momento para a estratégia $(n ; k)$, caso o retorno seja positivo.

Assim, a metodologia resumida do trabalho cumpriu as seguintes etapas:

- Etapa 1: análise da bibliografia nacional e internacional para identificar a metodologia utilizada nos principais estudos; 
- Etapa 2: coleta dos retornos mensais no sistema Economática, entre julho de 1994 a junho de 2015, excluídas as ações sem liquidez no período, e estatística descritiva para o Ibovespa;

- Etapa 3: elaboração das carteiras ganhadoras e perdedoras, de acordo com os decís de retorno em cada mês, a partir da utilização do software MATLAB R2015a;

- Etapa 4: cálculo do retorno médio para o primeiro e décimo decil e do p-valor entre as carteiras utilizando janelas móveis;

- Etapa 5: cálculo dos retornos mensais da estratégia de momento $\left(\mathrm{R}_{W}-\mathrm{R}_{L}\right)$ para as 24 estratégias estudadas caso o $p$-valor seja inferior a $5 \%$ e a diferença de retornos seja positiva;

- Etapa 6: cálculo dos retornos mensais da estratégia contrária $\left(\mathrm{R}_{L}-\mathrm{R}_{W}\right)$ para as 24 estratégias estudadas caso o $p$-valor seja inferior a $5 \%$ e a diferença de retornos seja negativa. 


\section{RESULTADOS}

O trabalho analisou a existência dos efeitos momento e contrário para as ações brasileiras no período de 21 anos, compreendidos entre julho de 1994 e junho de 2015.

Adotou-se quatro períodos distintos para formação das carteiras, com três, seis, nove e 12 meses. As carteiras resultantes foram acompanhadas por seis períodos diferentes, utilizando janelas móveis mensais, com duração de três, seis, nove, 12, 18 e 24 meses. Desta forma, chegou-se a um total de 24 carteiras analisadas.

Foram calculados os retornos mensais das carteiras ganhadoras (winners) e perdedoras (losers) de forma separada. Em seguida, utilizou-se o teste-t para avaliar a significância das diferenças de médias entre os retornos das carteiras ganhadoras e perdedoras, conforme pode ser observado na Tabela 3.

Tabela 3 - Retornos mensais das carteiras vencedoras e perdedoras

\begin{tabular}{|c|c|c|c|c|c|c|c|}
\hline \multirow{2}{*}{$\begin{array}{l}k \text { meses de } \\
\text { formação }\end{array}$} & & \multicolumn{6}{|c|}{$n$ meses de manutenção } \\
\hline & & 3 & 6 & 9 & 12 & 18 & 24 \\
\hline \multirow{4}{*}{3} & Winners & $1,0561 \%$ & $1,3166 \%$ & $1,4218 \%$ & $1,3855 \%$ & $1,3361 \%$ & $1,2039 \%$ \\
\hline & Losers & $0,8753 \%$ & $0,5594 \%$ & $0,4588 \%$ & $0,4652 \%$ & $0,6827 \%$ & $0,7196 \%$ \\
\hline & p-value & 0,5725 & 0,0017 & 0,0000 & 0,0000 & 0,0000 & 0,0000 \\
\hline & $\begin{array}{c}\text { WML } \\
\text { (momento) }\end{array}$ & $0,1808 \%$ & $0,7572 \%$ & $0,9630 \%$ & $0,9203 \%$ & $0,6534 \%$ & $0,4843 \%$ \\
\hline \multirow{4}{*}{6} & Winners & $1,3422 \%$ & $1,4571 \%$ & $1,4685 \%$ & $1,4888 \%$ & $1,3625 \%$ & $1,2112 \%$ \\
\hline & Losers & $0,4901 \%$ & $0,4349 \%$ & $0,2888 \%$ & $0,3980 \%$ & $0,6383 \%$ & $0,7349 \%$ \\
\hline & p-value & 0,0168 & 0,0003 & 0,0000 & 0,0000 & 0,0000 & 0,0000 \\
\hline & $\begin{array}{c}\text { WML } \\
\text { (momento) }\end{array}$ & $0,8521 \%$ & $1,0222 \%$ & $1,1797 \%$ & $1,0908 \%$ & $0,7242 \%$ & $0,4763 \%$ \\
\hline \multirow{4}{*}{9} & Winners & $1,6442 \%$ & $1,5747 \%$ & $1,5833 \%$ & $1,4643 \%$ & $1,3042 \%$ & $1,2112 \%$ \\
\hline & Losers & $0,2817 \%$ & $0,0916 \%$ & $0,1416 \%$ & $0,3066 \%$ & $0,5651 \%$ & $0,7349 \%$ \\
\hline & p-value & 0,0000 & 0,0000 & 0,0000 & 0,0000 & 0,0000 & 0,0000 \\
\hline & $\begin{array}{c}\text { WML } \\
\text { (momento) }\end{array}$ & $1,3625 \%$ & $1,4831 \%$ & $1,4417 \%$ & $1,1577 \%$ & $0,7391 \%$ & $0,4763 \%$ \\
\hline \multirow{4}{*}{12} & Winners & $1,6531 \%$ & $1,6192 \%$ & $1,5732 \%$ & $1,4487 \%$ & $1,2998 \%$ & $1,1484 \%$ \\
\hline & Losers & $0,0544 \%$ & $0,1846 \%$ & $0,2653 \%$ & $0,4275 \%$ & $0,5999 \%$ & $0,6873 \%$ \\
\hline & p-value & 0,0000 & 0,0000 & 0,0000 & 0,0000 & 0,0000 & 0,0000 \\
\hline & $\begin{array}{c}\text { WML } \\
\text { (momento) }\end{array}$ & $1,5987 \%$ & $1,4346 \%$ & $1,3079 \%$ & $1,0212 \%$ & $0,6999 \%$ & $0,4611 \%$ \\
\hline
\end{tabular}


Apenas a janela de três meses de formação e três meses de manutenção (carteira “3x3”) não foi significante ao nível de 5\% de confiança. Este resultado corrobora com o encontrado por Jegadeesh e Titman (1993) para o mercado norte-americano.

Com relaçao a análise descritiva do Ibovespa, o valor máximo encontrado foi de $28,02 \%$ em abril de 1995 e o valor mínimo foi de $-39,55 \%$ em agosto de 1998, conforme Tabela 4:

Tabela 4 - Retornos do Ibovespa, (em porcentagem)

\begin{tabular}{|c|c|}
\hline Média & 1,475 ao mês \\
\hline Mediana & 1,555 ao mês \\
\hline Desvio Padrão & 8,897 \\
\hline Mínimo & $-39,550$ \\
\hline Máximo & 28,020 \\
\hline
\end{tabular}

Para fins de comparaçao, o Gráfico 1 apresenta os retornos mensais do Ibovespa no período.

Gráfico 1 - Retornos mensais do Ibovespa entre julho de 1994 e junho de 2015 (em \%)

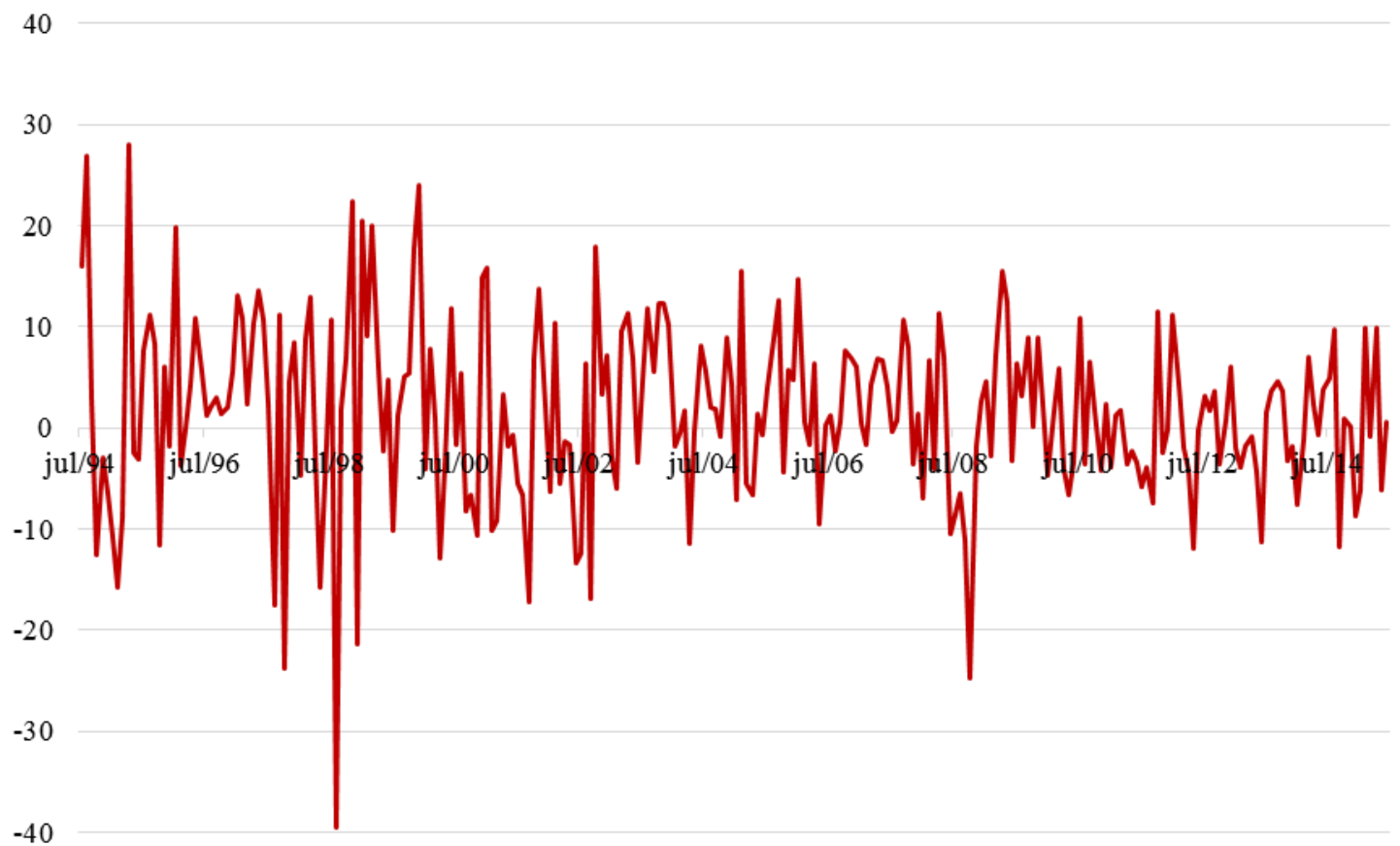

FONTE: Elaboração do autor a partir de dados do Economática

O Gráfico 2 apresenta o retorno acumulado do Ibovespa entre julho de 1994 e junho de 2015, em base 100 no início do período. O retorno acumulado desse índice no período de 21 anos foi de $1.364,6 \%$. O retorno médio mensal do Ibovespa foi de $1,475 \%$. 
Gráfico 2 - Evolução do Ibovespa (base 100 em 30 de junho de 1994)

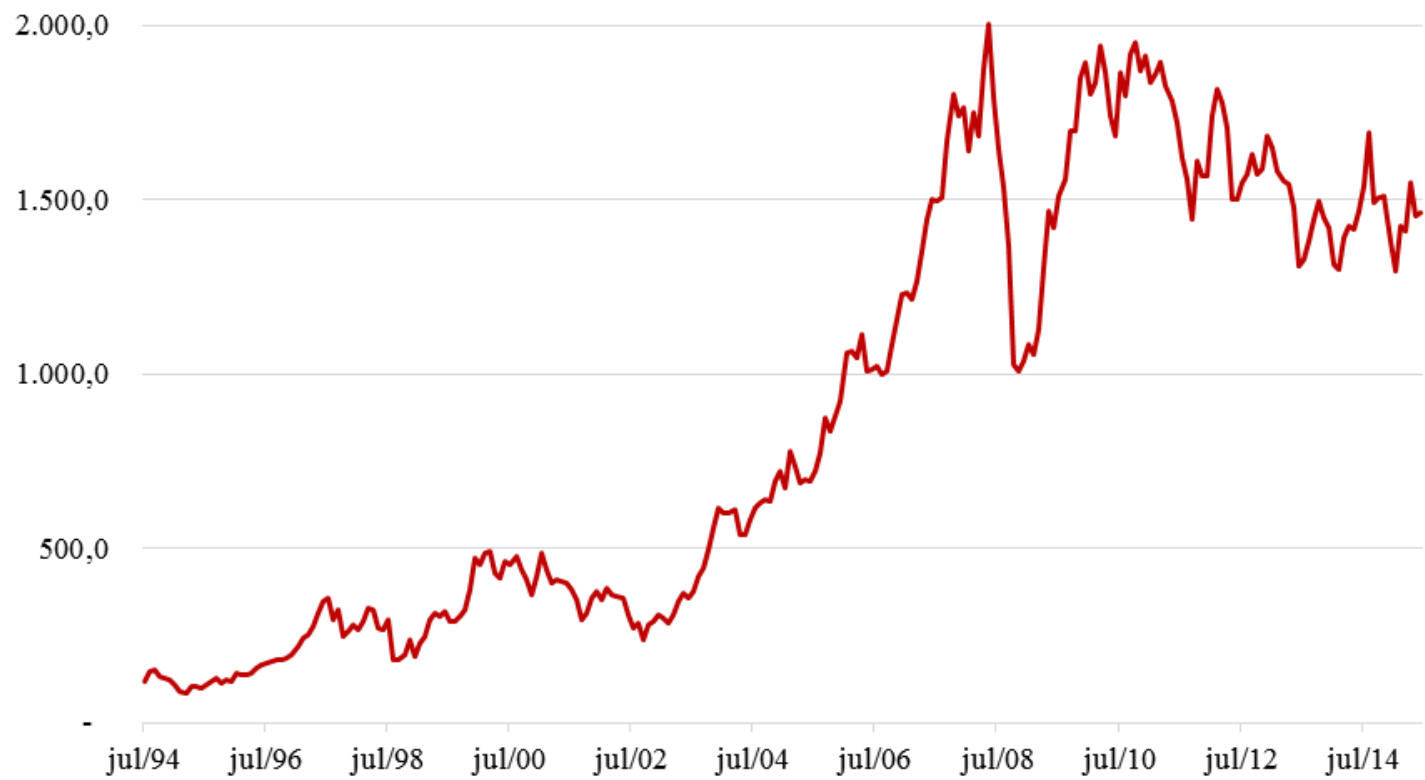

FONTE: Elaboração do autor a partir de dados do Economática

Todos os resultados apresentados na Tabela 5 referem-se ao efeito momento, estatisticamente significantes. Assim, o trabalho não apresenta evidências do efeito contrário, uma vez que não foram evidenciados retornos negativos na análise.

Tabela 5 - Retornos mensais da estratégia de momento

\begin{tabular}{ccccccc}
\hline \multirow{2}{*}{$\begin{array}{c}\boldsymbol{k} \text { meses de } \\
\text { formação }\end{array}$} & $\mathbf{3}$ & $\mathbf{6}$ & $\mathbf{9}$ & $\mathbf{1 2}$ & $\mathbf{1 8}$ & $\mathbf{2 4}$ \\
\cline { 2 - 7 } & - & $0,757 \%$ & $0,963 \%$ & $0,920 \%$ & $0,653 \%$ & $0,484 \%$ \\
$\mathbf{3}$ & $0,852 \%$ & $1,022 \%$ & $1,180 \%$ & $1,091 \%$ & $0,724 \%$ & $0,476 \%$ \\
$\mathbf{6}$ & $1,363 \%$ & $\mathbf{1 , 4 8 3 \%}$ & $1,442 \%$ & $1,158 \%$ & $0,739 \%$ & $0,476 \%$ \\
$\mathbf{9}$ & $\mathbf{1 , 5 9 9 \%}$ & $1,435 \%$ & $1,308 \%$ & $1,021 \%$ & $0,700 \%$ & $0,461 \%$ \\
\hline $\mathbf{1 2}$ & & & & &
\end{tabular}

Comparando-se com o retorno médio mensal do Ibovespa de 1,475\%, foram encontradas duas carteiras que superaram o índice no período. São elas, por ordem decrescente de retornos:

- Estratégia “12x3": formação a partir dos retornos dos 12 meses anteriores e manutenção por três meses posteriores, a qual apresentou retorno de 1,599\% ao mês, portanto, 0,124 ponto percentual acima do retorno médio mensal do Ibovespa no período ( $p$-valor $=0,1426)$, apresentado no Gráfico 3. 
Gráfico 3 - Retornos mensais das carteiras de estratégia "12x3" (em \%)

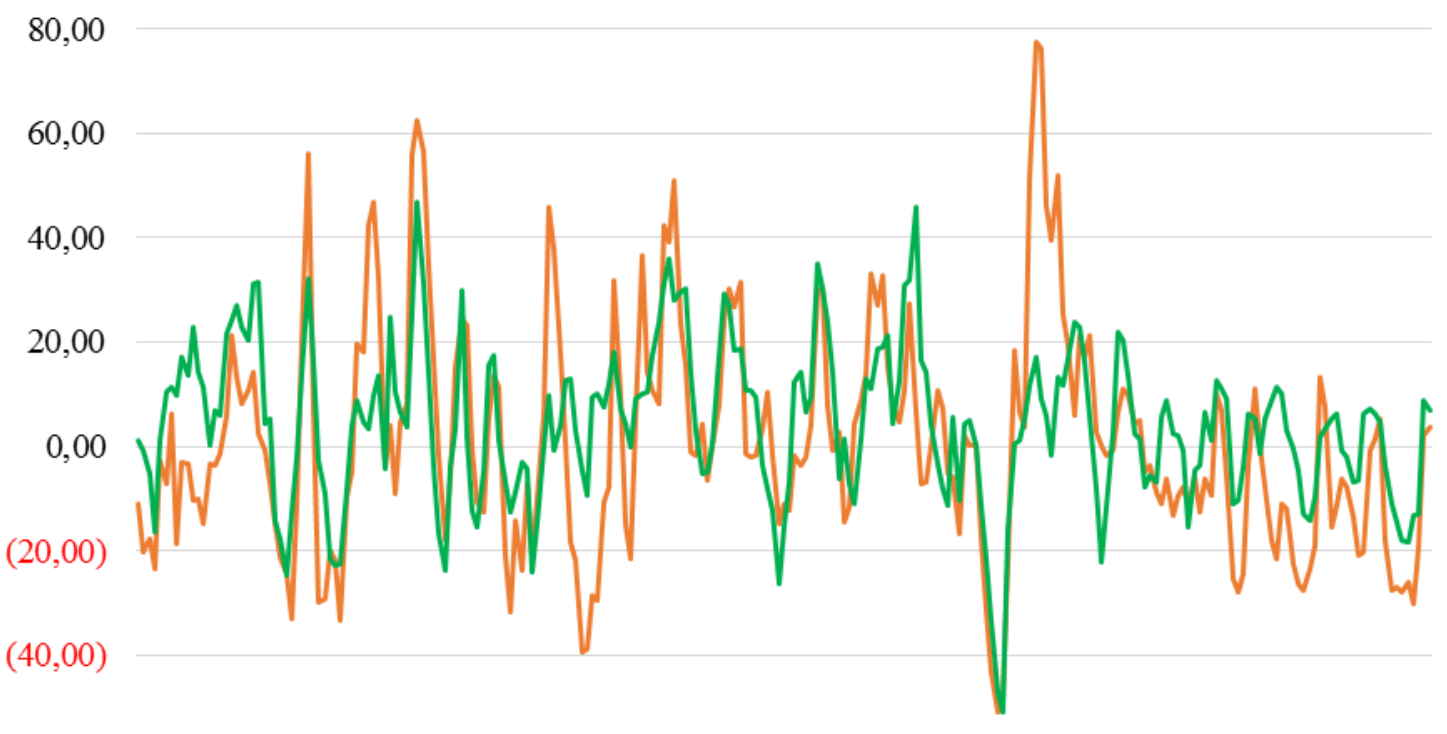

$(60,00)$

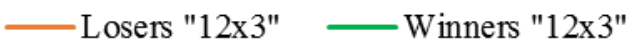

- Estratégia "9x6": formação partir dos retornos dos nove meses anteriores e manutenção por seis meses posteriores, a qual apresentou retorno de 1,483\% ao mês, portanto, 0,008 ponto percentual acima do retorno médio mensal do Ibovespa no período ( $p$-valor $=0,0279)$, apresentado no Gráfico 4.

Gráfico 4 - Retornos mensais das carteiras de estratégia “9x6” (em \%)

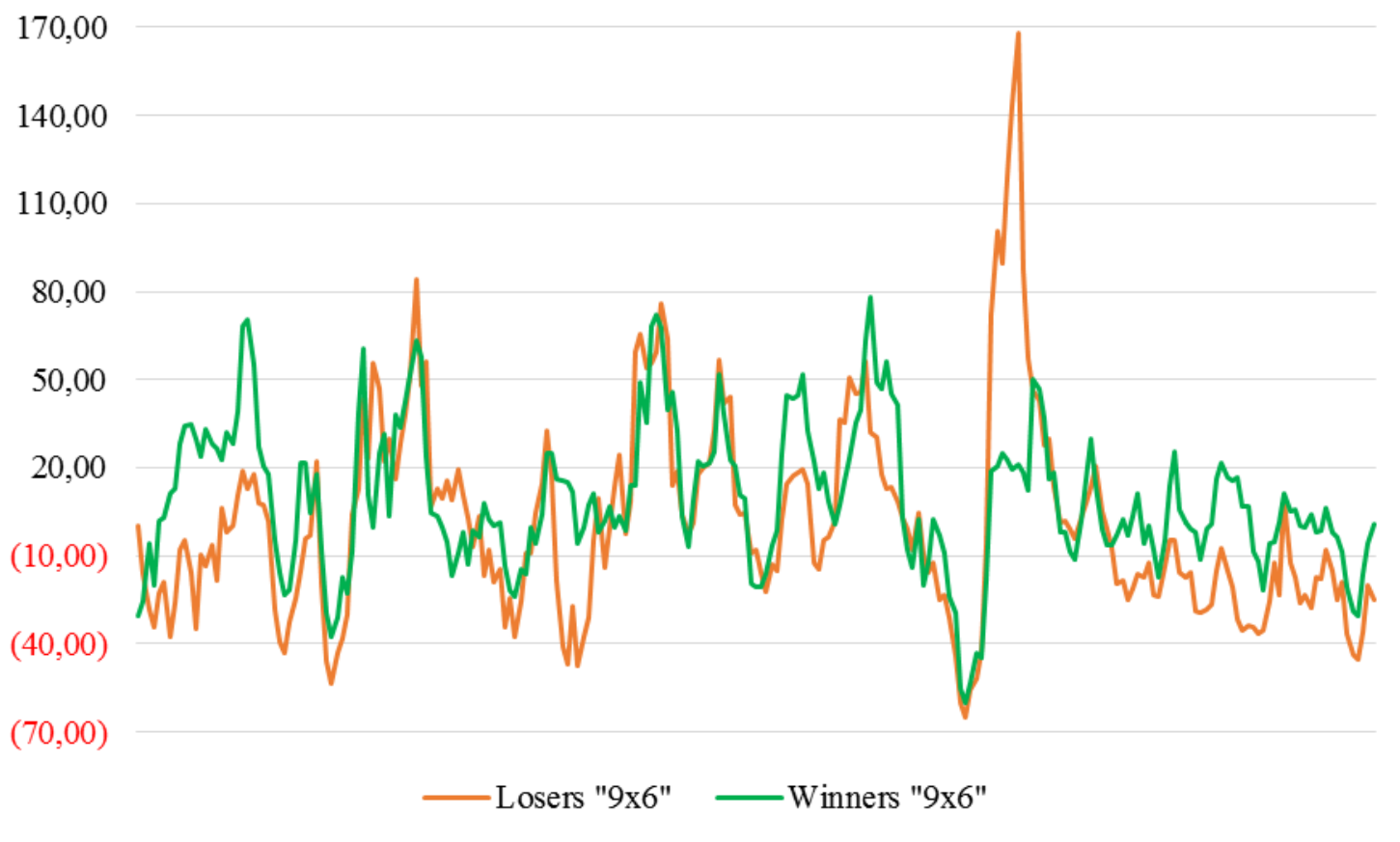


O

Gráfico 5 apresenta um comparativo da Ibovespa com estratégia 9x6", cuja diferença entre as médias de retornos apresentaram significância estatística ao nível de 5\% pelo teste-t de Student.

Gráfico 5 - Comparativo dos retornos do Ibovespa com a estratégia 9x6" (em \%)

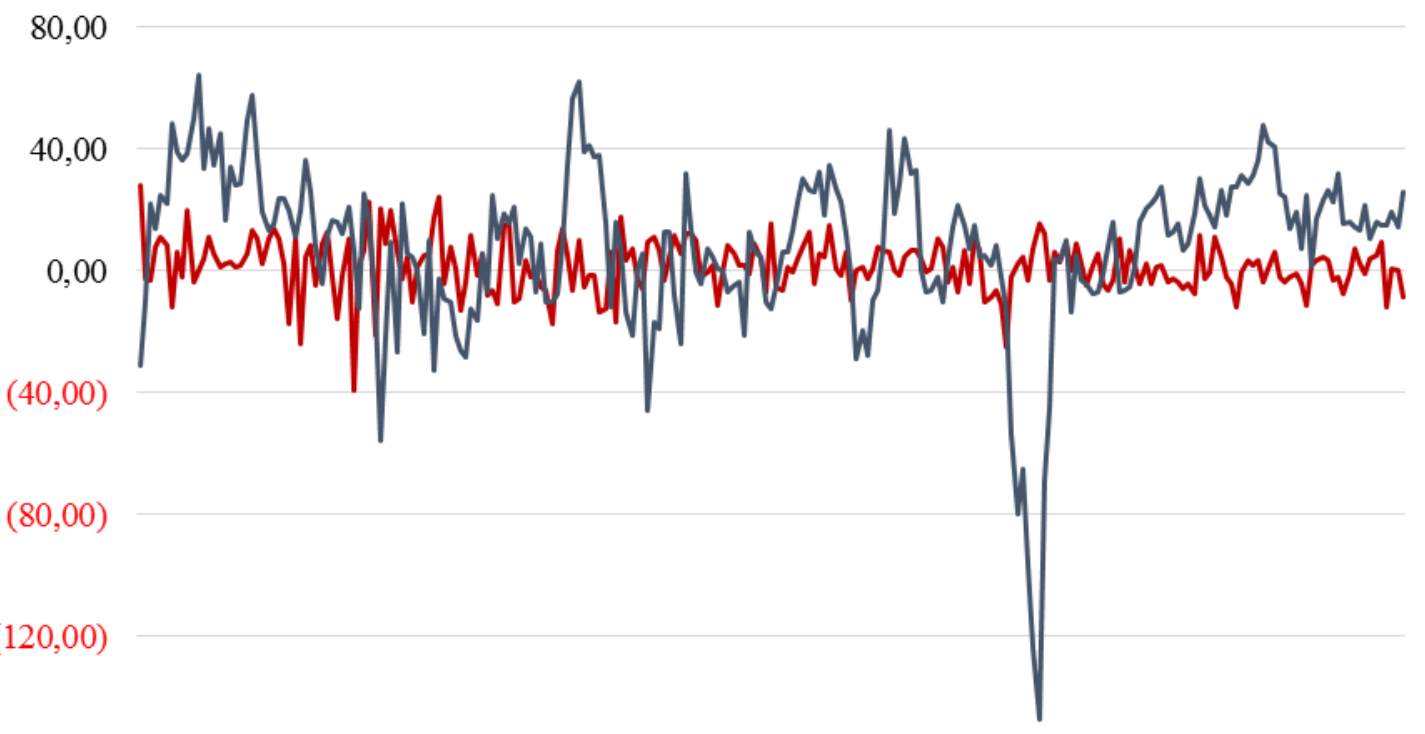

$(160,00)$

—Ibovespa —Momento "9x6"

Esses resultados corroboram com Jegadeesh e Titman (1993), que identificaram como estratégia mais bem-sucedida, em termos de retorno, aquela formada com base nos retornos de 12 meses anteriores e mantida pelos três meses seguintes (carteira“12x3”). Nesse caso, o retorno mensal encontrado por estes autores foi de $1,31 \%$ ao mês.

Sobre as hipóteses de pesquisa para o qual se buscava comprovação, pode-se afirmar que:

- A Hipótese $\mathrm{H}_{1}$ pode ser aceita, pois os retornos das carteiras ganhadoras menos os retornos das carteiras perdedoras foram positivos nas vinte e quatro estratégias analisadas, confirmando a existência de evidências do efeito momento no Brasil;

- A Hipótese $\mathrm{H}_{2}$ foi comprovada a partir da carteira "12x3", que apresenta o maior retorno no período estudado, com $1,60 \%$ ao mês;

- A Hipótese $\mathrm{H}_{3}$ foi rejeitada, pois os retornos das carteiras formadas por ações perdedoras menos ganhadoras foram negativos nas vinte e quatro estratégias analisadas, evidenciando a inexistência do efeito contrário no Brasil; 
- A Hipótese $\mathrm{H}_{4}$ não pode ser comprovada uma vez que não foi possível identificar o efeito contrário no mercado acionário brasileiro no período estudado.

Os motivos para tais resultados têm como base as explicações provenientes das finanças comportamentais, pela propensão dos investidores em cometerem erros ao avaliarem as expectativas de retornos com base em resultados passados (BONOMO; DALL'AGNOL, 2003, p. 212).

Como as análises pelas janelas móveis têm a propriedade de evitar o viés de seleção, não é possível capturar efeitos de intervalos de tempo muito curtos ou específicos, pois as diferenças de média entre carteiras ganhadoras e perdedoras não apresentam significância estatística. Entretanto, em uma análise específica para o período da crise do subprime, os resultados podem indicar a ocorrência do efeito contrário no Brasil, o que poderá ser desenvolvido em trabalhos futuros. 


\section{CONCLUSÕES}

A principal contribuição do trabalho foi comprovar a existência do efeito momento no mercado acionário brasileiro e refutar a existência do efeito contrário. As análises foram desenvolvidas para um período de 21 anos, compreendidos entre julho de 1994 e junho de 2015. A amostra utilizada foi de 662 ações, excluídas as que não apresentaram liquidez satisfatória. Essas características o tornam o estudo mais amplo já realizado para o mercado brasileiro.

Foram analisadas 24 estratégias, sendo que apenas a estratégia "3x3" não apresentou significância estatística para o efeito momento. Das demais estratégias, duas superaram o Ibovespa ("12x3" e "9x6"), sendo a estratégia "12x3" a de melhor desempenho, com retorno médio de $1,60 \%$ ao mês contra $1,48 \%$ ao mês do Ibovespa.

Esses resultados estão em linha com os obtidos por Jegadeesh e Titman (1993), nos mercados acionários norte-americanos, em que a estratégia " $3 \times 3$ " não foi significante e o melhor resultado foi o da carteira " $12 \times 3$ ”, com retorno mensal de $1,31 \%$.

De acordo com a visão de alguns autores, a existência do efeito momento evidencia uma anomalia da eficiência do mercado brasileiro e a irracionalidade dos investidores.

Como as análises pelas janelas móveis têm a propriedade de evitar o viés de seleção, não é possível capturar efeitos de intervalos de tempo muito curtos ou específicos, pois as diferenças de média entre carteiras ganhadoras e perdedoras não apresentam significância estatística. Entretanto, em uma análise específica para o período da crise do subprime, os resultados podem indicar a ocorrência do efeito contrário no Brasil, o que poderá ser desenvolvido em trabalhos futuros. 


\section{REFERÊNCIAS}

ANG, A; CHEN, J.; XING, Y. Downside risk and the momentum effect. National Bureau of Economic Research. NBER Working Paper Series, n. 8643, dez. 2001.

ANTUNES, M. A.; PROCIANOY, J. L. Os efeitos das decisões de investimento das empresas sobre os preços de suas ações no mercado de capitais. Revista de Administração (FEA-USP), v.38, n.1, p.5-14, jan./fev./mar. 2003.

ASNESS, C. S.; FRAZZINI, A.; ISRAEL, R.; MOSKOWITZ, T. J. Fact, Fiction and Momentum Investing. The Journal of Portfolio Management, v. 40, 2014.

ASNESS, C. S.; MOSKOWITZ, T. J.; PEDERSEN, L. H. Value and momentum everywhere. The Journal of Finance, v. 68, n. 3, p. 929-985, jun. 2013.

BONOMO, M.; DALL'AGNOL, I. Retornos anormais e estratégias contrárias. Revista Brasileira de Finanças, v. 1, n. 2, p. 165-215, dez. 2003.

CAMARGOS, M. A.; BARBOSA, F. V. Teoria e evidência da eficiência informacional do mercado de capitais brasileiro. Caderno de Pesquisas em Administração, v. 10, n. 1, jan./mar. 2003.

CAMARGOS, M. A.; ROMERO, J. A. R. Análise empírica da reação do mercado de capitais brasileiro a eventos corporativos: teste conjunto da Hipótese de Eficiência do Mercado. REGE. Revista de Gestão USP, v. 13, n. 3, p. 57-74, jul./set. 2006.

CARHART, M. M. On persistence in mutual fund performance. The Journal of Finance, v. 52, n. 1, mar. 1997.

CERVANTES, MONTOYA, CUETO. Momentum effect on the Mexican Stock Exchange. Working Paper, jan. 2014.

CHAN, L. K. C.; JEGADEESH, N.; LAKONISHOK, J. Momentum strategies. The Journal of Finance, v. 51, n. 5, dez. 1996.

CHOPRA, N.; LAKONISHOK, J.; RITTER, J. R. Measuring abnormal performance: Do stocks overreact? Journal of Financial Economics, v. 31, n. 2, p. 235-268, abr. 1992.

CONRAD, J.; KAUL, G. An anatomy of trading strategies. The Review of Financial Studies, v. 11, n. 3, p. 489-519, 1998.

COPELAND, WESTON, SHASTRI. Financial theory and corporate policy. 4th. ed., Pearson Education, 2005.

COSTA JR., N. C. A. Overreaction in the Brazilian stock market. Journal of Banking \& Finance, v. 18, n. 4, p. 633-642, set. 1994.

CRUZ, J. A. Aplicando estratégias simultâneas de momento e valor no mercado brasileiro. Rio de Janeiro, 2009. Dissertação (Mestrado em Finanças e Economia Empresarial) - Escola de Pós-Graduação em Economia da Fundação Getulio Vargas. 
DANIEL, K.; HIRSHLEIFER, D.; SUBRAHMANYAM, A. Investor psychology and security market under- and overreactions The Journal of Finance, v. 53, n. 6, dez.1998.

DE BONDT, W. F. M.; THALER, R. H. Does the stock market overreact? The Journal of Finance, v. 40, p. 793-805, Dallas: Jul. 1985.

Financial decision-making in markets and firms: A behavioral perspective. In: Jarrow, R. et al. (Eds.), Handbooks in OR and MS, v. 9, p. 385-410. Amsterdam: Elsevier, 1995.

Further evidence on investor overreaction and stock market seasonality. The Journal of Finance, v. 42, n. 3, jul. 1987.

FAMA, E. F. Efficient capital markets: A review of theory and empirical work. The Journal of Finance, v. 25, n. 2, p. 383-417, mai. 1970.

1991.

Efficient capital markets: II. The Journal of Finance, v. 46, n. 5, p. 1575-1617, dez.

Market efficiency, long-term returns, and behavioral finance. Journal of Financial Economics, v. 49, p. 283-306, 1998.

FAMA, E. F.; FRENCH, K. R. Common risk factors in the returns on stocks and bonds. The Journal of Finance, v. 33, 3-56, 1993.

. Dissecting Anomalies. The Journal of Finance, v. 63, n. 4, p. 1653-1678, ago. 2008

1996.

Multifactor explanations of asset pricing anomalies. The Journal of Finance. v. 51,

Size, value, and momentum in international stock returns. Journal of Financial Economics, v. 105, p. 457-472, 2012.

1992.

The cross-section of expected stock retuns. The Journal of Finance, v. 47, n. 2, jun.

FAMÁ, R.; CIOFFI, P. L. M.; COELHO, P. A. R. Contexto das finanças comportamentais: Anomalias e eficiência do mercado de capitais brasileiro. REGE. Revista de Gestão USP, v. 15, n. 2, p. 65-78. São Paulo: abr./jun. 2008.

GALARIOTIS, E. C.; HOLMES, P.; MA, X. S. Contrarian and momentum profitability revisited: Evidence from the London Stock Exchange 1964-2005. Journal of Multinational Financial Management, v. 17, p. 432-477, 2007.

GECZY, C. C.; SAMONOV, M. 215 Years of Global Multi-Asset Momentum: 1800-2014. Working Paper, mai. 2015.

GIL, A. C. Como elaborar projetos de pesquisa. 5. ed. - São Paulo: Atlas, 2010. 
GOETZMANN, W. N.; MASSA, M. Daily momentum and contrarian behavior of index fund investors. The Journal of Financial and Quantitative Analysis, v. 37, n. 3, p. 375-389, set. 2002.

GRAHAM. B.; DODD, D. Security analysis. McGraw-Hill, New York: 1934.

GRINBLATT, M.; TITMAN, S; WERMERS, R. Momentum investment strategies, portfolio performance, and herding: A study of mutual fund behavior. American Economic Review, 85, 1088-1105, 1995.

HAAN, L.; KAKES, J. Momentum or contrarian investment strategies: Evidence from Dutch institutional investors. Journal of Banking \& Finance, v. 35, p. 2245-2251, 2011.

HALFELD, M.; TORRES, F. F. L. Finanças Comportamentais: aplicações no contexto brasileiro. RAE - Revista de Administração de Empresas, v. 41, n. 2, p. 64-71, abr./jun. 2001.

HONG, H; LIM, T.; STEIN, J. C. Bad news travels slowly: Size, analyst coverage, and the profitability of momentum strategies. The Journal of Finance, v. 55, n. 1, fev. 2000.

HONG, H.; STEIN, J. C. A unified theory of underreaction, momentum trading and overreaction in asset markets. National Bureau of Economic Research. NBER Working Paper Series, n. 6324, dez 1997.

A unified theory of underreaction, momentum trading, and overreaction in asset markets. The Journal of Finance, n. 54, n. 6, 1999.

IMPROTA, João Paulo de Barros. Momentum and reversal effects in Brazil. São Paulo, 2012. Dissertação (Mestrado) - Departamento de Economia da Faculdade de Economia, Administração e Contabilidade da Universidade de São Paulo.

JEGADEESH, N. Evidence of predictable behavior of security returns. The Journal of Finance, v. 45, n. 3, p. 881-898, jul. 1990.

JEGADEESH, N.; TITMAN, S. Profitability of momentum strategies: An evaluation of alternative explanations. The Journal of Finance, v. 56, n. 2, abr. 2001.

Returns to buying winners and selling losers: Implications for stock market efficiency. The Journal of Finance, v. 48, n. 1, mar. 1993.

JENSEN, M. C. Some anomalous evidence regarding market efficiency. Journal of Financial Economics, v. 6, p. 95-101, set. 1978.

KAHNEMAN, D.; TVERSKY, A. Prospect Theory: An analysis of decision under risk. Econometrica, v. 47, n.2, p. 263-291, mar. 1979.

KANG, J.; LIU, M.; NI, S. X. Contrarian and momentum strategies in the China stock market: 1993-2000. Pacific-Basin Finance Journal, v. 10 p. 243-265, 2002. 
KANIEL, R; SAAR, G.; TITMAN, S. Individual investor trading and stock returns. The Journal of Finance, v. 63, n. 1, fev. 2008

KELlER, W. J.; BUTLER, A.; KIPNIS, I. Momentum and Markowitz: a Golden Combination. Working Paper, mai. 2015.

KIMURA, H. Aspectos comportamentais associados às reações do mercado de capitais. RAE Eletrônica (Online), v. 2, n. 1, jan./jun. 2003.

KIMURA, H.; BASSO, L. F. C.; KRAUTER, E. Paradoxos em finanças: teoria moderna versus finanças comportamentais. RAE - Revista de Administração de Empresas, v. 46, n. 1, p. 41-58, jan./mar. 2006.

LA PORTA, R.; LAKONISHOK, J.; SHLEIFER, A.; VISHNY, R. Good news for value stocks: Further evidence on market efficiency. The Journal of Finance, v. 52, n. 2, jun. 1997

LAKONISHOK, J.; SHLEIFER, A.; VISHNY, R.W. Contrarian Investment, Extrapolation, and Risk. The Journal of Finance, v. 49, n. 5, dez. 1994.

LIMA, M. V. Um estudo sobre finanças comportamentais. RAE Eletrônica (Online), v. 2, n. 1, jan./jun. 2003.

MARKOWITZ, H. M. Portfolio Selection. The Journal of Finance, v. 7, p. 77-91, 1952.

MCINISH, T. H.; DING, D. K.; PYUN, C. S.; WONGCHOTI, U. Short-horizon contrarian and momentum strategies in Asian markets: An integrated analysis. International Review of Financial Analysis, v. 17, p. 312-329, 2008.

MENGOLI, S. On the source of contrarian and momentum strategies in the Italian equity market. International Review of Financial Analysis, v. 13, p. 301-331, 2004.

MIFFRE, J.; RALLIS, G. Momentum strategies in commodity futures markets. Journal of Banking \& Finance, v. 31, p. 1863-1886, 2007.

MILANEZ, D. Y. Finanças Comportamentais no Brasil. São Paulo, 2003. Dissertação (Mestrado) - Programa de Pós-Graduação em Economia, Faculdade de Economia, Administração e Contabilidade da Universidade de São Paulo.

MINARDI, A. M. A. F. Retornos passados prevêem retornos futuros? RAE Eletrônica (Online), v. 3, n. 2, jul./dez. 2004.

MUGA, L.; SANTAMARÍA, R. The momentum effect in Latin American emerging markets Emerging Markets Finance and Trade. v. 43, n. 4, p. 24-45, jul./ago. 2007.

MUSSA, A.; SECURATO, J. R.; SANTOS, J. O.; FAMÁ, R. A Influência das Condições do Mercado Acionário e da Política Monetária no Comportamento dos Indicadores de Risco Tamanho, Índice Book-to-market e Momento, no Mercado Acionário Brasileiro. Revista de Ciências da Administração, v. 13, n. 29, p. 152-172, jan./abr. 2011. 
MUSSA, A.; TROVAO, R.; FAMÁ, R.; SANTOS, J. O. A estratégia de momento de Jegadeesh e Titman e suas implicações para a hipótese de eficiência do mercado acionário brasileiro. REGES: Revista Eletrônica de Gestão, v. 2, p. 73-88, 2008.

MUSSA, A.; YANG, E.; TROVÃO, R.; FAMÁ, R. Hipótese de Mercados Eficientes e Finanças Comportamentais: as discussões persistem. Uni-FACEF Pesquisa, v.11, n. 1, 2008.

PIRES, M. R. Os efeitos disponibilidade e momento no mercado acionário brasileiro Um estudo empírico. São Paulo: 2013. Dissertação (Mestrado em Economia e Finanças) Escola de Economia de São Paulo da Fundação Getúlio Vargas.

RABELO JUNIOR, T. S.; IKEDA, R. H. Mercados eficientes e arbitragem: Um estudo sob o enfoque das finanças comportamentais. Revista Contabilidade \& Finanças, n. 34, p. 97-107, São Paulo, jan./abr. 2004.

ROGERS, P.; SECURATO, J. R.; RIBEIRO, K. C. S. Finanças comportamentais no Brasil: um estudo comparativo. Revista de Economia e Administração, v. 6, n. 1, p. 49-68, jan./mar. 2007.

ROUWENHORST, K. G. International momentum strategies. The Journal of Finance, v. 53, n. 1, p. 267-284, 1998.

Local return factors and turnover in emerging stock markets. The Journal of Finance, v. 54, n. 4, p. 1439-1464, ago. 1999.

SANTOS, J. O.; FAMÁ, R; MUSSA, A. A adição do fator de risco momento ao modelo de precificação de ativos dos três fatores de Fama \& French aplicado ao mercado acionário brasileiro. REGE. Revista de Gestão USP, v. 19, n. 3, p. 453-472. São Paulo, jul./set. 2012.

SCHIERECK, D.; De BONDT, W. F. M.; WEBER, M. Contrarian and momentum strategies in Germany. Association for Investment Management and Research. Nov./dez. 1999.

SCHUMAKER, R. P.; CHEN, H. Evaluating a news-aware quantitative trader: The effect of momentum and contrarian stock selection strategies. Journal of the American Society for Information Science and Technology, v. 59, p. 247-255, 2008.

Textual analysis of stock market prediction using breaking financial news: The AZFinText System. ACM Transactions on Information Systems, v. 27, n. 2, fev. 2009.

SHARPE, W. F. Capital Asset Prices: A theory of market equilibrium under conditions of risk. The Journal of Finance, v. 19, n. 3, p. 425-442, 1964.

SHEN, Q.; SZAKMARY, A. C.; SHARMA, S. C. Momentum and contrarian strategies in international stock markets: Further evidence. Journal of Multinational Financial Management, v. 15, p. 235-255, 2005.

SHILLER, R. J. Do stock prices move too much to be justified by subsequent changes in dividends? National Bureau of Economic Research. NBER Working Paper Series, n. 456, fev. 1980. 
SHLEIFER, A. Inefficient Markets: An introduction to Behavioral Finance. Oxford University Press, 2000.

SILVA, W. V., PICCOLI, P. G. R., CRUZ, J. A. W., CLEMENTE, A. A eficiência do mercado de capitais brasileiros pela análise do efeito momento. Revista Economia \& Gestão, v. 14, n. 36, p. 113-137, jul./set. 2014.

SILVA NETO, O. S.; SILVA, V. L. A. M. S.; RABONI, P. L.; CARMONA, C. U. M.; ARAÚJO, L. F. Investimento em valor contrário no Brasil: Overreaction ou efeito tamanho? Revista de Finanças Aplicadas, v. 1, p. 1-20, 2012.

SILVA NETO, O. S.; SILVA, V. L. A. M. S.; RABONI, P. L.; OLIVEIRA, M. R. G. Efeito momentum no curto prazo: vale a pena comprar ações vencedoras no Brasil? RAM. Revista de Administração Mackenzie, v.15, n.4, p. 193-228, jul./ago. 2014.

TEIXEIRA, M. P. V. Value and momentum strategies in the Brazilian stock market: The 2008 financial crisis and its aftermath. Rio de Janeiro: 2011. Dissertação (Mestrado) Escola de Pós-Graduação em Economia da Fundação Getulio Vargas.

TVERSKY, A.; KAHNEMAN, D. Judgment under uncertainty: Heuristics and biases. Science, v. 185, n. 4157, p. 1124-1131, set. 1974.

VON NEUMANN, J.; MORGENSTERN, O. Theory of games and economic behavior. Princeton: Princeton University Press, 1944.

YAO, Y. Momentum, contrarian, and the January seasonality. Journal of Banking \& Finance, v. 36, p. 2757-2769, 2012.

YOSHINAGA, C. E. Análise da sobre-reação de preços no mercado de ações brasileiro durante o período de 1995 a 2003. São Paulo, 2004. Dissertação (Mestrado) - Programa de Pós-Graduação em Administração, Faculdade de Economia, Administração e Contabilidade da Universidade de São Paulo.

YOSHINAGA, C. E.; OLIVEIRA, R. F.; SILVEIRA, A. M.; BARROS, L. A. B. C. Finanças Comportamentais: uma introdução. REGE. Revista de Gestão USP, v. 15, n. 3, p. 25-35, São Paulo, jul./set. 2008. 


\section{APÊNDICE 1 - SCRIPT UTILIZADO NO MATLAB}

\%Carregar o arquivo BDMomento.xls e o arquivo time.xls load('BDMomento.mat','BDMomento');

\%linhas: empresas de capital aberto;

\%colunas: período de 1994-2015;

$\%$ Period of Formation Portfolio (k past months)

$\mathrm{k}=60$;

$\%$ Period of Holding Portfolio (n months ahead)

$\mathrm{n}=60$;

$\%$ Start Code

$\% \%$ Determinação do Formation Portfolio (Rolling-Window - 6 meses)

$\%$ Jegadeesh and Titman (JF,2001)

cont $=1$;

for $\mathrm{j}=\mathrm{k}$ :size(BDMomento, 2$)$

Formation_Port $(:, \operatorname{cont})=(\operatorname{prod}(1+\operatorname{BDMomento}(:, \mathrm{j}-\mathrm{k}+1: \mathrm{j}) / 100,2)-1) * 100$;

cont $=$ cont +1

end

$\% \%$ Determinação do Holding Portfolio

$\%$ Jegadeesh and Titman (JF,2001)

cont $=1$;

for $\mathrm{j}=\mathrm{k}+1$ :size(BDMomento, 2$)-\mathrm{n}$

Holding_Port $(:, \operatorname{cont})=(\operatorname{prod}(1+\mathrm{BDMomento}(:, \mathrm{j}: \mathrm{j}+\mathrm{n}-1) / 100,2)-1) * 100$;

cont $=$ cont +1 ;

end

\%Determinação das Carteiras Perdedoras (percentil de 10\%)

percentil10 $=$ repmat $($ prctile(Formation_Port,10),size(Formation_Port,1),1);

perdedoras $=$ Formation_Port $<$ percentil10;

perdedoras $=$ perdedoras $(:, 1: \operatorname{size}($ Holding_Port, 2$))$;

\%Determinação das Carteiras Vencedoras (percentil de 90\%)

percenti190 = repmat $($ prctile(Formation_Port,90),size(Formation_Port,1),1);

vencedoras $=$ Formation_Port $>$ percentil90;

vencedoras $=$ vencedoras $(:, 1: \operatorname{size}($ Holding_Port, 2$))$;

$\% \%$ Retornos das carteiras perdedoras para os próximos n meses

perd_ret $=$ Holding_Port .* perdedoras; \%Retornos obtidos

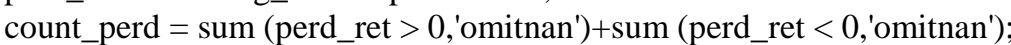

perd_ret(isnan(perd_ret) $)=0$;

soma_perd $=$ prod $(1+$ perd_ret $/ 100)$;

avg_perd $=\left(\left(\text { soma_perd } .^{\wedge}(1 . / \text { count_perd })\right)-1\right)^{*} 100$;

$\% \%$ Retornos das carteiras vencedoras para os próximos n meses

venc_ret $=$ Holding_Port.$*$ vencedoras; $\%$ Retornos obtidos

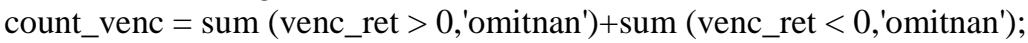

venc_ret(isnan(venc_ret) $)=0$;

soma_venc $=$ prod $(1+$ venc_ret $/ 100)$;

avg_venc $=\left(\left(\right.\right.$ soma_venc.$^{\wedge}(1 . /$ count_venc $\left.\left.)\right)-1\right) * 100$;

mean_venc $\left.=\left(((1+\text { mean }(\text { avg_venc }) / 100))^{\wedge}(1 . / \mathrm{n})\right)-1\right)^{*} 100$

mean_perd $\left.=\left(((1+\text { mean }(\text { avg_perd }) / 100))^{\wedge}(1 . / \mathrm{n})\right)-1\right) * 100$

spread = mean_venc - mean_perd

avg = cat (2,avg_perd',avg_venc');

\%Cálculo do Momento para os próximos n meses

momento_um = avg_venc - avg_perd;

$[\mathrm{h}, \mathrm{p}]=\mathrm{ttest}($ momento_um);p $=[\mathrm{p}]$

$\operatorname{subplot}(2,1,1)$;

plot(avg)

title(['Period: ' ,num2str(n),' month(s) ahead for holding and ',num2str(k),' month(s) for formation portfolios']) 


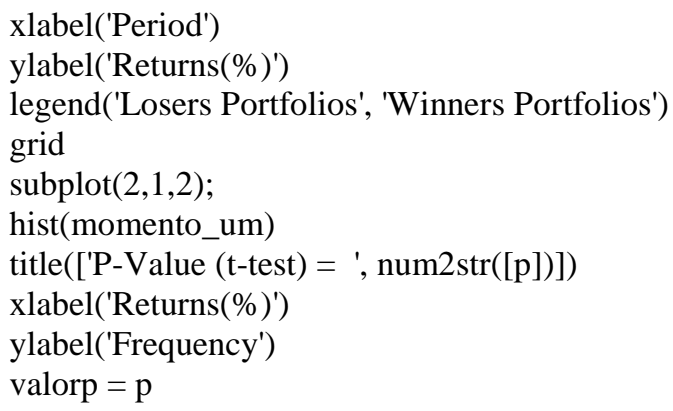




\section{APÊNDICE 2 - LISTA DE ATIVOS CONSIDERADOS}

\begin{tabular}{|l|}
\hline ABCB4 \\
\hline ABEV3 \\
\hline ABRE11+ABRE3 \\
\hline ABYA3 \\
\hline ACES4 \\
\hline ACGU3 \\
\hline AEDU3 \\
\hline AELP3 \\
\hline AESL3 \\
\hline AFLT3 \\
\hline AFLU3 \\
\hline AGEI3 \\
\hline AGEN33 \\
\hline AGIN3 \\
\hline AGRA4 \\
\hline AGRO3 \\
\hline AHEB5 \\
\hline ALBA3 \\
\hline ALLL3 \\
\hline ALLL3+RUMO3 \\
\hline ALPA4 \\
\hline ALSC3 \\
\hline ALUPI1 \\
\hline AMAR3 \\
\hline AMIL3 \\
\hline AMLC4 \\
\hline AMPI3 \\
\hline AMRI8 \\
\hline ANDG3B \\
\hline ANIM3 \\
\hline ANO5 \\
\hline ANPB5 \\
\hline ANTA3 \\
\hline APTI4 \\
\hline AQT4 \\
\hline ARCE3 \\
\hline ARCZ3 \\
\hline ARLA3 \\
\hline ARNO4 \\
\hline ARPS3 \\
\hline ARTE4 \\
\hline ARTR3 \\
\hline ARZZ3 \\
\hline ASSM3 \\
\hline ASTA4 \\
\hline AUTM3 \\
\hline AVIL3 \\
\hline AZEV4 \\
\hline BAHI3 \\
\hline BALM4 \\
\hline BARB3 \\
\hline BASU5 \\
\hline BAUH4 \\
\hline BAZA3 \\
\hline BBAS3 \\
\hline \\
\hline
\end{tabular}




\begin{tabular}{|l|}
\hline BBCM4 \\
\hline BBDC4 \\
\hline BBRK3 \\
\hline BBSE3 \\
\hline BBTG11 \\
\hline BBV4 \\
\hline BCE4 \\
\hline BCNA4 \\
\hline BDLL4 \\
\hline BECE3 \\
\hline BEEF3 \\
\hline BEES3 \\
\hline BEMA3 \\
\hline BEMG4 \\
\hline BEPA4 \\
\hline BERG3 \\
\hline BESP3 \\
\hline BFB3 \\
\hline BFCV4 \\
\hline BFIT3 \\
\hline BGIP4 \\
\hline BHEQ4 \\
\hline BHGR3 \\
\hline BICB4 \\
\hline BIOB4 \\
\hline BIOM3 \\
\hline BISA3 \\
\hline BMCT4 \\
\hline BMEB4 \\
\hline BMEF3 \\
\hline BMIN4 \\
\hline BMKS3 \\
\hline BMTO4 \\
\hline BNAC4 \\
\hline BNBR3 \\
\hline BNCA3 \\
\hline BNET4 \\
\hline BNNE3 \\
\hline BOBR4 \\
\hline BOVH3 \\
\hline BPAN4 \\
\hline BPAR3 \\
\hline BPCO4 \\
\hline BPHA3 \\
\hline BPIA3 \\
\hline BPLA5 \\
\hline BPRG4 \\
\hline BRAP4 \\
\hline BRDT4 \\
\hline BRFS3 \\
\hline BRGE3 \\
\hline BRIN3 \\
\hline BRIV4 \\
\hline BRKM5 \\
\hline BRML3 \\
\hline BRPR3 \\
\hline BRSR6 \\
\hline BRTP3 \\
\hline \\
\hline
\end{tabular}




\begin{tabular}{|l|}
\hline BRUM4 \\
\hline BSCT5 \\
\hline BSEG4 \\
\hline BSEV3 \\
\hline BSGR3 \\
\hline BSLI4 \\
\hline BSUL5 \\
\hline BTAS5 \\
\hline BTOW3 \\
\hline BTTL4 \\
\hline BUET3 \\
\hline BVMF3 \\
\hline CABR4 \\
\hline CAFE4 \\
\hline CALI4 \\
\hline CAMB4 \\
\hline CANT4B \\
\hline CARB5 \\
\hline CARD3 \\
\hline CASN4 \\
\hline CBAG3 \\
\hline CBEE3 \\
\hline CBMA4 \\
\hline CBTA4 \\
\hline CBVI4 \\
\hline CCHI3 \\
\hline CCIM3 \\
\hline CCPR3 \\
\hline CCRO3 \\
\hline CCTU4 \\
\hline CCXC3 \\
\hline CDOU4 \\
\hline CEBR5 \\
\hline CEDO3 \\
\hline CEEB3 \\
\hline CEED3 \\
\hline CEGR3 \\
\hline CELM3 \\
\hline CELP3 \\
\hline CEPE5 \\
\hline CESP6 \\
\hline CETE4 \\
\hline CEVA3 \\
\hline CFLU4 \\
\hline CGAS5 \\
\hline CGOS3 \\
\hline CGRA4 \\
\hline CHAP3 \\
\hline CIEL3 \\
\hline CIQU4 \\
\hline CLAN4 \\
\hline CLDX4 \\
\hline CLSC4 \\
\hline CMET4 \\
\hline CMIG4 \\
\hline CMMA4 \\
\hline CNFB4 \\
\hline COBE6B \\
\hline
\end{tabular}




\begin{tabular}{|l|}
\hline COCE5 \\
\hline COPA4 \\
\hline CORR4 \\
\hline CPCA4 \\
\hline CPFE3 \\
\hline CPFG3 \\
\hline CPFL4 \\
\hline CPFP4 \\
\hline CPLE6 \\
\hline CPNY3 \\
\hline CPRE3 \\
\hline CPSL3 \\
\hline CPTP3B \\
\hline CRBM7 \\
\hline CRDE3 \\
\hline CREM3 \\
\hline CREM4-old \\
\hline CRGT5 \\
\hline CRIV3 \\
\hline CRTP3 \\
\hline CRUZ3 \\
\hline CSAB4 \\
\hline CSAN3 \\
\hline CSMB3 \\
\hline CSMG3 \\
\hline CSNA3 \\
\hline CSPC4 \\
\hline CSRN3 \\
\hline CSTB4 \\
\hline CTAXI1 \\
\hline CTIP3 \\
\hline CTKA4 \\
\hline CTLU4 \\
\hline CTMI3 \\
\hline CTNM4 \\
\hline CTPC3 \\
\hline CTSA3 \\
\hline CTWR3 \\
\hline CVCB3 \\
\hline CVPT3 \\
\hline CYRE3 \\
\hline CZAR4 \\
\hline CZLT33 \\
\hline CZRS4 \\
\hline DAGB33 \\
\hline DASA3 \\
\hline DAYC4 \\
\hline DFVA4 \\
\hline DHBI4 \\
\hline DIRR3 \\
\hline DJON4 \\
\hline DOCA4 \\
\hline DOHL4 \\
\hline DOMO3 \\
\hline DPPI4 \\
\hline DSUL3 \\
\hline DTCY3 \\
\hline DTEX3 \\
\hline \\
\hline
\end{tabular}




\begin{tabular}{|l|}
\hline DUFB11 \\
\hline DUQE4 \\
\hline DURA3 \\
\hline DXTG4 \\
\hline EALT4 \\
\hline EBCO4 \\
\hline EBEN4 \\
\hline EBTP4 \\
\hline ECIS3 \\
\hline ECOR3 \\
\hline ECPR3 \\
\hline EDNE5 \\
\hline EEEL4 \\
\hline EKTR4 \\
\hline ELAT3 \\
\hline ELEK3 \\
\hline ELET3 \\
\hline ELEV3 \\
\hline ELPL11-old \\
\hline ELPL4 \\
\hline ELUM4 \\
\hline EMAE4 \\
\hline EMBR3 \\
\hline EMXS4 \\
\hline ENBR3 \\
\hline ENER6 \\
\hline ENEV3 \\
\hline ENGI11 \\
\hline ENMA3B \\
\hline ENMT4 \\
\hline EPTE4 \\
\hline EQTL3 \\
\hline ERIC4 \\
\hline ESCE3 \\
\hline ESTC3 \\
\hline ESTR4 \\
\hline ETER3 \\
\hline EUCA4 \\
\hline EVEN3 \\
\hline EZTC3 \\
\hline FAPC4 \\
\hline FBMC4 \\
\hline FBRA4 \\
\hline FCAP4 \\
\hline FESA4 \\
\hline FFTL4 \\
\hline FGOS4 \\
\hline FGUI4 \\
\hline FHER3 \\
\hline FIBR3 \\
\hline FIGE3 \\
\hline FJTA4 \\
\hline FLBR4 \\
\hline FLCL3 \\
\hline FLRY3 \\
\hline FRAS3 \\
\hline FRI4 \\
\hline FRIO3 \\
\hline \\
\hline
\end{tabular}




\begin{tabular}{|l|}
\hline FTRX3 \\
\hline FTSE4 \\
\hline FTSU4 \\
\hline FTZA4 \\
\hline GAFP3 \\
\hline GALO4 \\
\hline GAZO4 \\
\hline GEPA4 \\
\hline GETI4 \\
\hline GFSA3 \\
\hline GGBR4 \\
\hline GLAS4 \\
\hline GOAU4 \\
\hline GOLL4 \\
\hline GPAR3 \\
\hline GPCP3 \\
\hline GPIV33 \\
\hline GRND3 \\
\hline GRNL4 \\
\hline GSHP3 \\
\hline GTDP4B \\
\hline GUAR3 \\
\hline GVTT3 \\
\hline HAGA4 \\
\hline HBOR3 \\
\hline HBTS5 \\
\hline HETA4 \\
\hline HGTX3 \\
\hline HGTX4-old \\
\hline HOOT4 \\
\hline HYPE3 \\
\hline IBAN3 \\
\hline IBPI6 \\
\hline IBRC4 \\
\hline ICPI3 \\
\hline IDCO3 \\
\hline IDNT3 \\
\hline IDVL4 \\
\hline IENG3 \\
\hline IGBR3 \\
\hline IGTA3 \\
\hline IGUA6 \\
\hline ILLS4 \\
\hline ILMD4 \\
\hline IMBI3 \\
\hline IMCH3 \\
\hline IMCH3+MEAL3 \\
\hline IMPE4 \\
\hline INEP4 \\
\hline INET3 \\
\hline IRON3 \\
\hline ITEC3 \\
\hline ITLM5 \\
\hline ITPS4 \\
\hline ITSA4 \\
\hline ITUB4 \\
\hline IVEN3 \\
\hline IVIL4 \\
\hline \\
\hline
\end{tabular}




\begin{tabular}{|l|}
\hline JBDU4 \\
\hline JBSS3 \\
\hline JFAB4 \\
\hline JFEN3 \\
\hline JHSF3 \\
\hline JOPA3 \\
\hline JSLG3 \\
\hline KEPL3 \\
\hline KLBNI1 \\
\hline KROT3 \\
\hline KSSA3 \\
\hline LAME4 \\
\hline LARK4 \\
\hline LATS3 \\
\hline LCAM3 \\
\hline LECO4 \\
\hline LETO5 \\
\hline LEVE3 \\
\hline LFFE4 \\
\hline LGLO4 \\
\hline LHER4 \\
\hline LIAS4 \\
\hline LIGT3 \\
\hline LINX3 \\
\hline LIPR3 \\
\hline LITS3 \\
\hline LIXC4 \\
\hline LLIS3 \\
\hline LOAR4 \\
\hline LOGN3 \\
\hline LORZ4 \\
\hline LPSB3 \\
\hline LREN3 \\
\hline LUPA3 \\
\hline LUXM4 \\
\hline MADE4 \\
\hline MAFE3 \\
\hline MAGG3 \\
\hline MAGS5 \\
\hline MAHS4 \\
\hline MAKR3 \\
\hline MANM3 \\
\hline MAOR3B \\
\hline MAPT3 \\
\hline MDIA3 \\
\hline MEC4 \\
\hline MEDI3 \\
\hline$M E N D 5$ \\
\hline$M E R C 3$ \\
\hline MESB4 \\
\hline$M F L U 3$ \\
\hline$M G E L 4$ \\
\hline MGLU3 \\
\hline MILK33 \\
\hline MILS3 \\
\hline MLCF4 \\
\hline MLFT4 \\
\hline$M L P A 4$ \\
\hline
\end{tabular}




\begin{tabular}{|l|}
\hline MMAQ4 \\
\hline MMXM3 \\
\hline MNDL3 \\
\hline MNPR3 \\
\hline MNSA4 \\
\hline MOAR3 \\
\hline MPLU3 \\
\hline MRFG3 \\
\hline MRSA3B \\
\hline MRSL4 \\
\hline MRVE3 \\
\hline MSAN3 \\
\hline MSPA4 \\
\hline MTIG4 \\
\hline MTSA4 \\
\hline MULL4 \\
\hline MULT3 \\
\hline MWET4 \\
\hline MYPK3 \\
\hline NAFG4 \\
\hline NAKT4 \\
\hline NATU3 \\
\hline NEMO5 \\
\hline NETC4 \\
\hline NORD3 \\
\hline NUTR3 \\
\hline ODBE4 \\
\hline ODPV3 \\
\hline OFSA3 \\
\hline OGSA3 \\
\hline OGXP3 \\
\hline OIBR4 \\
\hline OLMA4 \\
\hline OLVB4 \\
\hline OPRE3B \\
\hline ORIO4 \\
\hline OSXB3 \\
\hline OXIT4 \\
\hline PALF3 \\
\hline PARC3 \\
\hline PATI4 \\
\hline PCAR4 \\
\hline PDGR3 \\
\hline PEAB3 \\
\hline PEFX3 \\
\hline PETR4 \\
\hline PFRM3 \\
\hline PINE4 \\
\hline PIPN4 \\
\hline PIRE4 \\
\hline PITI4 \\
\hline PLAS3 \\
\hline PLDN4 \\
\hline PLTO6 \\
\hline PMAM3 \\
\hline PMET6 \\
\hline PMT4 \\
\hline PNOR5 \\
\hline
\end{tabular}




\begin{tabular}{|l|}
\hline PNVL3 \\
\hline PNXS4 \\
\hline POLA3 \\
\hline POMO4 \\
\hline POPR4 \\
\hline PORP4 \\
\hline POSI3 \\
\hline PPAR3 \\
\hline PQUN3 \\
\hline PRBC4 \\
\hline PRBN4 \\
\hline PRIO3 \\
\hline PRML3 \\
\hline PRSC4 \\
\hline PRTX3 \\
\hline PRVI3 \\
\hline PSSA3 \\
\hline PTBL3 \\
\hline PTIP3 \\
\hline PTNT4 \\
\hline PTPA4 \\
\hline PTQS4 \\
\hline PVFS4 \\
\hline PVLT3 \\
\hline PVPR4 \\
\hline PXEC4 \\
\hline QGEP3 \\
\hline QGNE4 \\
\hline QUAL3 \\
\hline RADL3 \\
\hline RAIA3 \\
\hline RANI3 \\
\hline RAPT4 \\
\hline RCLL5 \\
\hline RCPRI2 \\
\hline RCSL4 \\
\hline RDCD3 \\
\hline RDNI3 \\
\hline RDTR3 \\
\hline REAL3 \\
\hline REDE4 \\
\hline REEM4 \\
\hline RENT3 \\
\hline REPA4 \\
\hline$R G E G 3$ \\
\hline RHDS3 \\
\hline RHER4 \\
\hline RHPR3 \\
\hline RIO4 \\
\hline RIPI4 \\
\hline RJCP3 \\
\hline RLOG3 \\
\hline RNAR3 \\
\hline RNEWI1 \\
\hline RNPT3 \\
\hline ROMI3 \\
\hline ROSI4 \\
\hline RPAD3 \\
\hline \\
\hline
\end{tabular}




\begin{tabular}{|l|}
\hline RPMG3 \\
\hline RPPR3 \\
\hline RPSA4 \\
\hline RSID3 \\
\hline RSIP4 \\
\hline RSUL4 \\
\hline SAD4 \\
\hline SAGR4 \\
\hline SALM3 \\
\hline SAMI4 \\
\hline SANB11 \\
\hline SAPR4 \\
\hline SASG3 \\
\hline SBSP3 \\
\hline SCAR3 \\
\hline SCLO4 \\
\hline SDIA3 \\
\hline SEBB11 \\
\hline SEER3 \\
\hline SEMP3 \\
\hline SFSA4 \\
\hline SGAS3 \\
\hline SGEN4 \\
\hline SGPS3 \\
\hline SHAP4 \\
\hline SHOW3 \\
\hline SHUL4 \\
\hline SIBR7 \\
\hline SIFC4 \\
\hline SJOS4 \\
\hline SLAL4 \\
\hline SLBR3 \\
\hline SLCE3 \\
\hline SLCP3 \\
\hline SLED4 \\
\hline SMLE3 \\
\hline SMTO3 \\
\hline SNSL3 \\
\hline SNSY5 \\
\hline SOLO4 \\
\hline SOND5 \\
\hline SPRI3 \\
\hline SPRT3B \\
\hline SSBR3 \\
\hline STBP11 \\
\hline STBRI1 \\
\hline STRP4 \\
\hline SUBA3 \\
\hline SULA11 \\
\hline SULT4 \\
\hline SUZB5 \\
\hline SWET3 \\
\hline SZPQ4 \\
\hline TAEE11 \\
\hline TAMM4 \\
\hline TAMR4 \\
\hline TARP11 \\
\hline TBAC3 \\
\hline \\
\hline
\end{tabular}




\begin{tabular}{|l|}
\hline TBCP4 \\
\hline TBLE3 \\
\hline TBRS4 \\
\hline TCHN4 \\
\hline TCNO4 \\
\hline TCOC3 \\
\hline TCSA3 \\
\hline TDBH3 \\
\hline TEBA5 \\
\hline TECN3 \\
\hline TEKA4 \\
\hline TELB3-old \\
\hline TELB4 \\
\hline TEMP3 \\
\hline TEND3 \\
\hline TENE7 \\
\hline TERI3 \\
\hline TETE3 \\
\hline TGMA3 \\
\hline TIBR5 \\
\hline TIMP3 \\
\hline TKNO4 \\
\hline TLCP3 \\
\hline TLPP3F \\
\hline TMAC8B \\
\hline TMAR3 \\
\hline TMCP4 \\
\hline TMGC7 \\
\hline TMGR6 \\
\hline TNCP3 \\
\hline TNEP3 \\
\hline TNLP3 \\
\hline TOTS3 \\
\hline TOYB4 \\
\hline TPEC6B \\
\hline TPIS3 \\
\hline TPRC6 \\
\hline TRBR4 \\
\hline TRFO4 \\
\hline TRIC4 \\
\hline TRIS3 \\
\hline TRJC6 \\
\hline TRMB 4 \\
\hline TROR4 \\
\hline TRPA4 \\
\hline TRPL4 \\
\hline TRPN3 \\
\hline TSEP3 \\
\hline TSPC3 \\
\hline TUPY3 \\
\hline TVIT3 \\
\hline TXRX4 \\
\hline UBBR3 \\
\hline UBHD3 \\
\hline UCAS3 \\
\hline UCOP4 \\
\hline UGPA3 \\
\hline UNIP6 \\
\hline \\
\hline
\end{tabular}




\begin{tabular}{|l|}
\hline UOLL4 \\
\hline USIM5 \\
\hline VAGR3 \\
\hline VAGV4 \\
\hline VALE5 \\
\hline VDNP3B \\
\hline VEMG4 \\
\hline VGOR4 \\
\hline VIGR3 \\
\hline VINE5 \\
\hline VIVO3 \\
\hline VIVR3 \\
\hline VIVT4 \\
\hline VLID3 \\
\hline VPSC4 \\
\hline VPTA4 \\
\hline VRLM4 \\
\hline VSMA3 \\
\hline VTEC4 \\
\hline VULC3 \\
\hline VVARI1 \\
\hline VVAXI1 \\
\hline WEGE3 \\
\hline WET4 \\
\hline WHMT3 \\
\hline WHRL4 \\
\hline WISA3 \\
\hline WMBY3 \\
\hline WSON33 \\
\hline ZIVI4 \\
\hline IBOV \\
\hline
\end{tabular}




\section{APÊNDICE 3 - RETORNOS MENSAIS DAS CARTEIRAS GANHADORAS E PERDEDORAS DA ESTRATÉGIA “ $12 \times 3 "$ EM COMPARÇAO COM O IBOVESPA APÓS CÁLCULO DO MOMENTO (em \%)}

\begin{tabular}{|c|c|c|c|c|}
\hline Período & Losers & Winners & Ibovespa & Momento \\
\hline $\mathrm{t}$ & $(10,91)$ & 1,11 & 7,61 & 12,02 \\
\hline$t+1$ & $(20,42)$ & $(0,85)$ & 11,17 & 19,57 \\
\hline$t+2$ & $(17,81)$ & $(5,15)$ & 8,34 & 12,66 \\
\hline$t+3$ & $(23,50)$ & $(16,44)$ & $(11,60)$ & 7,06 \\
\hline$t+4$ & $(2,75)$ & 1,14 & 6,06 & 3,89 \\
\hline$t+5$ & $(7,13)$ & 10,30 & $(1,82)$ & 17,43 \\
\hline$t+6$ & 6,40 & 11,44 & 19,83 & 5,04 \\
\hline$t+7$ & $(18,59)$ & 9,74 & $(3,76)$ & 28,33 \\
\hline$t+8$ & $(2,89)$ & 17,10 & $(0,06)$ & 19,99 \\
\hline$t+9$ & $(3,40)$ & 13,67 & 4,22 & 17,07 \\
\hline$t+10$ & $(10,50)$ & 22,83 & 10,92 & 33,33 \\
\hline$t+11$ & $(10,17)$ & 14,10 & 5,52 & 24,27 \\
\hline$t+12$ & $(14,76)$ & 11,22 & 1,31 & 25,98 \\
\hline$t+13$ & $(3,27)$ & 0,18 & 2,22 & 3,45 \\
\hline$t+14$ & $(3,65)$ & 6,82 & 2,99 & 10,47 \\
\hline$t+15$ & $(1,30)$ & 5,95 & 1,34 & 7,25 \\
\hline$t+16$ & 6,10 & 21,48 & 2,03 & 15,39 \\
\hline$t+17$ & 21,32 & 24,06 & 5,61 & 2,74 \\
\hline$t+18$ & 13,36 & 27,11 & 13,14 & 13,75 \\
\hline$t+19$ & 8,09 & 22,85 & 10,85 & 14,76 \\
\hline$t+20$ & 10,67 & 20,49 & 2,44 & 9,82 \\
\hline$t+21$ & 14,28 & 31,30 & 10,37 & 17,02 \\
\hline$t+22$ & 2,31 & 31,41 & 13,64 & 29,10 \\
\hline$t+23$ & $(0,77)$ & 4,46 & 10,78 & 5,23 \\
\hline$t+24$ & $(7,13)$ & 5,43 & 2,43 & 12,56 \\
\hline$t+25$ & $(14,93)$ & $(14,13)$ & $(17,58)$ & 0,81 \\
\hline$t+26$ & $(21,12)$ & $(17,64)$ & 11,20 & 3,48 \\
\hline$t+27$ & $(24,43)$ & $(24,60)$ & $(23,83)$ & $(0,17)$ \\
\hline$t+28$ & $(33,03)$ & $(12,55)$ & 4,54 & 20,48 \\
\hline$t+29$ & $(11,10)$ & $(2,10)$ & 8,54 & 8,99 \\
\hline$t+30$ & 20,04 & 14,05 & $(4,67)$ & $(5,99)$ \\
\hline$t+31$ & 56,28 & 32,30 & 8,74 & $(23,98)$ \\
\hline$t+32$ & 7,19 & 16,17 & 13,02 & 8,97 \\
\hline$t+33$ & $(29,83)$ & $(2,63)$ & $(2,25)$ & 27,19 \\
\hline$t+34$ & $(29,26)$ & $(9,17)$ & $(15,68)$ & 20,09 \\
\hline$t+35$ & $(20,05)$ & $(21,68)$ & $(1,71)$ & $(1,63)$ \\
\hline$t+36$ & $(21,80)$ & $(22,68)$ & 10,63 & $(0,88)$ \\
\hline$t+37$ & $(33,26)$ & $(22,49)$ & $(39,55)$ & 10,77 \\
\hline$t+38$ & $(9,71)$ & $(8,09)$ & 1,87 & 1,62 \\
\hline$t+39$ & $(4,91)$ & 4,09 & 6,89 & 9,01 \\
\hline$t+40$ & 19,77 & 8,86 & 22,48 & $(10,91)$ \\
\hline$t+41$ & 17,94 & 4,70 & $(21,40)$ & $(13,24)$ \\
\hline$t+42$ & 42,43 & 3,35 & 20,45 & $(39,08)$ \\
\hline$t+43$ & 46,99 & 9,90 & 9,04 & $(37,08)$ \\
\hline$t+44$ & 32,11 & 13,52 & 20,04 & $(18,59)$ \\
\hline
\end{tabular}




\begin{tabular}{|l|r|r|r|r|}
\hline $\mathrm{t}+45$ & $(4,11)$ & $(4,34)$ & 6,11 & $(0,23)$ \\
\hline $\mathrm{t}+46$ & 4,07 & 24,93 & $(2,30)$ & 20,86 \\
\hline $\mathrm{t}+47$ & $(8,97)$ & 10,41 & 4,84 & 19,38 \\
\hline $\mathrm{t}+48$ & 4,70 & 6,68 & $(10,19)$ & 1,98 \\
\hline $\mathrm{t}+49$ & 8,29 & 3,74 & 1,18 & $(4,55)$ \\
\hline $\mathrm{t}+50$ & 55,70 & 25,38 & 5,13 & $(30,32)$ \\
\hline $\mathrm{t}+51$ & 62,63 & 46,76 & 5,35 & $(15,87)$ \\
\hline $\mathrm{t}+52$ & 56,59 & 31,25 & 17,76 & $(25,34)$ \\
\hline $\mathrm{t}+53$ & 34,74 & 13,80 & 24,05 & $(20,94)$ \\
\hline $\mathrm{t}+54$ & 16,39 & $(3,98)$ & $(4,11)$ & $(20,37)$ \\
\hline $\mathrm{t}+55$ & $(1,62)$ & $(16,85)$ & 7,76 & $(15,23)$ \\
\hline $\mathrm{t}+56$ & $(18,19)$ & $(23,68)$ & 0,91 & $(5,50)$ \\
\hline $\mathrm{t}+57$ & $(5,74)$ & $(3,95)$ & $(12,81)$ & 1,78 \\
\hline $\mathrm{t}+58$ & 15,12 & 3,50 & $(3,74)$ & $(11,62)$ \\
\hline $\mathrm{t}+59$ & 24,64 & 29,80 & 11,84 & 5,16 \\
\hline $\mathrm{t}+60$ & 23,09 & 1,77 & $(1,63)$ & $(21,33)$ \\
\hline $\mathrm{t}+61$ & $(0,59)$ & $(12,17)$ & 5,42 & $(11,58)$ \\
\hline $\mathrm{t}+62$ & $(10,59)$ & $(15,53)$ & $(8,17)$ & $(4,94)$ \\
\hline $\mathrm{t}+63$ & $(12,73)$ & $(4,73)$ & $(6,66)$ & 8,00 \\
\hline $\mathrm{t}+64$ & 5,20 & 15,55 & $(10,63)$ & 10,35 \\
\hline $\mathrm{t}+65$ & 13,63 & 17,56 & 14,84 & 3,93 \\
\hline $\mathrm{t}+66$ & 11,25 & 1,08 & 15,81 & $(10,17)$ \\
\hline $\mathrm{t}+67$ & $(21,01)$ & $(7,00)$ & $(10,08)$ & 14,01 \\
\hline $\mathrm{t}+68$ & $(31,65)$ & $(12,68)$ & $(9,14)$ & 18,97 \\
\hline $\mathrm{t}+69$ & $(14,31)$ & $(8,91)$ & 3,32 & 5,40 \\
\hline $\mathrm{t}+70$ & $(23,81)$ & $(3,09)$ & $(1,80)$ & 20,72 \\
\hline $\mathrm{t}+71$ & $(7,31)$ & $(4,23)$ & $(0,61)$ & 3,08 \\
\hline $\mathrm{t}+72$ & $(21,67)$ & $(24,08)$ & $(5,53)$ & $(2,41)$ \\
\hline $\mathrm{t}+73$ & $(10,17)$ & $(14,99)$ & $(6,65)$ & $(4,81)$ \\
\hline $\mathrm{t}+74$ & 6,40 & $(0,29)$ & $(17,17)$ & $(6,69)$ \\
\hline $\mathrm{t}+75$ & 45,80 & 9,77 & 6,85 & $(36,04)$ \\
\hline $\mathrm{t}+76$ & 37,87 & $(0,81)$ & 13,79 & $(38,68)$ \\
\hline $\mathrm{t}+77$ & 17,65 & 4,03 & 5,00 & $(13,61)$ \\
\hline $\mathrm{t}+78$ & 0,66 & 12,69 & $(6,30)$ & 12,04 \\
\hline $\mathrm{t}+79$ & $(18,25)$ & 12,94 & 10,31 & 31,19 \\
\hline $\mathrm{t}+80$ & $(21,82)$ & 3,03 & $(5,55)$ & 24,85 \\
\hline $\mathrm{t}+81$ & $(39,62)$ & $(4,58)$ & $(1,28)$ & 35,04 \\
\hline $\mathrm{t}+82$ & $(38,77)$ & $(9,52)$ & $(1,71)$ & 29,25 \\
\hline $\mathrm{t}+83$ & $(28,54)$ & 9,30 & $(13,39)$ & 37,84 \\
\hline $\mathrm{t}+84$ & $(29,62)$ & 10,06 & $(12,36)$ & 39,68 \\
\hline $\mathrm{t}+85$ & $(10,60)$ & 7,51 & 6,35 & 18,11 \\
\hline $\mathrm{t}+86$ & $(7,92)$ & 12,08 & $(16,95)$ & 20,00 \\
\hline $\mathrm{t}+87$ & 31,75 & 18,22 & 17,92 & $(13,53)$ \\
\hline $\mathrm{t}+88$ & 9,83 & 7,24 & 3,35 & $(2,59)$ \\
\hline & $(14,86)$ & 4,33 & 7,23 & 19,18 \\
\hline $\mathrm{t}+90$ & 5,22 & $(0,02)$ & $(2,90)$ & 21,44 \\
\hline
\end{tabular}




\begin{tabular}{|l|r|r|r|r|}
\hline $\mathrm{t}+97$ & 39,10 & 35,86 & 11,81 & $(3,24)$ \\
\hline $\mathrm{t}+98$ & 51,02 & 27,91 & 5,51 & $(23,11)$ \\
\hline $\mathrm{t}+99$ & 23,49 & 29,50 & 12,32 & 6,01 \\
\hline $\mathrm{t}+100$ & 15,59 & 30,33 & 12,24 & 14,75 \\
\hline $\mathrm{t}+101$ & $(0,98)$ & 14,16 & 10,17 & 15,14 \\
\hline $\mathrm{t}+102$ & $(1,77)$ & 3,02 & $(1,73)$ & 4,78 \\
\hline $\mathrm{t}+103$ & 4,50 & $(5,15)$ & $(0,44)$ & $(9,65)$ \\
\hline $\mathrm{t}+104$ & $(6,60)$ & $(4,86)$ & 1,78 & 1,74 \\
\hline $\mathrm{t}+105$ & 0,28 & 0,65 & $(11,45)$ & 0,37 \\
\hline $\mathrm{t}+106$ & 7,76 & 17,45 & $(0,32)$ & 9,69 \\
\hline $\mathrm{t}+107$ & 24,33 & 29,43 & 8,21 & 5,10 \\
\hline $\mathrm{t}+108$ & 30,28 & 27,18 & 5,62 & $(3,10)$ \\
\hline $\mathrm{t}+109$ & 26,80 & 18,37 & 2,09 & $(8,43)$ \\
\hline $\mathrm{t}+110$ & 31,40 & 18,89 & 1,94 & $(12,51)$ \\
\hline $\mathrm{t}+111$ & $(1,31)$ & 10,65 & $(0,83)$ & 11,96 \\
\hline $\mathrm{t}+112$ & $(2,16)$ & 10,61 & 9,01 & 12,77 \\
\hline $\mathrm{t}+113$ & $(1,67)$ & 9,43 & 4,25 & 11,10 \\
\hline $\mathrm{t}+114$ & 3,24 & $(3,75)$ & $(7,05)$ & $(6,99)$ \\
\hline $\mathrm{t}+115$ & 10,44 & $(8,14)$ & 15,56 & $(18,58)$ \\
\hline $\mathrm{t}+116$ & $(1,71)$ & $(12,22)$ & $(5,43)$ & $(10,50)$ \\
\hline $\mathrm{t}+117$ & $(14,73)$ & $(26,34)$ & $(6,64)$ & $(11,62)$ \\
\hline $\mathrm{t}+118$ & $(11,08)$ & $(15,08)$ & 1,47 & $(4,00)$ \\
\hline $\mathrm{t}+119$ & $(12,18)$ & $(6,84)$ & $(0,62)$ & 5,34 \\
\hline $\mathrm{t}+120$ & $(1,80)$ & 12,19 & 3,96 & 13,98 \\
\hline $\mathrm{t}+121$ & $(3,49)$ & 14,26 & 7,69 & 17,75 \\
\hline $\mathrm{t}+122$ & $(1,95)$ & 6,50 & 12,62 & 8,45 \\
\hline $\mathrm{t}+123$ & 4,06 & 9,35 & $(4,40)$ & 5,29 \\
\hline $\mathrm{t}+124$ & 29,49 & 35,04 & 5,71 & 5,54 \\
\hline $\mathrm{t}+125$ & 30,50 & 30,35 & 4,82 & $(0,15)$ \\
\hline $\mathrm{t}+126$ & 7,75 & 23,72 & 14,73 & 15,96 \\
\hline $\mathrm{t}+127$ & $(0,83)$ & 14,15 & 0,59 & 14,98 \\
\hline $\mathrm{t}+128$ & 2,73 & $(6,29)$ & $(1,71)$ & $(9,03)$ \\
\hline $\mathrm{t}+129$ & $(14,62)$ & 1,34 & 6,36 & 15,95 \\
\hline $\mathrm{t}+130$ & $(11,63)$ & $(7,31)$ & $(9,50)$ & 4,32 \\
\hline $\mathrm{t}+131$ & 4,30 & $(11,05)$ & 0,27 & $(15,35)$ \\
\hline $\mathrm{t}+132$ & 8,93 & 1,39 & 1,22 & $(7,54)$ \\
\hline $\mathrm{t}+133$ & 13,78 & 12,86 & $(2,28)$ & $(0,92)$ \\
\hline $\mathrm{t}+134$ & 33,02 & 11,11 & 0,60 & $(21,92)$ \\
\hline $\mathrm{t}+135$ & 27,13 & 18,72 & 7,72 & $(8,41)$ \\
\hline $\mathrm{t}+136$ & 32,87 & 18,99 & 6,80 & $(13,88)$ \\
\hline $\mathrm{t}+137$ & 15,20 & 21,24 & 6,06 & 6,04 \\
\hline $\mathrm{t}+138$ & 8,18 & 4,21 & 0,38 & $(3,97)$ \\
\hline $\mathrm{t}+139$ & 4,64 & 12,72 & $(1,68)$ & 8,08 \\
\hline $\mathrm{t}+140$ & 10,65 & 30,94 & 4,36 & 20,29 \\
\hline $\mathrm{t}+141$ & 27,32 & 31,72 & 6,88 & 4,41 \\
\hline $\mathrm{t}+142$ & 6,49 & 45,77 & 6,77 & 39,28 \\
\hline $\mathrm{t}+143$ & $(7,26)$ & 16,51 & 4,06 & 23,76 \\
\hline & & 14,36 & $(0,39)$ & 21,33 \\
\hline
\end{tabular}




\begin{tabular}{|l|r|r|r|r|}
\hline $\mathrm{t}+149$ & $(5,94)$ & 5,60 & 1,40 & 11,54 \\
\hline $\mathrm{t}+150$ & $(16,72)$ & $(10,42)$ & $(6,88)$ & 6,30 \\
\hline $\mathrm{t}+151$ & 2,09 & 4,31 & 6,72 & 2,21 \\
\hline $\mathrm{t}+152$ & 0,29 & 4,88 & $(3,97)$ & 4,59 \\
\hline $\mathrm{t}+153$ & 0,19 & 0,30 & 11,32 & 0,11 \\
\hline $\mathrm{t}+154$ & $(17,65)$ & $(11,23)$ & 6,96 & 6,41 \\
\hline $\mathrm{t}+155$ & $(31,43)$ & $(21,62)$ & $(10,44)$ & 9,80 \\
\hline $\mathrm{t}+156$ & $(43,17)$ & $(33,33)$ & $(8,48)$ & 9,84 \\
\hline $\mathrm{t}+157$ & $(50,87)$ & $(47,12)$ & $(6,43)$ & 3,76 \\
\hline $\mathrm{t}+158$ & $(48,13)$ & $(51,06)$ & $(11,03)$ & $(2,93)$ \\
\hline $\mathrm{t}+159$ & $(22,38)$ & $(16,12)$ & $(24,80)$ & 6,25 \\
\hline $\mathrm{t}+160$ & 18,50 & 0,59 & $(1,77)$ & $(17,91)$ \\
\hline $\mathrm{t}+161$ & 6,61 & 0,99 & 2,61 & $(5,62)$ \\
\hline $\mathrm{t}+162$ & 3,76 & 5,29 & 4,66 & 1,53 \\
\hline $\mathrm{t}+163$ & 51,35 & 11,56 & $(2,84)$ & $(39,79)$ \\
\hline $\mathrm{t}+164$ & 77,47 & 16,98 & 7,18 & $(60,49)$ \\
\hline $\mathrm{t}+165$ & 76,33 & 9,13 & 15,55 & $(67,20)$ \\
\hline $\mathrm{t}+166$ & 46,36 & 6,05 & 12,49 & $(40,31)$ \\
\hline $\mathrm{t}+167$ & 39,56 & $(1,62)$ & $(3,26)$ & $(41,19)$ \\
\hline $\mathrm{t}+168$ & 51,83 & 13,20 & 6,41 & $(38,63)$ \\
\hline $\mathrm{t}+169$ & 25,35 & 11,58 & 3,15 & $(13,77)$ \\
\hline $\mathrm{t}+170$ & 19,45 & 16,71 & 8,90 & $(2,75)$ \\
\hline $\mathrm{t}+171$ & 5,87 & 23,84 & 0,05 & 17,97 \\
\hline $\mathrm{t}+172$ & 21,29 & 23,00 & 8,93 & 1,71 \\
\hline $\mathrm{t}+173$ & 17,23 & 16,15 & 2,30 & $(1,08)$ \\
\hline $\mathrm{t}+174$ & 21,24 & 5,53 & $(4,65)$ & $(15,71)$ \\
\hline $\mathrm{t}+175$ & 2,77 & $(8,28)$ & 1,68 & $(11,05)$ \\
\hline $\mathrm{t}+176$ & 0,23 & $(22,27)$ & 5,82 & $(22,50)$ \\
\hline $\mathrm{t}+177$ & $(1,69)$ & $(11,62)$ & $(4,04)$ & $(9,93)$ \\
\hline $\mathrm{t}+178$ & $(0,73)$ & 2,60 & $(6,64)$ & 3,32 \\
\hline $\mathrm{t}+179$ & 6,69 & 22,00 & $(3,35)$ & 15,31 \\
\hline $\mathrm{t}+180$ & 11,20 & 20,21 & 10,80 & 9,01 \\
\hline $\mathrm{t}+181$ & 9,78 & 13,63 & $(3,51)$ & 3,85 \\
\hline $\mathrm{t}+182$ & 4,23 & 2,35 & 6,58 & $(1,88)$ \\
\hline $\mathrm{t}+183$ & 5,07 & 1,59 & 1,79 & $(3,48)$ \\
\hline $\mathrm{t}+184$ & $(5,01)$ & $(7,93)$ & $(4,20)$ & $(2,92)$ \\
\hline $\mathrm{t}+185$ & $(3,77)$ & $(5,61)$ & 2,36 & $(1,84)$ \\
\hline $\mathrm{t}+186$ & $(8,79)$ & $(6,88)$ & $(3,94)$ & 1,91 \\
\hline $\mathrm{t}+187$ & $(11,02)$ & 5,56 & 1,22 & 16,58 \\
\hline $\mathrm{t}+188$ & $(6,18)$ & 8,69 & 1,79 & 14,87 \\
\hline $\mathrm{t}+189$ & $(13,26)$ & 2,31 & $(3,58)$ & 15,57 \\
\hline $\mathrm{t}+190$ & $(9,56)$ & 2,20 & $(2,29)$ & 11,75 \\
\hline $\mathrm{t}+191$ & $(7,65)$ & $(0,74)$ & $(3,43)$ & 6,91 \\
\hline $\mathrm{t}+192$ & $(11,19)$ & $(15,52)$ & $(5,74)$ & $(4,32)$ \\
\hline $\mathrm{t}+193$ & $(5,90)$ & $(4,68)$ & $(3,96)$ & 1,22 \\
\hline $\mathrm{t}+194$ & $(12,59)$ & $(3,78)$ & $(7,38)$ & 8,82 \\
\hline $\mathrm{t}+195$ & $(6,08)$ & 6,74 & 11,49 & 12,81 \\
\hline $\mathrm{t}+196$ & $(9,39)$ & 1,03 & $(2,51)$ & 10,42 \\
\hline & 10,04 & 12,72 & $(0,21)$ & 2,68 \\
\hline
\end{tabular}




\begin{tabular}{|l|r|r|r|r|}
\hline$t+201$ & $(27,97)$ & $(10,38)$ & $(4,17)$ & 17,59 \\
\hline $\mathrm{t}+202$ & $(24,42)$ & $(3,93)$ & $(11,86)$ & 20,49 \\
\hline $\mathrm{t}+203$ & $(3,57)$ & 6,34 & $(0,25)$ & 9,91 \\
\hline $\mathrm{t}+204$ & 11,19 & 5,18 & 3,21 & $(6,01)$ \\
\hline $\mathrm{t}+205$ & 0,23 & $(1,37)$ & 1,72 & $(1,60)$ \\
\hline $\mathrm{t}+206$ & $(7,87)$ & 5,23 & 3,70 & 13,10 \\
\hline $\mathrm{t}+207$ & $(18,03)$ & 8,95 & $(3,56)$ & 26,98 \\
\hline $\mathrm{t}+208$ & $(21,50)$ & 11,40 & 0,71 & 32,90 \\
\hline $\mathrm{t}+209$ & $(11,06)$ & 9,98 & 6,05 & 21,04 \\
\hline $\mathrm{t}+210$ & $(11,84)$ & 3,16 & $(1,95)$ & 15,00 \\
\hline $\mathrm{t}+211$ & $(22,66)$ & $(0,58)$ & $(3,91)$ & 22,08 \\
\hline $\mathrm{t}+212$ & $(26,36)$ & $(4,52)$ & $(1,87)$ & 21,84 \\
\hline $\mathrm{t}+213$ & $(27,50)$ & $(13,07)$ & $(0,78)$ & 14,43 \\
\hline $\mathrm{t}+214$ & $(23,50)$ & $(14,05)$ & $(4,30)$ & 9,44 \\
\hline $\mathrm{t}+215$ & $(19,14)$ & $(9,58)$ & $(11,31)$ & 9,56 \\
\hline $\mathrm{t}+216$ & 13,46 & 1,63 & 1,64 & $(11,83)$ \\
\hline $\mathrm{t}+217$ & 7,43 & 3,26 & 3,68 & $(4,16)$ \\
\hline $\mathrm{t}+218$ & $(15,43)$ & 5,31 & 4,65 & 20,74 \\
\hline $\mathrm{t}+219$ & $(11,34)$ & 6,16 & 3,66 & 17,50 \\
\hline $\mathrm{t}+220$ & $(6,32)$ & $(0,74)$ & $(3,27)$ & 5,59 \\
\hline $\mathrm{t}+221$ & $(7,86)$ & $(1,95)$ & $(1,86)$ & 5,91 \\
\hline $\mathrm{t}+222$ & $(13,61)$ & $(6,76)$ & $(7,51)$ & 6,85 \\
\hline $\mathrm{t}+223$ & $(21,06)$ & $(6,57)$ & $(1,14)$ & 14,49 \\
\hline $\mathrm{t}+224$ & $(20,38)$ & 6,16 & 7,05 & 26,54 \\
\hline $\mathrm{t}+225$ & $(0,78)$ & 7,21 & 2,40 & 7,99 \\
\hline $\mathrm{t}+226$ & 1,35 & 6,26 & $(0,75)$ & 4,91 \\
\hline $\mathrm{t}+227$ & 5,31 & 4,82 & 3,76 & $(0,50)$ \\
\hline $\mathrm{t}+228$ & $(17,89)$ & $(3,57)$ & 5,00 & 14,31 \\
\hline $\mathrm{t}+229$ & $(27,68)$ & $(11,05)$ & 9,78 & 16,64 \\
\hline $\mathrm{t}+230$ & $(26,98)$ & $(14,53)$ & $(11,70)$ & 12,45 \\
\hline $\mathrm{t}+231$ & $(27,94)$ & $(17,92)$ & 0,95 & 10,03 \\
\hline $\mathrm{t}+232$ & $(26,15)$ & $(18,46)$ & 0,18 & 7,69 \\
\hline $\mathrm{t}+233$ & $(30,15)$ & $(13,22)$ & $(8,62)$ & 16,93 \\
\hline $\mathrm{t}+234$ & $(19,17)$ & $(12,84)$ & $(6,20)$ & 6,34 \\
\hline $\mathrm{t}+235$ & 2,14 & 8,95 & 9,97 & 6,81 \\
\hline $\mathrm{t}+236$ & 3,64 & 7,01 & $(0,84)$ & 3,37 \\
\hline & & & & \\
\hline
\end{tabular}




\section{APÊNDICE 4 - RETORNOS MENSAIS DAS CARTEIRAS GANHADORAS E PERDEDORAS DA ESTRATÉGIA "9x6" EM COMPARÇAO COM O IBOVESPA APÓS CÁLCULO DO MOMENTO (em \%)}

\begin{tabular}{|c|c|c|c|c|}
\hline Período & Losers & Winners & Ibovespa & Momento \\
\hline $\mathrm{t}$ & 0,50 & $(30,40)$ & 28,02 & $(30,90)$ \\
\hline$t+1$ & $(15,92)$ & $(25,68)$ & $(2,44)$ & $(9,76)$ \\
\hline$t+2$ & $(28,01)$ & $(5,77)$ & $(3,15)$ & 22,25 \\
\hline$t+3$ & $(34,28)$ & $(20,20)$ & 7,61 & 14,08 \\
\hline$t+4$ & $(22,51)$ & 2,14 & 11,17 & 24,65 \\
\hline$t+5$ & $(18,82)$ & 3,15 & 8,34 & 21,97 \\
\hline$t+6$ & $(37,54)$ & 11,01 & $(11,60)$ & 48,55 \\
\hline $\mathrm{t}+7$ & $(26,27)$ & 13,10 & 6,06 & 39,37 \\
\hline $\mathrm{t}+8$ & $(8,00)$ & 28,41 & $(1,82)$ & 36,40 \\
\hline $\mathrm{t}+9$ & $(4,74)$ & 34,07 & 19,83 & 38,81 \\
\hline$t+10$ & $(15,64)$ & 34,58 & $(3,76)$ & 50,23 \\
\hline$t+11$ & $(34,63)$ & 29,71 & $(0,06)$ & 64,34 \\
\hline$t+12$ & $(9,81)$ & 23,90 & 4,22 & 33,70 \\
\hline$t+13$ & $(13,69)$ & 33,04 & 10,92 & 46,72 \\
\hline$t+14$ & $(6,28)$ & 28,42 & 5,52 & 34,70 \\
\hline$t+15$ & $(18,61)$ & 26,65 & 1,31 & 45,26 \\
\hline$t+16$ & 6,11 & 22,82 & 2,22 & 16,72 \\
\hline $\mathrm{t}+17$ & $(1,71)$ & 32,34 & 2,99 & 34,05 \\
\hline $\mathrm{t}+18$ & 0,04 & 28,05 & 1,34 & 28,01 \\
\hline$t+19$ & 10,69 & 39,20 & 2,03 & 28,51 \\
\hline$t+20$ & 19,08 & 68,36 & 5,61 & 49,28 \\
\hline$t+21$ & 13,00 & 70,62 & 13,14 & 57,62 \\
\hline$t+22$ & 17,79 & 55,28 & 10,85 & 37,49 \\
\hline$t+23$ & 7,86 & 27,36 & 2,44 & 19,49 \\
\hline$t+24$ & 7,60 & 20,70 & 10,37 & 13,09 \\
\hline$t+25$ & 2,17 & 17,77 & 13,64 & 15,60 \\
\hline$t+26$ & $(28,15)$ & $(4,44)$ & 10,78 & 23,72 \\
\hline$t+27$ & $(39,32)$ & $(15,62)$ & 2,43 & 23,70 \\
\hline $\mathrm{t}+28$ & $(43,26)$ & $(23,37)$ & $(17,58)$ & 19,88 \\
\hline$t+29$ & $(32,87)$ & $(21,63)$ & 11,20 & 11,24 \\
\hline$t+30$ & $(24,53)$ & $(4,73)$ & $(23,83)$ & 19,80 \\
\hline$t+31$ & $(14,89)$ & 21,70 & 4,54 & 36,58 \\
\hline$t+32$ & $(4,31)$ & 21,79 & 8,54 & 26,10 \\
\hline$t+33$ & $(3,12)$ & 4,61 & $(4,67)$ & 7,74 \\
\hline$t+34$ & 22,22 & 18,09 & 8,74 & $(4,13)$ \\
\hline$t+35$ & $(19,53)$ & $(8,08)$ & 13,02 & 11,45 \\
\hline$t+36$ & $(45,97)$ & $(29,49)$ & $(2,25)$ & 16,49 \\
\hline$t+37$ & $(53,46)$ & $(37,46)$ & $(15,68)$ & 16,00 \\
\hline $\mathrm{t}+38$ & $(43,25)$ & $(31,04)$ & $(1,71)$ & 12,21 \\
\hline$t+39$ & $(38,10)$ & $(17,33)$ & 10,63 & 20,76 \\
\hline$t+40$ & $(29,79)$ & $(22,90)$ & $(39,55)$ & 6,90 \\
\hline $\mathrm{t}+41$ & 3,85 & $(8,36)$ & 1,87 & $(12,20)$ \\
\hline$t+42$ & 13,03 & 38,60 & 6,89 & 25,57 \\
\hline$t+43$ & 43,71 & 60,68 & 22,48 & 16,98 \\
\hline$t+44$ & 23,19 & 10,49 & $(21,40)$ & $(12,70)$ \\
\hline
\end{tabular}




\begin{tabular}{|c|c|c|c|c|}
\hline $\mathrm{t}+45$ & 55,45 & $(0,50)$ & 20,45 & $(55,95)$ \\
\hline $\mathrm{t}+46$ & 46,80 & 24,87 & 9,04 & $(21,93)$ \\
\hline $\mathrm{t}+47$ & 22,05 & 31,67 & 20,04 & 9,62 \\
\hline $\mathrm{t}+48$ & 30,10 & 3,33 & 6,11 & $(26,77)$ \\
\hline$t+49$ & 16,09 & 37,94 & $(2,30)$ & 21,85 \\
\hline$t+50$ & 28,27 & 33,72 & 4,84 & 5,45 \\
\hline$t+51$ & 38,07 & 42,65 & $(10,19)$ & 4,58 \\
\hline$t+52$ & 51,22 & 51,59 & 1,18 & 0,37 \\
\hline$t+53$ & 83,93 & 63,18 & 5,13 & $(20,75)$ \\
\hline$t+54$ & 47,81 & 57,91 & 5,35 & 10,10 \\
\hline$t+55$ & 56,45 & 23,75 & 17,76 & $(32,71)$ \\
\hline$t+56$ & 6,94 & 4,60 & 24,05 & $(2,33)$ \\
\hline$t+57$ & 12,78 & 3,55 & $(4,11)$ & $(9,23)$ \\
\hline$t+58$ & 9,82 & $(0,44)$ & 7,76 & $(10,25)$ \\
\hline$t+59$ & 15,86 & $(5,46)$ & 0,91 & $(21,33)$ \\
\hline$t+60$ & 8,95 & $(16,91)$ & $(12,81)$ & $(25,86)$ \\
\hline$t+61$ & 19,29 & $(9,09)$ & $(3,74)$ & $(28,38)$ \\
\hline$t+62$ & 10,55 & $(1,65)$ & 11,84 & $(12,20)$ \\
\hline$t+63$ & 3,24 & $(13,08)$ & $(1,63)$ & $(16,32)$ \\
\hline$t+64$ & $(6,77)$ & $(1,11)$ & 5,42 & 5,66 \\
\hline$t+65$ & 3,31 & $(3,45)$ & $(8,17)$ & $(6,76)$ \\
\hline$t+66$ & $(16,80)$ & 8,07 & $(6,66)$ & 24,87 \\
\hline$t+67$ & $(8,17)$ & 2,56 & $(10,63)$ & 10,73 \\
\hline$t+68$ & $(18,86)$ & 0,13 & 14,84 & 18,99 \\
\hline$t+69$ & $(14,33)$ & 1,18 & 15,81 & 15,51 \\
\hline$t+70$ & $(34,49)$ & $(13,47)$ & $(10,08)$ & 21,03 \\
\hline $\mathrm{t}+71$ & $(24,35)$ & $(21,88)$ & $(9,14)$ & 2,48 \\
\hline$t+72$ & $(37,48)$ & $(23,75)$ & 3,32 & 13,73 \\
\hline$t+73$ & $(25,68)$ & $(14,73)$ & $(1,80)$ & 10,95 \\
\hline$t+74$ & $(9,02)$ & $(15,89)$ & $(0,61)$ & $(6,87)$ \\
\hline$t+75$ & $(9,09)$ & $(0,38)$ & $(5,53)$ & 8,71 \\
\hline$t+76$ & 4,77 & $(5,52)$ & $(6,65)$ & $(10,28)$ \\
\hline$t+77$ & 14,60 & 4,22 & $(17,17)$ & $(10,38)$ \\
\hline$t+78$ & 32,84 & 25,14 & 6,85 & $(7,70)$ \\
\hline $\mathrm{t}+79$ & 16,49 & 24,73 & 13,79 & 8,24 \\
\hline$t+80$ & $(18,56)$ & 16,44 & 5,00 & 34,99 \\
\hline$t+81$ & $(41,08)$ & 15,81 & $(6,30)$ & 56,89 \\
\hline$t+82$ & $(46,61)$ & 15,32 & 10,31 & 61,93 \\
\hline$t+83$ & $(27,14)$ & 11,80 & $(5,55)$ & 38,93 \\
\hline$t+84$ & $(47,14)$ & $(5,66)$ & $(1,28)$ & 41,48 \\
\hline$t+85$ & $(37,32)$ & $(0,00)$ & $(1,71)$ & 37,31 \\
\hline$t+86$ & $(30,79)$ & 7,49 & $(13,39)$ & 38,28 \\
\hline$t+87$ & $(4,50)$ & 11,00 & $(12,36)$ & 15,50 \\
\hline $\mathrm{t}+88$ & 9,86 & $(1,88)$ & 6,35 & $(11,74)$ \\
\hline$t+89$ & $(14,18)$ & 1,80 & $(16,95)$ & 15,98 \\
\hline$t+90$ & $(0,17)$ & 6,88 & 17,92 & 7,05 \\
\hline$t+91$ & 13,35 & $(0,39)$ & 3,35 & $(13,74)$ \\
\hline $\mathrm{t}+92$ & 24,53 & 3,45 & 7,23 & $(21,08)$ \\
\hline $\mathrm{t}+93$ & $(2,23)$ & $(1,37)$ & $(2,90)$ & 0,86 \\
\hline$t+94$ & 8,60 & 14,18 & $(6,04)$ & 5,58 \\
\hline$t+95$ & 59,73 & 14,10 & 9,66 & $(45,63)$ \\
\hline$t+96$ & 65,50 & 48,96 & 11,38 & $(16,54)$ \\
\hline
\end{tabular}




\begin{tabular}{|l|r|r|r|r|}
\hline $\mathrm{t}+97$ & 54,12 & 35,19 & 6,89 & $(18,93)$ \\
\hline $\mathrm{t}+98$ & 55,63 & 68,47 & $(3,35)$ & 12,83 \\
\hline $\mathrm{t}+99$ & 59,52 & 72,15 & 4,62 & 12,62 \\
\hline $\mathrm{t}+100$ & 75,92 & 67,98 & 11,81 & $(7,94)$ \\
\hline $\mathrm{t}+101$ & 63,92 & 39,79 & 5,51 & $(24,13)$ \\
\hline $\mathrm{t}+102$ & 13,88 & 45,78 & 12,32 & 31,91 \\
\hline $\mathrm{t}+103$ & 18,70 & 32,56 & 12,24 & 13,86 \\
\hline $\mathrm{t}+104$ & 3,96 & 3,82 & 10,17 & $(0,14)$ \\
\hline $\mathrm{t}+105$ & $(2,23)$ & $(6,63)$ & $(1,73)$ & $(4,39)$ \\
\hline $\mathrm{t}+106$ & 1,37 & 8,85 & $(0,44)$ & 7,49 \\
\hline $\mathrm{t}+107$ & 17,62 & 22,32 & 1,78 & 4,69 \\
\hline $\mathrm{t}+108$ & 19,83 & 20,62 & $(11,45)$ & 0,79 \\
\hline $\mathrm{t}+109$ & 21,91 & 21,85 & $(0,32)$ & $(0,06)$ \\
\hline $\mathrm{t}+110$ & 32,54 & 25,70 & 8,21 & $(6,85)$ \\
\hline $\mathrm{t}+111$ & 56,58 & 51,72 & 5,62 & $(4,85)$ \\
\hline $\mathrm{t}+112$ & 41,94 & 38,22 & 2,09 & $(3,73)$ \\
\hline $\mathrm{t}+113$ & 44,35 & 22,88 & 1,94 & $(21,46)$ \\
\hline $\mathrm{t}+114$ & 7,61 & 20,38 & $(0,83)$ & 12,77 \\
\hline $\mathrm{t}+115$ & 4,00 & 10,60 & 9,01 & 6,59 \\
\hline $\mathrm{t}+116$ & 4,81 & 9,57 & 4,25 & 4,76 \\
\hline $\mathrm{t}+117$ & $(9,23)$ & $(19,67)$ & $(7,05)$ & $(10,44)$ \\
\hline $\mathrm{t}+118$ & $(7,94)$ & $(20,57)$ & 15,56 & $(12,63)$ \\
\hline $\mathrm{t}+119$ & $(15,72)$ & $(20,75)$ & $(5,43)$ & $(5,03)$ \\
\hline $\mathrm{t}+120$ & $(22,37)$ & $(16,39)$ & $(6,64)$ & 5,98 \\
\hline $\mathrm{t}+121$ & $(12,69)$ & $(6,56)$ & 1,47 & 6,13 \\
\hline $\mathrm{t}+122$ & $(15,06)$ & $(1,53)$ & $(0,62)$ & 13,53 \\
\hline $\mathrm{t}+123$ & 2,24 & 24,93 & 3,96 & 22,69 \\
\hline $\mathrm{t}+124$ & 14,74 & 44,82 & 7,69 & 30,08 \\
\hline $\mathrm{t}+125$ & 17,15 & 43,66 & 12,62 & 26,51 \\
\hline $\mathrm{t}+126$ & 18,38 & 44,41 & $(4,40)$ & 26,04 \\
\hline $\mathrm{t}+127$ & 19,32 & 51,65 & 5,71 & 32,32 \\
\hline $\mathrm{t}+128$ & 14,40 & 32,56 & 4,82 & 18,16 \\
\hline $\mathrm{t}+129$ & $(12,21)$ & 22,32 & 14,73 & 34,53 \\
\hline $\mathrm{t}+130$ & $(14,27)$ & 12,80 & 0,59 & 27,07 \\
\hline $\mathrm{t}+131$ & $(4,39)$ & 18,20 & $(1,71)$ & 22,58 \\
\hline $\mathrm{t}+145$ & $(3,39)$ & 8,69 & 6,36 & 12,07 \\
\hline $\mathrm{t}+132$ & 1495 & 0,67 & $(9,50)$ & $(1,29)$ \\
\hline $\mathrm{t}+133$ & $3,95,32$ & 41,17 & 6,77 & 32,85 \\
\hline $\mathrm{t}+148$ & 35,67 & 7,68 & 0,27 & $(29,00)$ \\
\hline $\mathrm{t}+134$ & 35,31 & 15,83 & 1,22 & $(19,48)$ \\
\hline $\mathrm{t}+136$ & 50,88 & 23,17 & $(2,28)$ & $(27,71)$ \\
\hline $\mathrm{t}+137$ & 45,22 & 35,55 & 0,60 & $(9,67)$ \\
\hline $\mathrm{t}+138$ & 45,86 & 39,60 & 7,72 & $(6,26)$ \\
\hline $\mathrm{t}+139$ & 56,45 & 63,15 & 6,80 & 6,70 \\
\hline & 32,24 & 78,37 & 6,06 & 46,13 \\
\hline $\mathrm{t}+140$ & 49,09 & 0,38 & 18,67 \\
\hline
\end{tabular}




\begin{tabular}{|c|c|c|c|c|}
\hline$t+149$ & 4,66 & 2,46 & 10,67 & $(2,20)$ \\
\hline$t+150$ & $(9,80)$ & $(19,84)$ & 8,02 & $(10,05)$ \\
\hline$t+151$ & $(15,49)$ & $(12,27)$ & $(3,54)$ & 3,22 \\
\hline$t+152$ & $(12,18)$ & 2,49 & 1,40 & 14,66 \\
\hline$t+153$ & $(24,74)$ & $(3,21)$ & $(6,88)$ & 21,53 \\
\hline$t+154$ & $(23,52)$ & $(8,77)$ & 6,72 & 14,75 \\
\hline$t+155$ & $(31,23)$ & $(23,69)$ & $(3,97)$ & 7,54 \\
\hline$t+156$ & $(43,96)$ & $(29,22)$ & 11,32 & 14,74 \\
\hline$t+157$ & $(60,03)$ & $(55,27)$ & 6,96 & 4,76 \\
\hline$t+158$ & $(65,20)$ & $(59,95)$ & $(10,44)$ & 5,25 \\
\hline$t+159$ & $(55,50)$ & $(53,61)$ & $(8,48)$ & 1,90 \\
\hline$t+160$ & $(51,57)$ & $(42,93)$ & $(6,43)$ & 8,63 \\
\hline$t+161$ & $(42,69)$ & $(44,86)$ & $(11,03)$ & $(2,17)$ \\
\hline$t+162$ & $(6,43)$ & $(18,61)$ & $(24,80)$ & $(12,18)$ \\
\hline$t+163$ & 72,32 & 18,91 & $(1,77)$ & $(53,41)$ \\
\hline$t+164$ & 100,58 & 20,78 & 2,61 & $(79,80)$ \\
\hline$t+165$ & 89,90 & 24,98 & 4,66 & $(64,92)$ \\
\hline$t+166$ & 118,84 & 22,53 & $(2,84)$ & $(96,31)$ \\
\hline$t+167$ & 143,26 & 19,33 & 7,18 & $(123,93)$ \\
\hline$t+168$ & 168,19 & 21,10 & 15,55 & $(147,09)$ \\
\hline$t+169$ & 87,25 & 18,17 & 12,49 & $(69,08)$ \\
\hline$t+170$ & 57,40 & 12,49 & $(3,26)$ & $(44,91)$ \\
\hline$t+171$ & 46,16 & 50,20 & 6,41 & 4,04 \\
\hline$t+172$ & 43,26 & 46,68 & 3,15 & 3,43 \\
\hline$t+173$ & 27,45 & 37,25 & 8,90 & 9,79 \\
\hline$t+174$ & 29,62 & 16,12 & 0,05 & $(13,49)$ \\
\hline$t+175$ & 13,39 & 18,47 & 8,93 & 5,08 \\
\hline$t+176$ & 1,51 & $(1,84)$ & 2,30 & $(3,35)$ \\
\hline $\mathrm{t}+177$ & 1,98 & $(2,01)$ & $(4,65)$ & $(3,99)$ \\
\hline$t+178$ & $(0,98)$ & $(8,36)$ & 1,68 & $(7,37)$ \\
\hline$t+179$ & $(4,11)$ & $(11,00)$ & 5,82 & $(6,89)$ \\
\hline$t+180$ & 2,94 & 1,78 & $(4,04)$ & $(1,16)$ \\
\hline$t+181$ & 7,90 & 15,98 & $(6,64)$ & 8,08 \\
\hline$t+182$ & 13,43 & 29,64 & $(3,35)$ & 16,21 \\
\hline$t+183$ & 20,58 & 13,77 & 10,80 & $(6,81)$ \\
\hline$t+184$ & 5,30 & $(0,86)$ & $(3,51)$ & $(6,16)$ \\
\hline$t+185$ & $(0,98)$ & $(6,54)$ & 6,58 & $(5,56)$ \\
\hline$t+186$ & $(7,39)$ & $(6,21)$ & 1,79 & 1,18 \\
\hline$t+187$ & $(19,22)$ & $(3,28)$ & $(4,20)$ & 15,94 \\
\hline$t+188$ & $(18,48)$ & 2,21 & 2,36 & 20,68 \\
\hline$t+189$ & $(24,80)$ & $(2,81)$ & $(3,94)$ & 21,99 \\
\hline$t+190$ & $(20,86)$ & 3,73 & 1,22 & 24,58 \\
\hline$t+191$ & $(16,25)$ & 11,43 & 1,79 & 27,68 \\
\hline$t+192$ & $(17,36)$ & $(5,60)$ & $(3,58)$ & 11,76 \\
\hline$t+193$ & $(12,26)$ & 0,47 & $(2,29)$ & 12,73 \\
\hline$t+194$ & $(23,12)$ & $(7,68)$ & $(3,43)$ & 15,43 \\
\hline$t+195$ & $(23,65)$ & $(17,06)$ & $(5,74)$ & 6,59 \\
\hline$t+196$ & $(13,33)$ & $(4,61)$ & $(3,96)$ & 8,71 \\
\hline$t+197$ & $(4,62)$ & 14,17 & $(7,38)$ & 18,80 \\
\hline$t+198$ & $(4,85)$ & 25,36 & 11,49 & 30,21 \\
\hline$t+199$ & $(15,73)$ & 5,90 & $(2,51)$ & 21,63 \\
\hline$t+200$ & $(17,12)$ & 1,20 & $(0,21)$ & 18,32 \\
\hline
\end{tabular}




\begin{tabular}{|c|c|c|c|c|}
\hline$t+201$ & $(15,54)$ & $(1,01)$ & 11,13 & 14,53 \\
\hline$t+202$ & $(28,75)$ & $(2,02)$ & 4,34 & 26,72 \\
\hline$t+203$ & $(29,54)$ & $(11,04)$ & $(1,98)$ & 18,50 \\
\hline$t+204$ & $(28,42)$ & $(1,06)$ & $(4,17)$ & 27,36 \\
\hline$t+205$ & $(26,75)$ & 0,86 & $(11,86)$ & 27,61 \\
\hline$t+206$ & $(15,30)$ & 15,92 & $(0,25)$ & 31,22 \\
\hline$t+207$ & $(7,13)$ & 21,53 & 3,21 & 28,66 \\
\hline$t+208$ & $(15,07)$ & 16,59 & 1,72 & 31,66 \\
\hline$t+209$ & $(20,64)$ & 15,54 & 3,70 & 36,18 \\
\hline$t+210$ & $(31,32)$ & 16,77 & $(3,56)$ & 48,09 \\
\hline$t+211$ & $(35,53)$ & 7,11 & 0,71 & 42,64 \\
\hline$t+212$ & $(33,67)$ & 6,99 & 6,05 & 40,66 \\
\hline$t+213$ & $(34,27)$ & $(8,66)$ & $(1,95)$ & 25,61 \\
\hline$t+214$ & $(36,29)$ & $(11,95)$ & $(3,91)$ & 24,34 \\
\hline$t+215$ & $(35,13)$ & $(21,49)$ & $(1,87)$ & 13,63 \\
\hline$t+216$ & $(25,35)$ & $(5,98)$ & $(0,78)$ & 19,38 \\
\hline$t+217$ & $(12,36)$ & $(5,29)$ & $(4,30)$ & 7,08 \\
\hline$t+218$ & $(23,29)$ & 1,41 & $(11,31)$ & 24,71 \\
\hline$t+219$ & 9,48 & 11,02 & 1,64 & 1,54 \\
\hline$t+220$ & $(12,07)$ & 5,00 & 3,68 & 17,06 \\
\hline$t+221$ & $(17,48)$ & 5,71 & 4,65 & 23,19 \\
\hline$t+222$ & $(26,29)$ & 0,13 & 3,66 & 26,41 \\
\hline$t+223$ & $(23,20)$ & $(0,46)$ & $(3,27)$ & 22,74 \\
\hline$t+224$ & $(27,71)$ & 4,23 & $(1,86)$ & 31,94 \\
\hline$t+225$ & $(17,43)$ & $(1,95)$ & $(7,51)$ & 15,48 \\
\hline$t+226$ & $(17,63)$ & $(1,29)$ & $(1,14)$ & 16,34 \\
\hline$t+227$ & $(8,20)$ & 6,35 & 7,05 & 14,55 \\
\hline$t+228$ & $(14,92)$ & $(1,83)$ & 2,40 & 13,08 \\
\hline$t+229$ & $(24,93)$ & $(3,49)$ & $(0,75)$ & 21,44 \\
\hline$t+230$ & $(19,10)$ & $(8,68)$ & 3,76 & 10,41 \\
\hline$t+231$ & $(36,63)$ & $(20,71)$ & 5,00 & 15,91 \\
\hline$t+232$ & $(43,43)$ & $(28,64)$ & 9,78 & 14,78 \\
\hline$t+233$ & $(45,20)$ & $(30,26)$ & $(11,70)$ & 14,94 \\
\hline$t+234$ & $(35,89)$ & $(16,30)$ & 0,95 & 19,60 \\
\hline$t+235$ & $(20,04)$ & $(5,78)$ & 0,18 & 14,26 \\
\hline$t+236$ & $(24,90)$ & 1,04 & $(8,62)$ & 25,94 \\
\hline
\end{tabular}

